2003

\title{
Design and analysis of a modified power-split continuously variable transmission
}

Andrew John Fox

West Virginia University

Follow this and additional works at: https://researchrepository.wvu.edu/etd

\section{Recommended Citation}

Fox, Andrew John, "Design and analysis of a modified power-split continuously variable transmission" (2003). Graduate Theses, Dissertations, and Problem Reports. 1315.

https://researchrepository.wvu.edu/etd/1315 


\title{
Design and Analysis of a Modified Power Split Continuously Variable Transmission
}

\author{
Andrew J. Fox \\ Thesis Submitted to the College of Engineering and Mineral \\ Resources at West Virginia University in partial fulfillment of the \\ requirements for the degree of \\ Master of Science \\ in \\ Mechanical Engineering \\ James Smith, Ph.D., Chair \\ Victor Mucino, Ph.D. \\ Gregory Thompson, Ph.D. \\ 2003 \\ Morgantown, West Virginia
}

Keywords: CVT, Transmission, Simulation

Copyright 2003 Andrew J. Fox 


\title{
ABSTRACT \\ Design and Analysis of a Modified Power Split Continuously Variable Transmission
}

\begin{abstract}
Andrew J. Fox
The continuously variable transmission (CVT) has been considered to be a viable alternative to the conventional stepped ratio transmission because it has the advantages of smooth stepless shifting, simplified design, and a potential for reduced fuel consumption and tailpipe emissions. These benefits have driven all of the major automobile manufacturers to explore different designs of the CVT for the last century. Through this work, the CVT has been developed into a practical alternative to the conventional transmission for vehicles in the lower two thirds of the power spectrum.

The power split CVPST has a potentially higher mechanical efficiency than a conventional shaft-to-shaft CVT, but it is unknown whether that efficiency can be increased further. For the CVPST, the branch control circuit that contains the CVT can be disengaged at the ring gear for a 1:1 overall transmission ratio, which will interrupt the power flow through the CVT. This could increase overall efficiency because the branch control circuit is no longer transmitting any power.

This thesis involves the study of just such a CVPST system. This system is compared to a conventional CVPST, a direct-drive CVPST that disconnects the entire branch control system, and a shaft-to-shaft CVT. A set of computer programs is produced to study the mechanical losses for each system over the entire operating range of a representative simulation model. From this analysis, the value of disengaging the branch control circuit at the ring gear can be determined.
\end{abstract}




\section{Acknowledgements}

I would like to thank Dr. Victor Mucino for his assistance throughout my thesis work, and I would like to thank Dr. Gregory Thompson for his practical advice and constructive comments. I would also like to extend a special thanks to Dr. James Smith for his endless patience, advice, and enthusiasm which carried me through the more difficult parts of this process and, in the end, made it all possible.

In addition, I would like to thank my parents, Paul and Karen Fox. Their advice, assistance, and love made my dreams of a college education possible by ensuring that I was always taken care of. Finally, I would like to thank Brooke Campbell, for her loving companionship made life seem so wonderful even at the most difficult of times.

I also want to thank God, for we are all blessed to have the opportunity to take this journey through life. 


\section{Table of Contents}

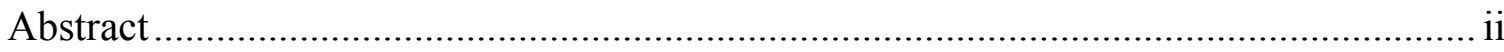

Acknowledgements............................................................................................ ii

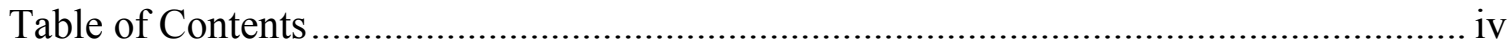

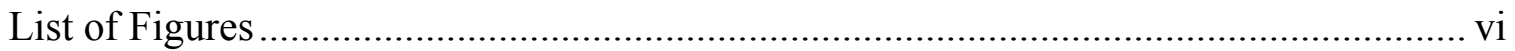

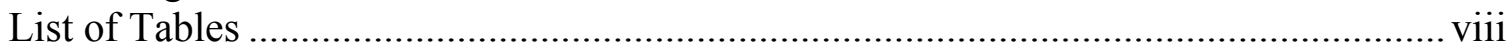

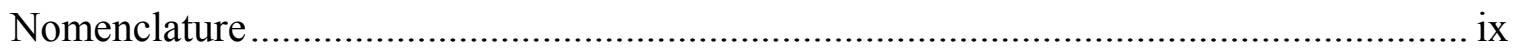

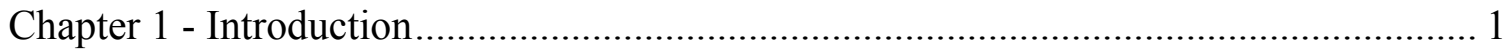

1.1 Problem Statement and Thesis Objectives..................................................... 3

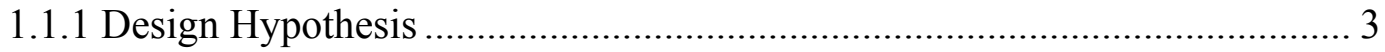

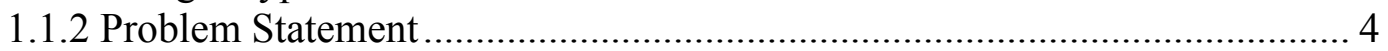

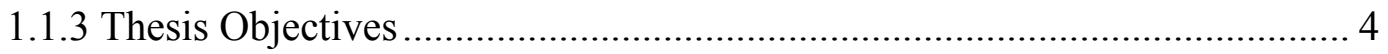

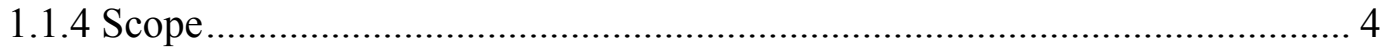

Chapter 2 - Review of Relevant Literature ............................................................... 6

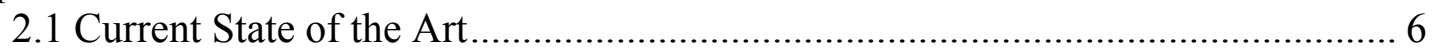

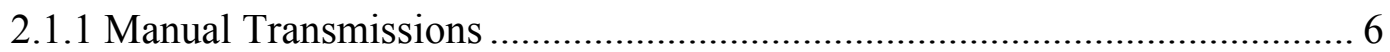

2.1.2 Automated Manual Transmissions ........................................................... 8

2.1.3 Automatic Transmissions....................................................................... 9

2.2 Continuously Variable Transmissions ............................................................ 11

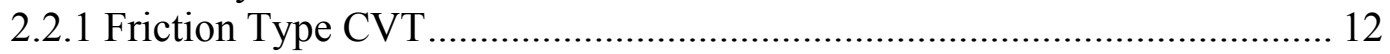

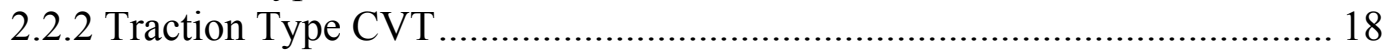

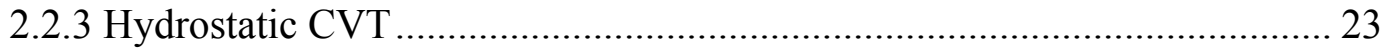

2.2.4 Electric CVT ………………………………...................................... 24

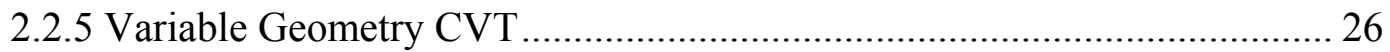

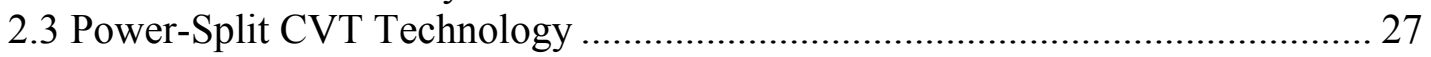

2.3.1 Continuously Variable Power Split Transmission........................................ 28

2.3.2 Infinitely Variable Transmission ............................................................... 29

Chapter 3 - Continuously Variable Power Split Transmissions - Definition and Analysis

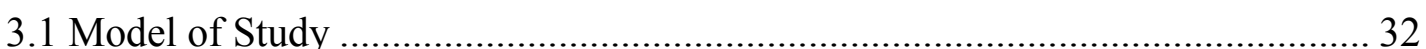

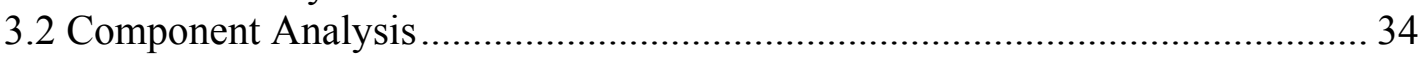

3.2.1 Kinematic Analysis of Planetary Gears ...................................................... 35

3.2.2 Motion Analysis of Planetary Gears ........................................................ 36

3.2.3 Torque and Power Analysis of Planetary Gears ........................................ 38

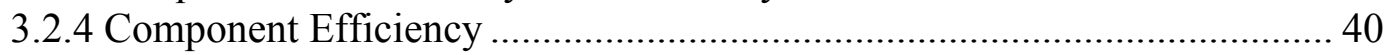

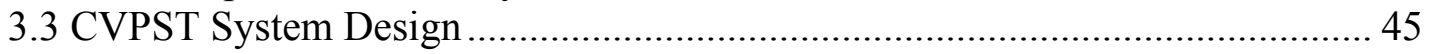

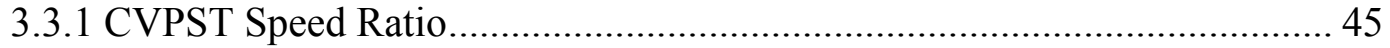

3.3.2 CVPST Torque and Power Analysis........................................................ 48

3.3.3 CVPST Efficiency Analysis ...................................................................... 48

Chapter 4 - Continuously Variable Power Split Transmission Simulation Design ......... 51

4.1 CVPST Simulation Program......................................................................... 51

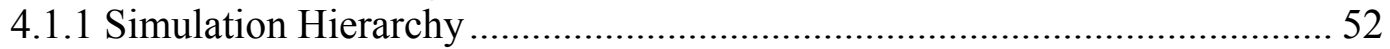

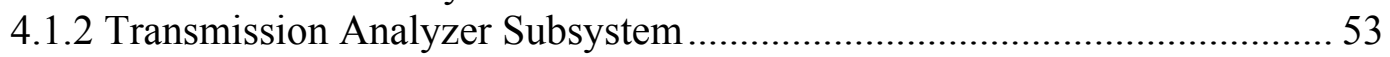




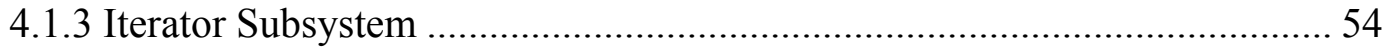

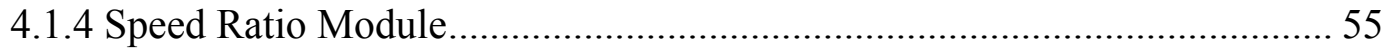

4.1.5 Power Split Module .................................................................................. 55

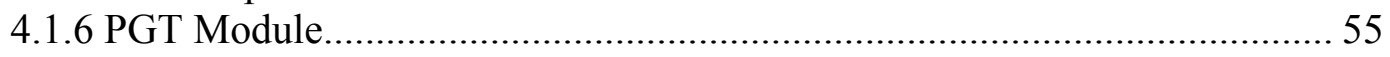

4.1.7 Gear Module ......................................................................................... 55

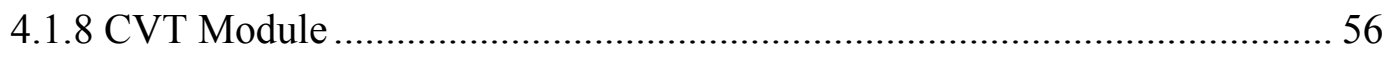

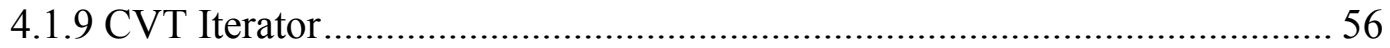

4.1.10 CVT Efficiency Module ........................................................................ 57

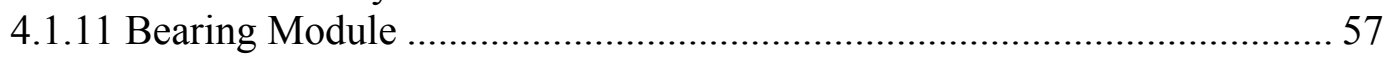

4.2 Modified CVPST Simulation Program ............................................................ 57

4.3 Direct-Drive CVPST Simulation Program ....................................................... 59

Chapter 5 - Continuously Variable Power Split Simulation Results and Analysis......... 61

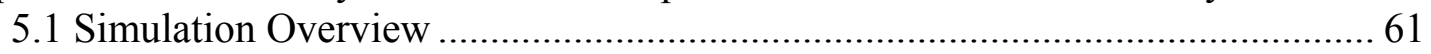

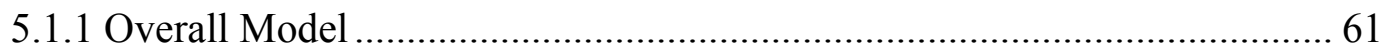

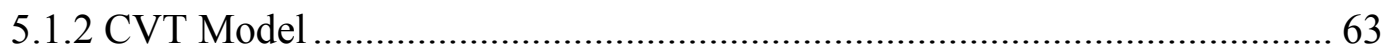

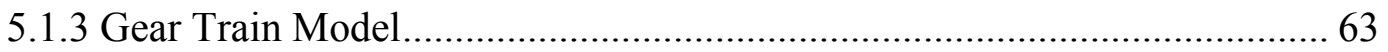

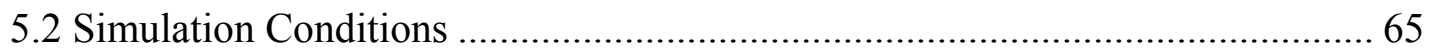

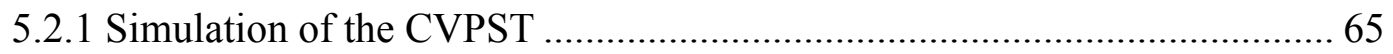

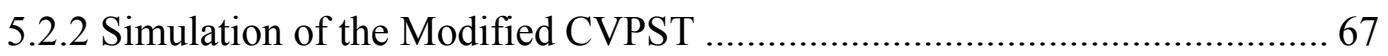

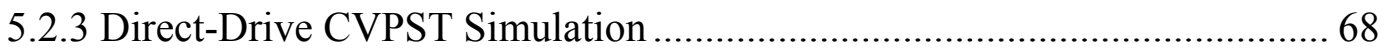

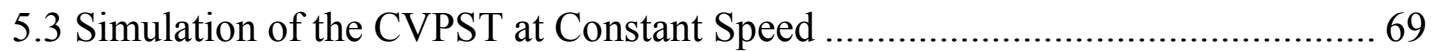

5.4 Simulation of the CVPST at Constant Torque.................................................. 72

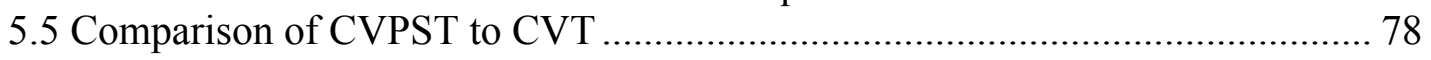

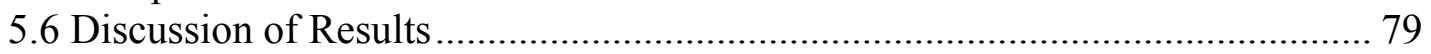

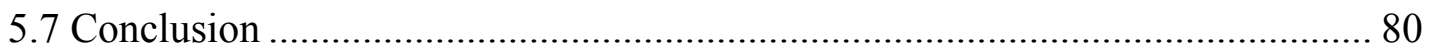

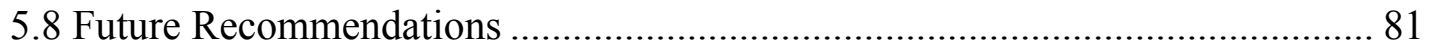

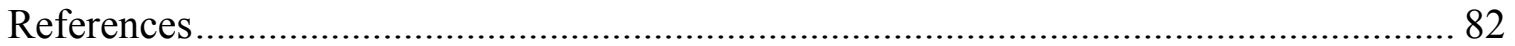

Appendix A - Glossary of Function Blocks ............................................................ 85

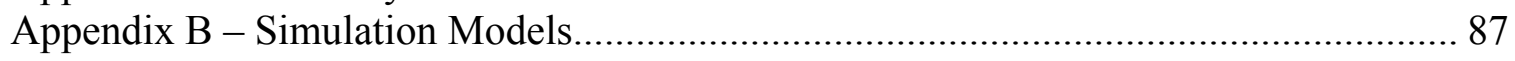

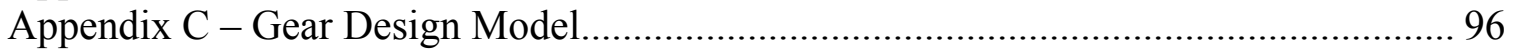

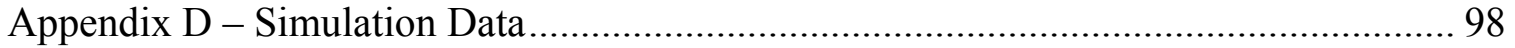

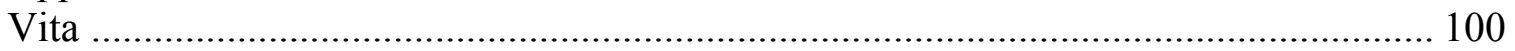




\section{List of Figures}

Figure 1-1. The Operating Principle of the Modified CVPST .......................................... 4

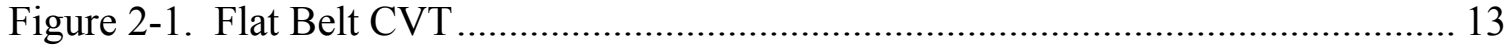

Figure 2-2. Illustration of Operation of Belt and Sheave CVT....................................... 15

Figure 2-3. Cut-away Drawing of Daf 55 Equipped With the Variomatic CVT............ 16

Figure 2-4. Cut-away View of Van Doorne Metal Belt CVT Unit ................................ 17

Figure 2-5. Audi A4 Equipped With the Multitronic CVT ............................................. 18

Figure 2-6. Different Kinematic Arrangements for Traction CVTs ................................ 19

Figure 2-7. Nutating Traction Drive CVT …………................................................ 21

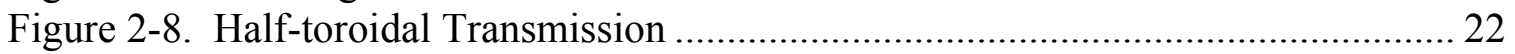

Figure 2-9. Nissan Gloria Equipped With the Extroid CVT ........................................... 23

Figure 2-10. Honda Rubicon ATV With Hondamatic Hydrostatic Transmission........... 24

Figure 2-11. Layout of Series Hybrid for Heavy-Duty Buses ......................................... 25

Figure 2-12. Komatsu 930E Heavy Diesel Truck With Electric Drive ........................... 25

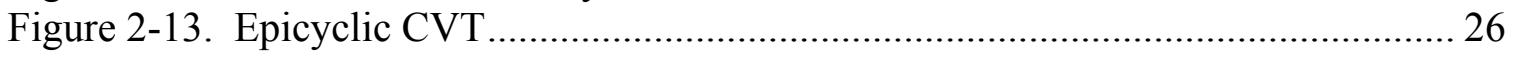

Figure 2-14. Continuously Variable Power Split Transmission ....................................... 29

Figure 2-15. General Motors Infinitely Variable Transmission ........................................ 31

Figure 3-1. Illustration of CVT Arrangements ......................................................... 32

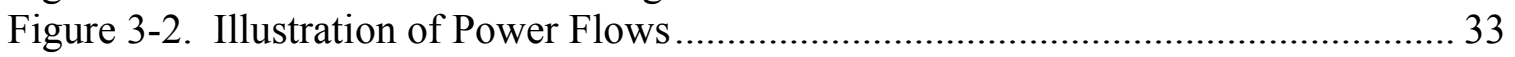

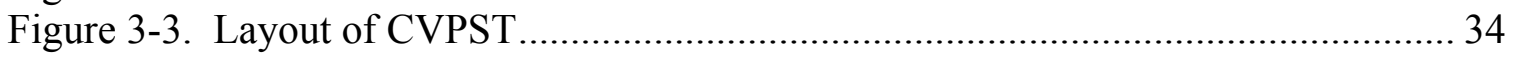

Figure 3-4. Skeleton and Kinematic Graph of Planetary Gear Set.................................. 36

Figure 3-5. Basic Planetary Gear System ................................................................. 36

Figure 3-6. Complete Velocity Diagram for Basic Planetary System .............................. 36

Figure 3-7. Layout of Power-Split Circuit ..................................................................... 38

Figure 3-8. Power Flow in Planetary Gear Set .......................................................... 41

Figure 3-9. Skeleton Diagram of CVPST .................................................................. 45

Figure 3-10. The Interaction of Components and Their Efficiencies in the CVPST....... 48

Figure 3-11. Transmission Power Path in Cruise Mode ................................................ 49

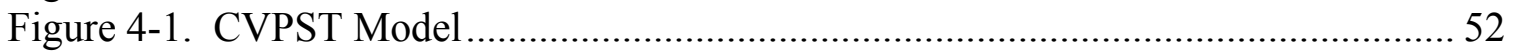

Figure 4-2. CVPST Transmission Simulation Model Hierarchy ...................................... 53

Figure 4-3. Modified CVPST Transmission Simulation Hierarchy ………………….... 58

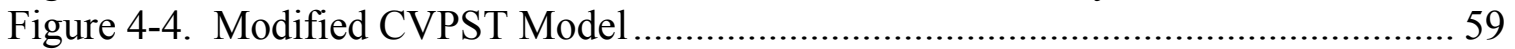

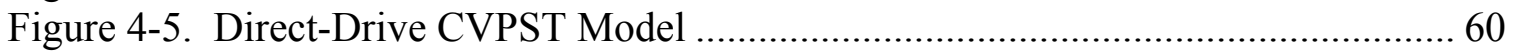

Figure 4-6. Direct-Drive CVPST Simulation Block Diagram.......................................... 60

Figure 5-1. Diagram of Transmission Model ............................................................... 62

Figure 5-2. Graph of the Power Split Factor at the Synchronous Point .......................... 67

Figure 5-3. Simulation Model for Modified Power Split CVPST .................................... 68

Figure 5-4. Simulation Model for the Direct-Drive CVPST ........................................... 69

Figure 5-5. Comparison of Total Transmission Efficiency for Varying Torques at 1000

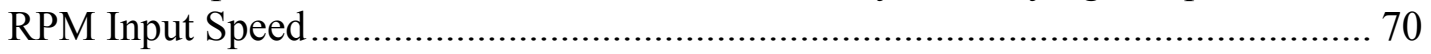

Figure 5-6. Comparison of Total Transmission Efficiency for Varying Torques at 2000

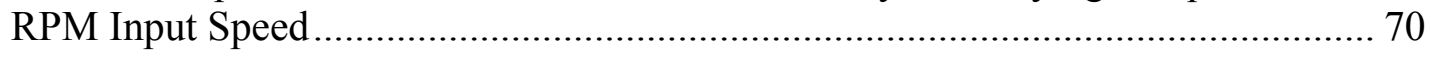

Figure 5-7. Comparison of Total Transmission Efficiency for Varying Torques at 3000

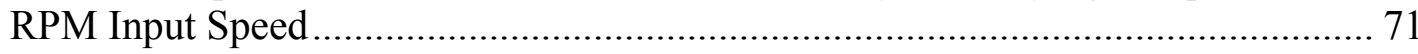


Figure 5-8. Comparison of Total Transmission Efficiency for Varying Torques at 4000

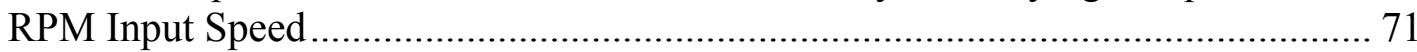

Figure 5-9. Comparison of Total Transmission Efficiency for Varying Speeds at a

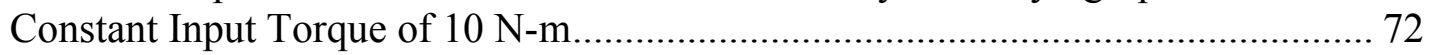

Figure 5-10. Comparison of Total Transmission Efficiency for Varying Speeds at a

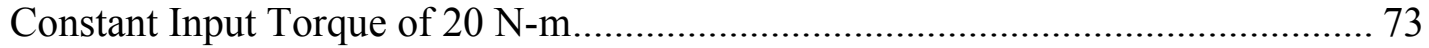

Figure 5-11. Comparison of Total Transmission Efficiency for Varying Speeds at a

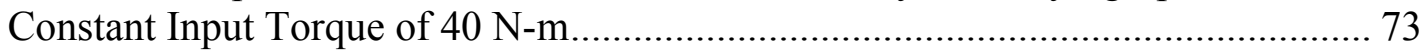

Figure 5-12. Comparison of Total Transmission Efficiency for Varying Speeds at a

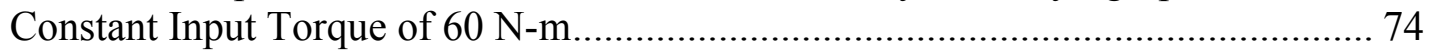

Figure 5-13. Comparison of Total Transmission Efficiency for Varying Speeds at a

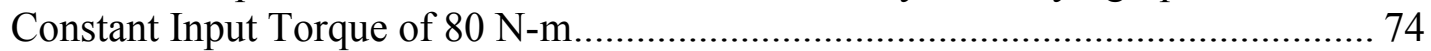

Figure 5-14. Comparison of Total Transmission Efficiency for Varying Speeds at a

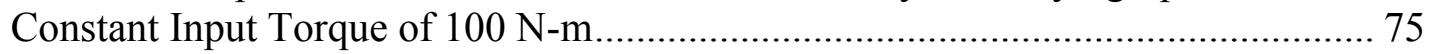

Figure 5-15. Comparison of Total Transmission Efficiency for Varying Speeds at a

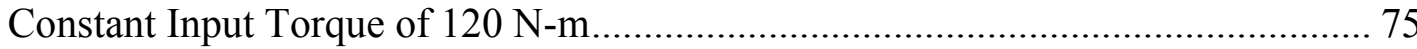

Figure 5-16. This is the Overall Transmission Efficiency for the CVPST in Terms of

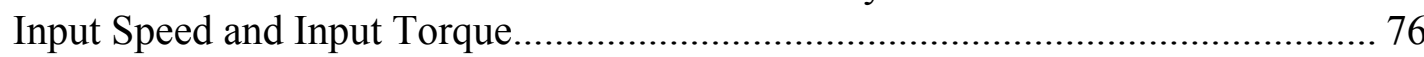

Figure 5-17. This is the Overall Transmission Efficiency for the Modified CVPST in Terms of Input Speed and Input Torque .................................................................. 77

Figure 5-18. This is the Overall Transmission Efficiency for the Direct-Drive CVPST in Terms of Input Speed and Input Torque .............................................................. 77

Figure 5-19. Comparison of the Shaft-to-Shaft CVT Efficiency to the Other CVPST Cases for Varying Torques and a Constant 2000 RPM Input Speed....................... 78

Figure 5-20. Comparison of the Shaft-to-Shaft CVT Efficiency to the Other CVPST Cases for Varying Input Speeds and a Constant $60 \mathrm{~N}-\mathrm{m}$ Input Torque.................... 79 


\section{List of Tables}

Table 2-1. Classification of Continuously Variable Transmission Devices ................... 11

Table 2-2. Belt CVT Efficiencies for Various Operating Conditions ........................... 18

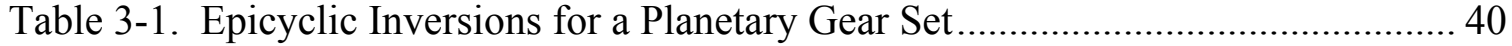

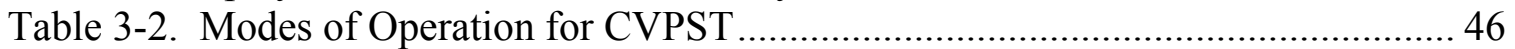

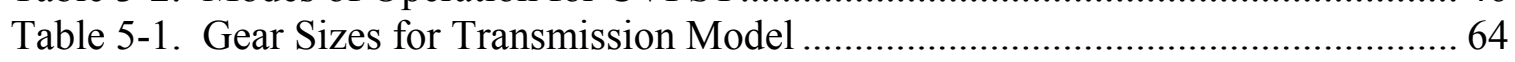

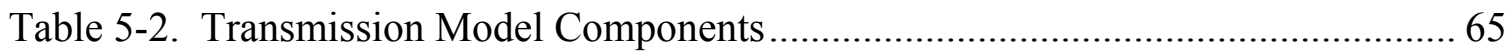

Table 5-2. Comparison of Average Efficiencies for Each Simulation Model ................. 79 


\section{Nomenclature}

\section{Acronyms Used In Document}

$\begin{array}{ll}\text { AMT } & \text { Automated Manual Transmission } \\ \text { CVPST } & \text { Continuously Variable Power Split Transmission } \\ \text { CVT } & \text { Continuously Variable Transmission } \\ \text { IVT } & \text { Infinitely Variable Transmission } \\ \text { PGT } & \text { Planetary Gear Train }\end{array}$

\section{Symbols Used In Document}

\begin{tabular}{|c|c|}
\hline A & Ring Gear \\
\hline $\mathrm{a}$ & Element Connected to the Input Circuit \\
\hline B & Sun Gear \\
\hline $\mathrm{b}$ & Element Connected to the Control Circuit \\
\hline $\mathrm{C}$ & Gear Carrier \\
\hline $\mathrm{c}$ & Element Connected to the Output Circuit \\
\hline $\mathrm{C}_{1}$ & Clutch 1 \\
\hline $\mathrm{C}_{2}$ & Clutch 2 \\
\hline $\mathrm{d}$ & Shaft Diameter, mm \\
\hline Fn & Normal Force at Shaft Surface, N \\
\hline$f_{1}$ & Number of Single Degree of Freedom Joints \\
\hline$f_{2}$ & Number of Dual Degree of Freedom Joints \\
\hline $\mathrm{G}_{1}$ & Planetary Inversion Case \#1 \\
\hline $\mathrm{G}_{2}$ & Planetary Inversion Case \#2 \\
\hline $\mathrm{k}$ & Value at Iteration Step \\
\hline $\mathrm{M}$ & Number of Degrees of Freedom \\
\hline$n$ & Number of Links \\
\hline $\mathrm{N}_{\mathrm{A}}$ & Number of Teeth in Gear A \\
\hline $\mathrm{N}_{\mathrm{B}}$ & Number of Teeth in Gear B \\
\hline $\mathrm{N}_{\mathrm{R}}$ & Number of Teeth on Ring Gear \\
\hline $\mathrm{N}_{\mathrm{S}}$ & Number of Teeth on Sun Gear \\
\hline $\mathrm{P}_{\mathrm{A}}$ & Power in Ring Gear, W \\
\hline $\mathrm{P}_{\mathrm{A}}$ & Corrected Power in Ring Gear, W \\
\hline $\mathrm{P}_{\mathrm{B}}$ & Power in Sun Gear, W \\
\hline $\mathrm{P}_{\mathrm{B}}$ & Corrected Power in Sun Gear, W \\
\hline $\mathrm{P}_{\mathrm{c}}$ & Power at Output Circuit, W \\
\hline $\mathrm{P}_{\mathrm{CIR}}$ & Power Circulating in Branch Control Circuit, W \\
\hline $\mathrm{P}_{\mathrm{IN}}$ & Power at Input Shaft, W \\
\hline$P_{\text {loss }}$ & Power Loss in Transmission \\
\hline $\mathrm{P}_{\text {OUT }}$ & Power at Output Shaft, W \\
\hline $\mathrm{R}$ & $\omega_{\mathrm{a}} / \omega_{\mathrm{c}}$ \\
\hline $\mathrm{r}$ & $\omega_{\mathrm{b}} / \omega_{\mathrm{a}}$ \\
\hline $\mathrm{T}_{\mathrm{a}}$ & Torque at Input Circuit, N-m \\
\hline $\mathrm{T}_{\mathrm{b}}$ & Torque at Control Circuit, N-m \\
\hline
\end{tabular}




\begin{tabular}{|c|c|}
\hline $\mathrm{T}_{\mathrm{BR}}$ & Torque at Branch Control Circuit \\
\hline $\mathrm{T}_{\mathrm{c}}$ & Torque at Output Circuit, N-m \\
\hline $\mathrm{T}_{\mathrm{CVT}}$ & Torque in CVT, $\mathrm{N}-\mathrm{m}$ \\
\hline $\mathrm{t}_{\mathrm{CVT}}$ & Normalized Torque in CVT \\
\hline $\mathrm{T}_{\mathrm{CVT} / \mathrm{MAX}}$ & CVT Maximum Rated Torque, N-m \\
\hline $\mathrm{T}_{\text {OUT }}$ & Torque out of Transmission \\
\hline $\mathrm{W}_{\mathrm{CVT}}$ & Normalized Speed in CVT \\
\hline$\gamma$ & Power Split Factor \\
\hline$\gamma_{\mathrm{CVT}}$ & CVT Speed Ratio \\
\hline$\gamma_{\text {CVT/MAX }}$ & Maximum CVT Speed Ratio \\
\hline$\gamma_{\mathrm{CVT} / \mathrm{MIN}}$ & Minimum CVT Speed Ratio \\
\hline$\gamma_{\mathrm{PGT}}$ & Planetary Gear Train Speed Ratio \\
\hline$\gamma_{\mathrm{T}}$ & Transmission Speed Ratio \\
\hline$\gamma_{\mathrm{T} / \mathrm{MAX}}$ & Maximum Transmission Speed Ratio \\
\hline$\gamma_{\mathrm{T} / \mathrm{MIN}}$ & Minimum Transmission Speed Ratio \\
\hline$\gamma_{1}$ & Gear Train Speed Ratio \\
\hline$\eta_{\mathrm{A}(\mathrm{B}-\mathrm{C})}$ & Efficiency with A fixed, B the input, and C the output \\
\hline$\eta_{\mathrm{B}(\mathrm{A}-\mathrm{C})}$ & Efficiency with B fixed, A the input, and C the output \\
\hline$\eta_{\text {CVT }}$ & Efficiency of CVT \\
\hline$\eta_{\text {gear }}$ & Efficiency of Gear Pair \\
\hline$\eta_{\text {PGT }}$ & Efficiency of Planetary Gear Train \\
\hline$\eta_{\mathrm{T}}$ & Efficiency of Transmission \\
\hline$\eta_{\gamma}$ & Efficiency With Respect To Speed Ratio \\
\hline$\eta_{0.4}$ & Efficiency at Minimum Speed Ratio of 0.4 with respect to Torque \\
\hline$\eta_{1}$ & Efficiency of Gear Mesh in Case \#1 \\
\hline$\eta_{2}$ & Efficiency of Gear Mesh in Case \#2 \\
\hline$\eta_{2.5}$ & Efficiency at Maximum Speed Ratio of 2.5 with respect to Torque \\
\hline$\mu$ & Bearing Coefficient of Friction \\
\hline$\phi_{\mathrm{CVT}}$ & Ratio Span of CVT \\
\hline$\phi_{\mathrm{T}}$ & Ratio Span of Transmission \\
\hline$\omega_{\mathrm{A}}$ & Angular Velocity of Planetary Arm, $\mathrm{rad} / \mathrm{s}$ \\
\hline$\omega_{\mathrm{a}}$ & Angular Velocity at Input Circuit, $\mathrm{rad} / \mathrm{s}$ \\
\hline$\omega_{\mathrm{b}}$ & Angular Velocity at Control Circuit, $\mathrm{rad} / \mathrm{s}$ \\
\hline$\omega_{\mathrm{c}}$ & Angular Velocity at Output Circuit, $\mathrm{rad} / \mathrm{s}$ \\
\hline$\omega_{\mathrm{CVT}}$ & Angular Velocity in CVT, rad/s \\
\hline$\omega_{\mathrm{CVT} / \mathrm{MAX}}$ & CVT Maximum Rated Angular Velocity, $\mathrm{rad} / \mathrm{s}$ \\
\hline$\omega_{\text {IN }}$ & Angular Speed at Input Shaft, $\mathrm{rad} / \mathrm{s}$ \\
\hline$\omega_{\text {OUT }}$ & Angular Speed at Output Shaft, $\mathrm{rad} / \mathrm{s}$ \\
\hline$\omega_{\mathrm{R}}$ & Angular Velocity of Ring Gear, $\mathrm{rad} / \mathrm{s}$ \\
\hline$\omega_{\mathrm{S}}$ & Angular Velocity of Sun Gear, $\mathrm{rad} / \mathrm{s}$ \\
\hline$\omega_{21}$ & Angular Velocity of Link 2 with respect to Link 1, rad/s \\
\hline$\omega_{24}$ & Angular Velocity of Link 2 with respect to Link 4, $\mathrm{rad} / \mathrm{s}$ \\
\hline$\omega_{31}$ & Angular Velocity of Link 3 with respect to Link 1, rad/s \\
\hline$\omega_{34}$ & Angular Velocity of Link 3 with respect to Link 4, $\mathrm{rad} / \mathrm{s}$ \\
\hline$\omega_{41}$ & Angular Velocity of Link 4 with respect to Link 1, rad/s \\
\hline
\end{tabular}




\section{Chapter 1 - Introduction}

During the infancy of automobile development in the late $19^{\text {th }}$ century, it was recognized that varying the drive ratio during vehicle operation would achieve good efficiency and vehicle performance (Chan et al., 1984). Many of the first automobiles to make it to market were equipped with continuously variable transmissions (CVTs) that could vary the ratio range continuously within a range of gear ratios. The CVT was perceived to be superior to conventional gearboxes because, with the CVT, speed ratio can be selected independent of transmitted torque. This was superior to conventional gearboxes because they have discrete gear ratios that must be selected based upon the required torque at a given vehicle speed (Mechanical Engineering, 1984). Unfortunately, the drawbacks of poor reliability and durability, and the poor control schemes developed in that era outweighed the perceived benefits of CVTs, and they were abandoned in favor of conventional transmissions (Chan et al., 1984).

Renewed interest in CVTs in the early 1930's led to the development of a transmission for the British Austin, which was produced in small quantities. General Motors also performed extensive research and development work on the CVT in this time period, but its work was halted at the testing stage of development (Hewko, 1986). This work was resumed in the 1960's by Perbury Gear, which produced an automotive transmission with a higher power capacity. Their success was, in turn, overtaken by the Van Doorne design which has undergone extensive development work over the past four decades to become the most visible and successful CVT design (Fenton, 1996). Cars utilizing transmissions based on the Van Doorne design are currently being produced by automakers such as Audi, BMW, and Honda who recognize that the CVT is lighter, 
simpler, and cheaper than a conventional automatic transmission (Mechanical Engineering, 1984).

While technical development has brought the CVT back into the realm of automotive design, it still suffers from such problems as poor launch feel or reduced high speed fuel economy because of limited ratio coverage and torque capacity (Vahabzadeh, 1990), and the CVT has shorter transmission life at high power densities when compared to conventional transmissions (Hewko, 1986). These problems can be overcome by combining the CVT with one or more epicyclic gears to create a power-split transmission (Beccari and Cammalleri, 2001).

The concept of a power-split transmission is nothing new. Epicyclic, or planetary gears have been well known in the design of transmissions. The unique "summing" characteristic of this gear arrangement allows two power sources to be summed into a single output (Fussner and Singh, 2002). This technology has been used in the hydraulics industry for off-road vehicles and farm equipment.

Interest in power-spit technology for automotive applications began in the 1980's with renewed research at GM (Macey and Vahabzadeh, 1987). They recognized that the range of the CVT could be extended with the use of a planetary gear set. This design did not require the starting clutch or reversing mechanism of other transmissions, but its arrangement placed a greater power demand on the CVT (Vahabzadeh and Macey, 1990). Other designs actually placed less of a load on the CVT for a true power-split design (Mucino et al., 1997). It was recognized through this research that the qualities of extended ratio range and extended power envelope were inversely proportional (Beccari and Cammalleri, 2001). 
It is recognized that the power capacities of CVTs still fall far short of the power output of large-displacement engines used in larger automobiles. These power capacities can be extended when the CVT is combined with an epicyclic gear set (Beccari and Cammalleri, 2001), and the life of the CVT can be extended if its transmitted power is kept to a minimum (Hewko, 1986)

\subsection{Problem Statement and Thesis Objectives}

\subsubsection{Design Hypothesis}

All the previous work in the field of continuously variable transmissions have been concerned with improving the efficiency and power capacity of the variable unit through better designs and materials. The only proposed alternative route to improving CVT efficiency has been to combine it with an epicyclic gear set in order to extend its power envelope. Vahabzadeh (1990) and, most recently Torotrak transmissions have modified this concept by adding a combination of clutches to their systems so that the transmission operates as an IVT for part of the operating cycle and a direct shaft-to-shaft CVT for another part of the cycle (Brockbank and Heumann, 2002).

An alternative dual-range design could operate for part of the driving cycle like previous transmissions, but the second range would be different from previous designs. Instead of directing all of the power flow through the variable element, the power flow could be directed through the conventional gears. In this design, there would be a directdrive mode that could eliminate CVT inefficiencies by disconnecting it from the power path for a single speed ratio (Figure 1-1). 


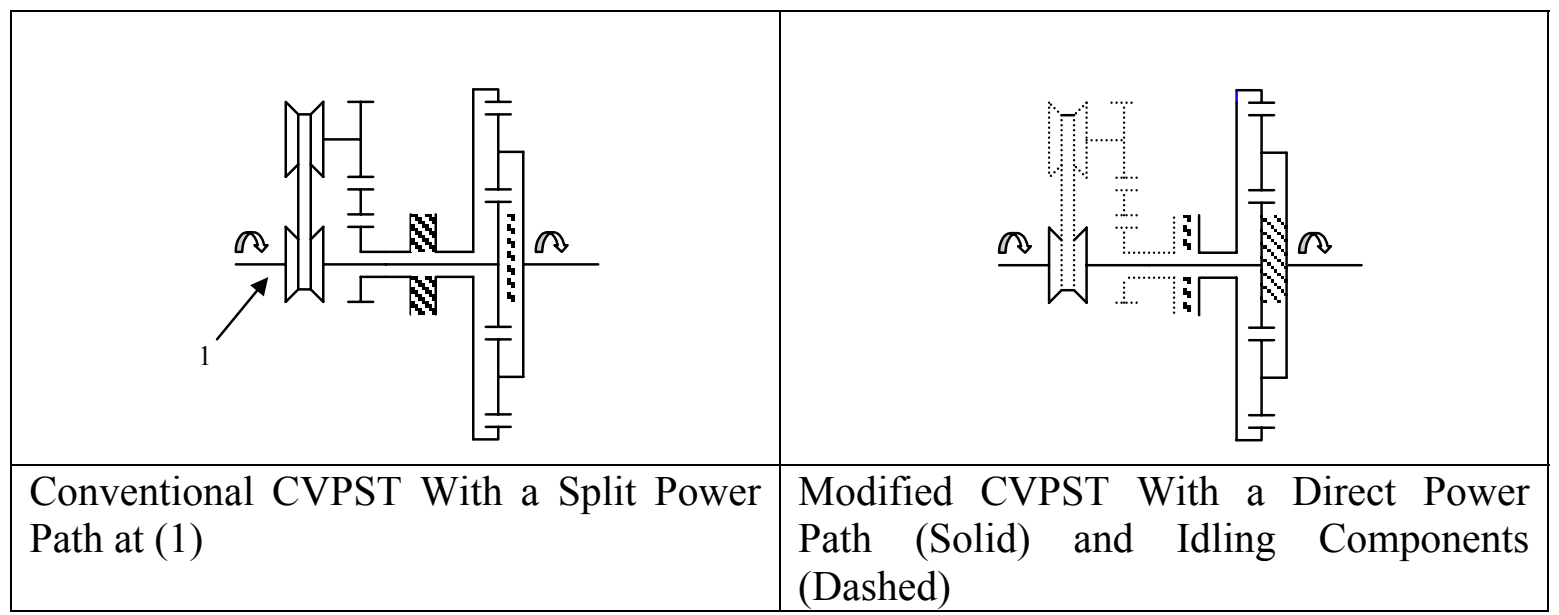

Figure 1.1. The Operating Principle of the Modified CVPST

\subsubsection{Problem Statement}

It is unknown whether a dual-mode CVPST will be any more efficient than a conventional CVPST with one, continuously variable mode, or whether parasitic losses from idling components will decrease overall efficiency to the point that it does not justify the extra complexity, cost, and weight of the transmission.

\subsubsection{Thesis Objectives}

The objective of this work will be to evaluate the efficiency of a common CVPST, a modified CVPST that disengages the branch control circuit at the ring gear shaft, and a pure direct-drive CVPST that disengages the branch control circuit at the input shaft. This analysis will be performed at the 1:1 input/output ratio where the planetary gear set is synchronized.

\subsubsection{Scope}

This first part of this study will be centered on deriving all of the relations that apply to power-splitting transmissions so that the power flows in all modes of operation are known. Then, the parasitic losses due to bearing friction, gear friction, and CVT friction will be calculated for a range of operating conditions. The three transmission 
arrangements will be evaluated for steady-state power losses at constant velocity and constant torque where there is no angular acceleration. The kinematic and dynamic relations will be derived, and then they will be applied to actual system design if any of the last two arrangements can be used for direct drive at high speeds without CVT losses. 


\section{Chapter 2 - Review of Relevant Literature}

\subsection{Current State of the Art}

The automotive transmission has undergone many changes and improvements over the lifetime of the automobile, but the established methods of power transmission have remained basically the same for most of that period. Even though systems such as CVTs, electric, and hybrid-electric drive trains have made inroads into the automobile marketplace at different times over the past century, the gearbox with discrete, shifting gear ratios has still been the standard by which other systems are judged. Even though the basic transmission designs have been around for most of the past century, continued refinement and research has improved conventional transmissions to the point where they will be accepted as the standard until a truly cost effective and efficient piece of technology can replace them (Wagner, 2001).

Currently, the two standard designations in automotive transmissions are the manual and automatic transmission. These are established designs, which are familiar to almost any driver, but recent improvements in both technologies have blurred the line between the two systems in an attempt to improve efficiency and the driver experience.

\subsubsection{Manual Transmissions}

The manual transmission is a system that is distinctive because of the driver's role in its operation; in this system, the driver undertakes the actuation force. The driver's right (or left) foot applies actuation force to the clutch while the left (or right) hand shifts between the gear ratios. There is a mechanical connection between the actuation elements of the clutch pedal, shift lever, and the transmission (Wagner, 2001). The driver 
is responsible for modulating the engine throttle in harmony with the clutch so that there is enough torque available for smooth transitions from a standing stop to motion, and the driver must select the proper gear ratio at a given vehicle speed for acceptable performance and economy.

The manual transmission system can be divided into two parts, the gearbox and the clutch. Inside of most modern gearboxes, there are two parallel gear shafts that typically contain thirteen gears and four synchronizers. These gear shafts are supported across their length by three bearings. The gears are helical cut, and they are typically manufactured from high strength steel and heat-treated to an Rc 58 value (Kluger and Long, 1999). Designs with more or less forward gear ratios will only vary in the number of gears and synchronizers, as a significant increase in forward gear ratios would require another gear shaft. The clutch is interposed between the gearbox and the engine, and it serves two functions. The first function of the clutch is to allow the transmission and engine to be disconnected for the selection of a new gear ratio. The second function is to allow the driver to modulate the clutch so that the proper amount of torque is available for starting the vehicle from rest. This design is advantageous in that the driver can modify the shifting schedule so that the desired performance or economy is attained. The main disadvantage is that the power flow is interrupted during a gear shift when the clutch is engaged which can hurt performance during hard acceleration (Wagner, 2001).

The manual transmission operates by passing power from the input shaft to a lay shaft, and then transmitting power from that lay shaft back to the output shaft. In this design, all of the gears stay in mesh and rotate at all times. Individual gears are locked to the output shaft by means of a splined shift collar activated by the gearshift lever that 
changes the gear ratios. The resulting power path for this transmission starts from the engine, moves through the clutch into the input shaft, from the input shaft into the lay shaft, and then it moves from the lay shaft to the output shaft and into the differential. This path is used for all but the direct-drive fourth gear, where a 1:1 input to output ratio exists. An average efficiency for the common five-speed manual transmission is 96 percent with a 3-5 percent increase in the direct-drive gear. Reducing the torquedependent losses in the gears, reducing bearing losses, and minimizing the windage losses in the transmission case can increase the efficiency, but this increase would only be about one percent (Kluger and Long, 1999).

\subsubsection{Automated Manual Transmissions}

The automated manual transmission (AMT) is essentially the same as a standard manual transmission, but the actuation force for the clutch and gearshift lever is provided by hydraulic or electronic actuators. The mechanical connection between the shift lever is omitted while the clutch pedal is eliminated altogether. In this design, there is a control system that manages clutch operation while the gear shifts can be controlled by either the driver or shifted automatically.

This system was first designed for racing applications. The aim was to shorten the gear shifting time and relieve the driver. Manufacturers such as Alfa Romeo, BMW, and Toyota identified that the AMT had the cost and efficiency benefits of the standard manual transmission with easier operation, and these manufacturers have AMTs available. These transmissions will become more prevalent in the future, but the issues of control complexity and driver comfort will have to be addressed further if they are to displace automatic transmissions completely (Wagner, 2001). 


\subsubsection{Automatic Transmissions}

Automatic transmissions with multiple gear ratios are mechanical transmissions that shift on their own. The driver does not disengage the clutch to engage the driveline or select gear ratios with a gearshift lever. Because there is no clutch to engage, gear shifting occurs without an interruption of power through the driveline, and these shifts are executed automatically with a shifting program in the transmission (Wagner, 2001).

The automatic transmission is divided into three main parts, the pump, torque converter, and gearbox. The pump is a driven accessory that pressurizes the transmission fluid to supply the torque converter and valve body. These pumps can be either crescent type, gerotor, or hypocycloidal, with some manufacturers also moving toward variable displacement pumps to improve efficiency (Kluger and Long, 1999). The torque converter is a fluid coupling that allows smooth, automatic gearshifts without interrupting the power flow through the transmission. The torque converter, like the clutch in a manual transmission, is also located between the engine and the gearbox. Most modern torque converters are based on the hydrokinetic type patented by Fottinger in 1905 . In these torque converters, the drive shaft-mounted impeller imparts kinetic energy to a fluid, which is transferred to the driven turbine member (Fenton, 1996). At low engine speeds, the torque converter's fluid coupling is not transferring much torque to the vehicle, and the vehicle can be held still with the brake pedal, while increasing engine speeds increase the torque output of the torque converter. The transmission can be shifted under power as this just changes the speed of the driven turbine in the fluid coupling. The gearbox in most common automatic transmissions uses epicyclic gears to shift between ratios. These gearshifts are accomplished through activating a combination 
of bands and internal clutches which are operated by either a mechanical-hydraulic or electronic control system.

The automatic transmission operates by passing power through the torque converter to the input shaft of the gearbox. This input shaft is then connected to the sun, ring, or planet carrier of a planetary gear set by means of bands and clutches that can connect, disconnect, or constrain these elements to produce multiple forward and reverse gear ratios. The control system of the automatic transmission must operate these bands and clutches sequentially in order to get the correct gear ratio for a given set of vehicular operating conditions. These control systems used to be purely mechanical and hydraulic, but microprocessor control systems are now the standard.

Unlike the standard transmission, the automatic transmission has many components that require power to operate. The major sources for losses are in the pump and torque converter, and gearbox losses are comprised of gearbox windage, torque losses in the gear, bearing losses, and clutch pack drag. Variable displacement pumps and better design have minimized the pump losses, while torque converter losses can be reduced by installing a lockup clutch between the impeller and turbine. The gearbox losses can also be reduced through more thorough design of the individual components. The average mechanical efficiency of modern five-speed automatic transmissions are around 85 percent, and further modifications to the current designs would only yield about a one percent improvement in mechanical efficiency (Kluger and Long, 1999). 


\subsection{Continuously Variable Transmissions}

A continuously variable transmission (CVT) is a power device whose speed ratio can be varied in a continuous manner. A CVT transmits power without any abrupt changes in output torque and speed, and it has an infinite number of intermediate speed ratios between the bounds of its highest and lowest speed ratio (Singh and Nair, 1992). This aspect of the CVT has been very attractive to automotive designers as tightening environmental regulations, increased performance requirements, and increased emphasis on customer satisfaction have forced them to rethink the automotive powertrain (Chan, 1986). Even though automatic and manual transmissions will still dominate the market for some time to come, CVTs will have an increasing presence in the automotive landscape (Wagner, 2001).

The CVT concept has been around since the fifteenth century when Leonardo da Vinci made a sketch that indicated the potential of the stepless continuously variable transmission (Birch, 2000). Of these designs, there have only been a few that have received significant attention from automotive designers. These CVT designs can be classified into five categories: these are friction CVTs, traction CVTs, hydrostatic CVTs, electric CVTs, and other variable geometry CVTs (Table 2-1).

Table 2-1. Classification of Continuously Variable Transmission Devices

\begin{tabular}{|l|l|}
\hline \multirow{2}{*}{ Friction Type } & - Rubber Flat Belt CVT \\
& - Rubber V-Belt CVT \\
& - Metal Pushing Belt CVT \\
\hline Traction Type & - Nutating Traction Drive CVT \\
& - Toric CVT \\
\hline Hydrostatic CVT & - Hydraulic Pump and Motor \\
\hline Electric CVT & - Series Hybrid Vehicle Drive \\
\hline Variable Geometry CVT & - Epicyclic CVT \\
& - Other Designs \\
\hline
\end{tabular}




\subsubsection{Friction Type CVT}

The definition of a friction type CVT is a transmission device that uses friction as a medium for power transmission. This friction is of the "static" type in that the design is intended to transmit power from one element to the other with no relative displacement between the two elements (Hewko, 1986). An example of this phenomenon is the variable diameter pulley and belt system, where the belt slides axially or radially, but frictional force prevents tangential belt slip (Kluger and Fussner, 1997).

The most general arrangement for friction type CVTs consists of two pulleys and a flexible belt. This arrangement transmits power in the same fashion as the common fixed diameter pulleys, but the variable diameter of these pulleys is what makes the friction CVT unique. These pulleys can vary in diameter, with the driving pulley increasing in diameter while the driven pulley decreases in diameter, or vice versa. The mechanism for the pulley diameter variation and the belt material is what varies in these particular CVTs.

\section{Rubber Flat Belt CVT}

The rubber flat belt CVT is a device that uses a flat elastomer belt that is based upon the internal combustion engine fixed-radius type engine timing belts. Variable diameter pulleys are utilized in order to allow for a continuously variable speed ratio.

The belt used in this design is normally fabricated from high strength tensile members; usually this is Kevlar cords in an elastomer matrix such as neoprene. Because the belt is flat, more of the allowable belt tension can be devoted to transmitting power than generating belt to sheave forces (Kluger and Fussner, 1997). This is because the flat belt has a large amount of its surface area on the interior surface where it interacts with 
the belt drive elements on the pulleys, so a normal force does not need to be applied to any of the other surfaces of the belt to increase torque transmission.

The variable diameter pulley consists of a number of belt drive elements, positioned radially by the intersection of logarithmic spiral slots to adjust the pulley diameter. In each pulley, the spiral slots are opposing in direction, and the belt drive elements are supported by the intersection of the spiral tracks on each side of the pulley. These contact elements form a discontinuous "pulley" which varies in diameter as the belt drive elements move inward and outward on their individual tracks when a hydraulic actuator rotates the disks with respect to the pulley center (Fig. 2-1). There is a hydraulic actuator on the driving and the driven pulley, and a typical control system will set the hydraulic pressure in one actuator to maintain belt tension, while the hydraulic pressure in the other actuator sets the speed ratio (Kluger and Fussner, 1997).

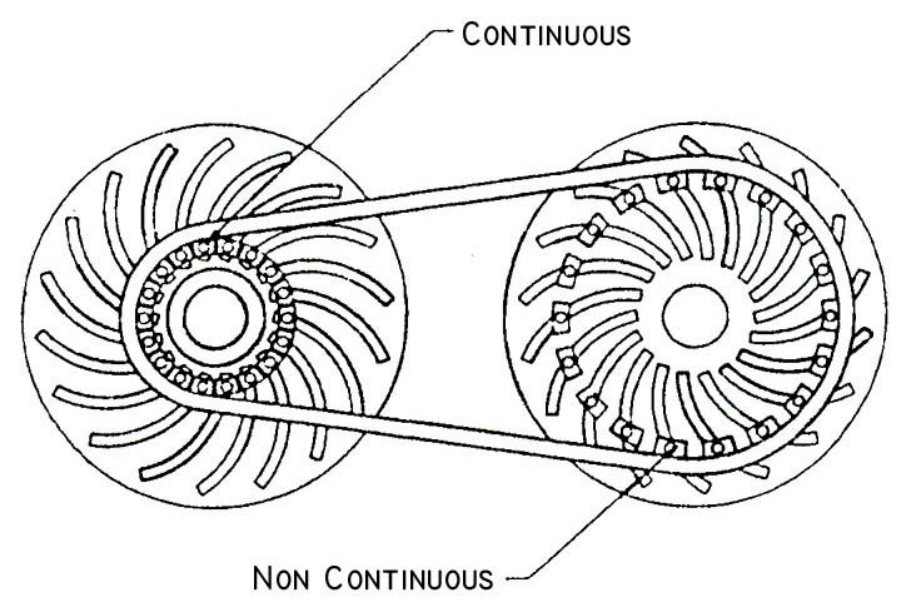

Figure 2-1. Flat Belt CVT (Kluger, 1997)

The flat belt CVT can attain belt efficiency values as high as 97 percent at high power levels and high driven pulley speeds, whereas the belt efficiency is around 94 percent for 
light loads. The steady state efficiency drops off as the output pulley speeds increase above 3000 revolutions per minute (Kluger and Fussner, 1997). Currently, there are no major automobile manufacturers marketing vehicles with this transmission, as the power rating of this unit is still too small for automotive use.

\section{Rubber V-Belt CVT}

The rubber V-belt CVT is a device that uses an elastomer belt similar in design to the flat belt CVT. Variable diameter pulleys are utilized in order to allow for a continuously variable speed ratio. Unlike the flat belt CVT, the variable pulleys used in this design consist of split, conical pulleys where the conical sections are able to move axially. The continuously variable ratio results from contracting one set of conical sheaves while expanding the set on the other shaft (Fig. 2-2). The belt rides on the surface of these sheaves, so it moves radially inward on one set and radially outward on the other. This stepless change in sheave diameter is what causes the stepless ratio change in the transmission. The mechanism for the sheave motion is usually either a hydraulic actuator or a mechanical spring system.

The belt used in this design is constructed in a similar fashion to the belt in the flat belt CVT, but its design is modified to accommodate different loading conditions. The friction surface on this belt is comprised of the two sides of the belt that mate with the conical sheaves on the pulley, so the belt must be squeezed in order to prevent slip. This creates a loading condition on the belt, which is a combination of a buckling load over the axial surface of the belt and a tensile load on the belt between the two pulleys (Kluger and Fussner, 1997). The power is transmitted from the tensile force on the belt as a result of the friction force created by the sheaves pressure on the belt, so the belt 
stress is the limiting factor in the power capacity of a V-belt CVT (Beccari and Cammalleri, 2001).

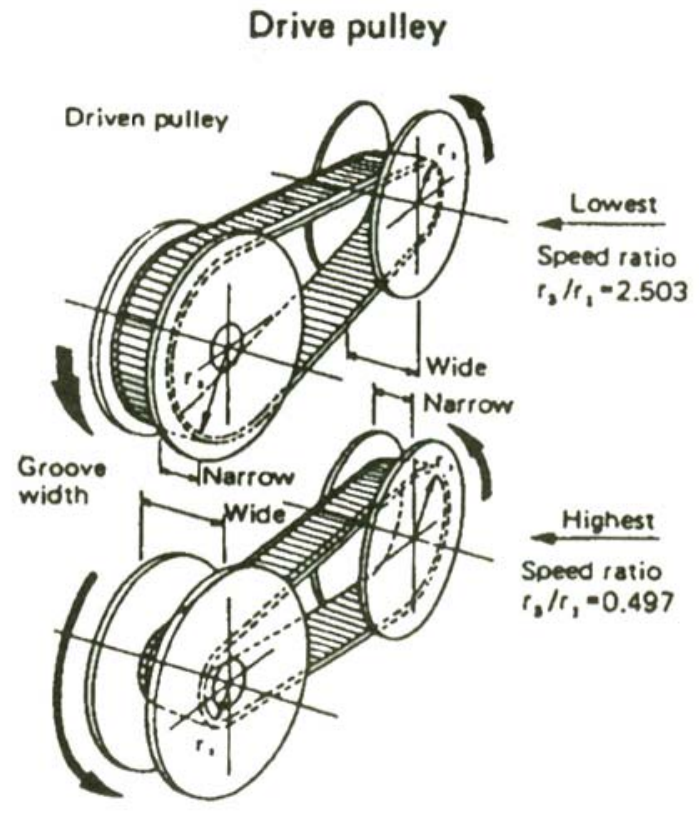

Figure 2-2. Illustration of Operation of Belt and Sheave CVT (Fenton, 1996)

The split-conical sheave design of the V-Belt CVT requires some source of axial force in order for the transmission to transmit power efficiently. There are CVTs in which the axial thrusts on the movable sheaves are produced by simple devices (helical springs, centrifugal masses, etc.), which require no sophisticated regulation system (Mantriota, 2001). These transmissions are usually found in the lower end of the power spectrum in such vehicles as snowmobiles, go-karts, and personal scooters. For higherpowered applications, the CVTs are controlled with hydraulic actuators with either mechanical or electronic regulation schemes. In these automotive designs, the addition of either a starting clutch or a torque converter is required just as in a conventional transmission (Vahabzadeh and Macey, 1990). 
The design for the V-Belt CVT is credited to Hub Van Doorne, who designed the system for a Dutch car called the Daffodil, or Daf (Fig. 2-3). Introduced in 1959, the transmission was marketed as the Variomatic, and was fitted into the Daf 33. The original Van Doorne design had a transmission range between 16.4 and 3.9:1, and it was mated to a $0.6-$ liter engine. This design used a combination of mechanical and electropneumatic actuators to control the transmission (Fenton, 1996). The Van Doorne design went through continuous development from that original design until the present even though Daf was bought out by Volvo in the 1970's, and the Variomatic became the most successful CVT produced in the automotive marketplace with production ending in 1991 (Ritzinger, 2003).

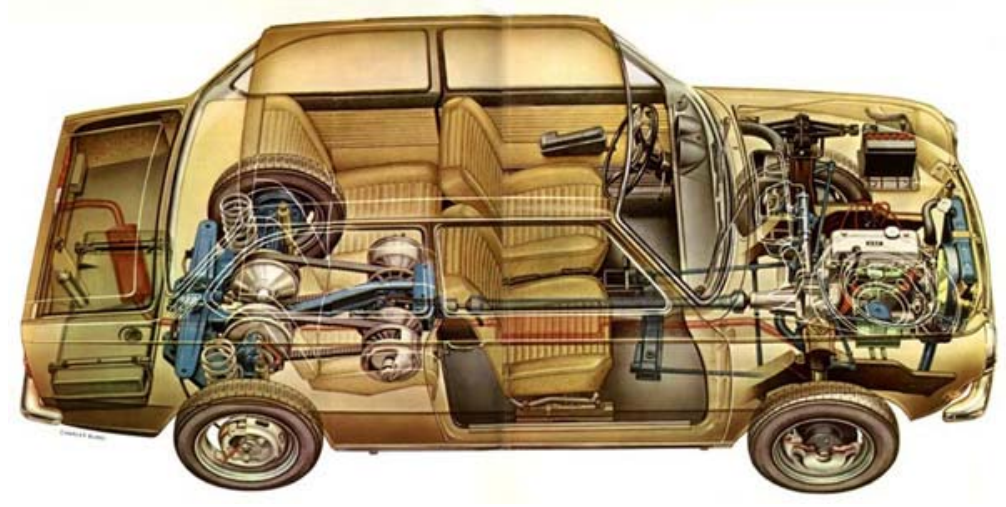

Figure 2-3. Cut-away drawing of Daf 55 equipped with the Variomatic CVT (Ritzinger, 2003)

\section{Metal Pushing Belt CVT}

The metal pushing belt CVT is a refinement of the original Van Doorne design. Its operation is based on the same principles as the earlier design, but a metal belt is used for increased power capacity (Fig. 2-4). 


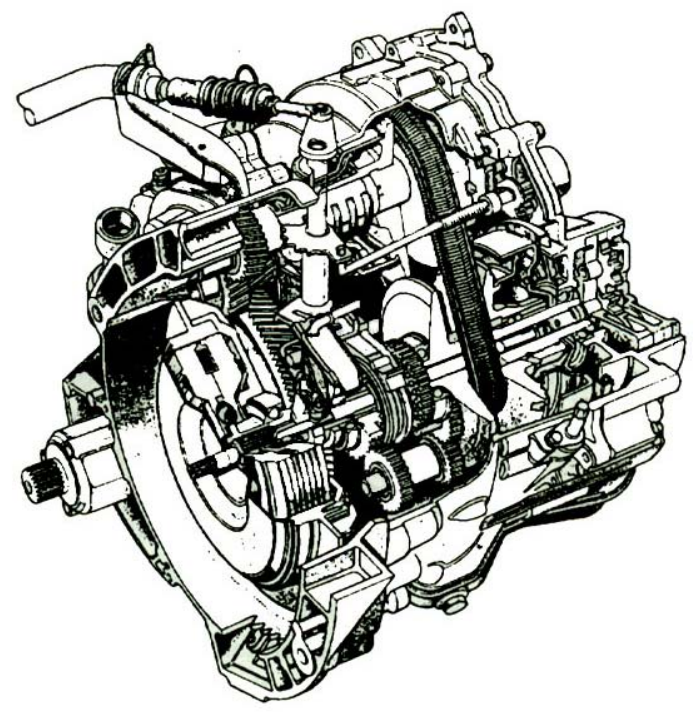

Figure 2-4. Cut-away View of Van Doorne Metal Belt CVT Unit (Fenton, 1996)

The metal belt consists of segmented, thick-stamped steel blocks with cutouts on both sides that contain stacked ribbons of steel referred to as bands. The metal cutouts are stacked onto these bands so that they form a belt that is flexible enough to wrap around the drive sheaves while being rigid in compression. The metal belt has more buckling strength than the previous rubber design, so a greater amount of axial force can be applied to the belt by the sheaves. The metal belt can also transmit more power than its rubber counterpart because it transmits power with compression rather than tension because the steel blocks resist deformation to transmit power whereas the rubber belt transmits power through belt tension. There is still a component of tension in this design because the tension in the steel bands needs to be sufficient enough to prevent bucking of the stack of steel blocks while holding them in contact with the sheave faces with enough normal force to generate adequate tangential friction forces. Thus, the steel bands are the limiting factor in the metal pushing belt CVT (Kluger and Fussner, 1997). 


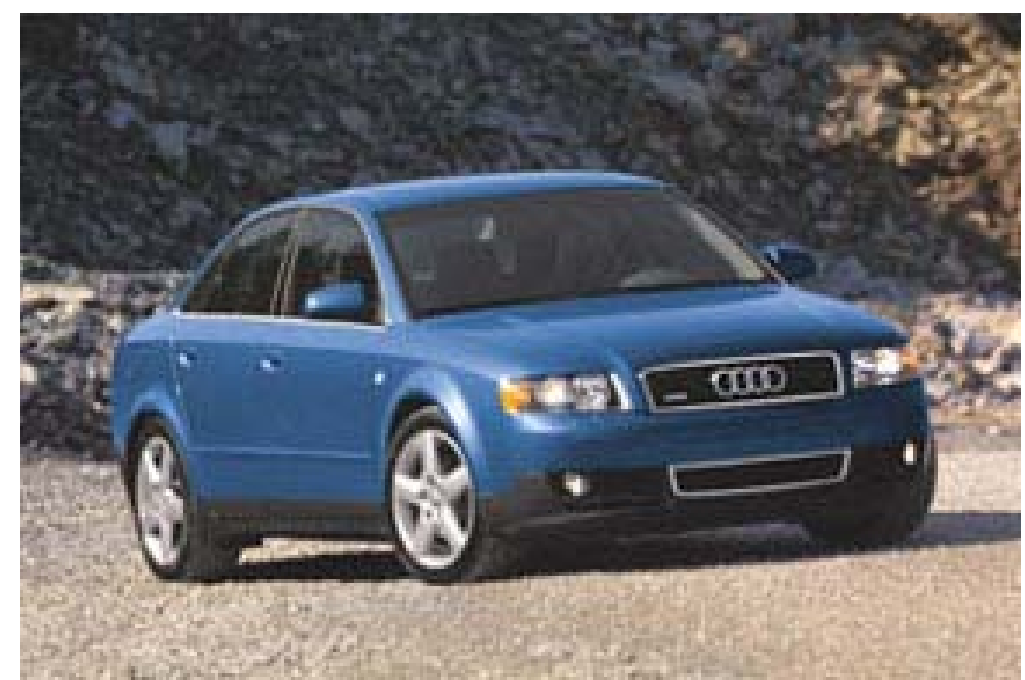

Figure 2-5. Audi A4 Equipped With the Multitronic CVT (Csere, 2002)

The Van Doorne transmission equipped with the metal pushing V-Belt was introduced in 1976 as the Transmatic transmission. This design soon became the standard for CVT applications in automobiles. Currently, almost all of the CVTequipped automobiles sold worldwide utilize a transmission based around the Van Doorne design. These transmissions have continued to improve in refinement, power capacity, and performance (Table 2-2). Whereas the original application of the Van Doorne design was for a 0.6-liter engine, the new Multitronic metal pushing belt CVT from Audi (Fig. 2-5) is designed to handle the output for a 3.0-liter engine (Wagner, 2001).

Table 2-2. Belt CVT Efficiencies for Various Operating Conditions (Kluger, 1999)

\begin{tabular}{|c|c|c|c|}
\hline & Low-Speed Ratio & Mid-Speed Ratio & High-Speed Ratio \\
High-Input Torque & Mid-Input Torque & Low-Input Torque \\
Mid-Speed & $84 \%$ & $86 \%$ & $77 \%$ \\
High-Speed & $86 \%$ & $89 \%$ & $80 \%$ \\
\hline
\end{tabular}

\subsubsection{Traction Type CVT}

The definition of a traction type CVT is a transmission that uses rolling contact between two rotating bodies to transmit power. Traction drives transmit power through 
tractive forces, which are a function of the radius at the location where the tractive forces are applied (Kluger and Long, 1999). Kinematically speaking, any smooth body in revolution in contact with another smooth body of revolution can be considered a traction drive, but a traction CVT uses this contact in conjunction with a variable contact radius to achieve stepless changes in ratio (Fig. 2-6). Traction drives that used purely rolling contact were the earliest designs for automotive applications. These traction CVTs rely upon the frictional contact of dry surfaces, and their resulting power capacity is limited (Hewko, 1986).

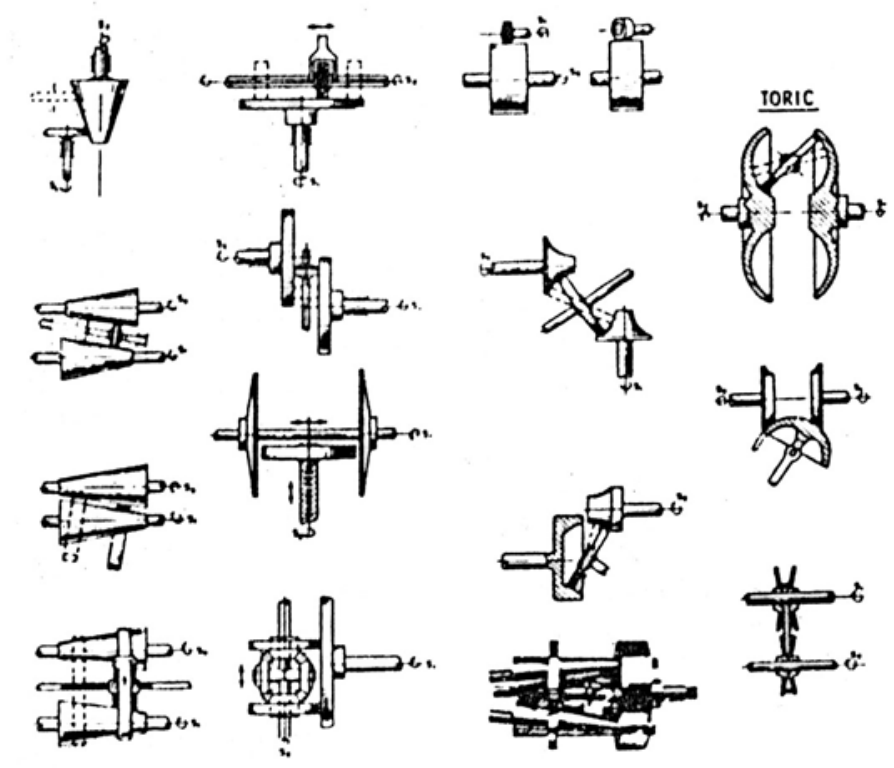

Figure 2-6. Different Kinematic Arrangements for Traction CVTs (Hewko, 1986)

The advent of traction fluids has greatly increased the power capacity of traction drives. Two rolling elements in contact place the traction fluid between them into extreme shear. At pressures around $2.8 \mathrm{GPa}$, the traction fluid viscosity increases to the point where the fluid becomes almost glasslike. Under these conditions, the transmission can transmit a high level of torque (Kluger and Long, 1999). Traction fluid also lubricates and cools the traction elements, which are constructed of high strength steel 
(Hewko, 1986). The continued development of traction drive CVTs will center on the improvement of traction fluids and traction element materials, because the size, and therefore the weight, of traction drives is directly related to the traction coefficient of the traction fluid (Kluger and Long, 1999).

\section{Nutating Traction Drive CVT}

The nutating traction drive CVT is a transmission comprised of conical rollers and control rings situated inside of a transmission casing. In this design, the input and output shafts are aligned on the same axis, and the entire transmission is contained inside of a cylindrical case. The heart of this transmission is a dual cone element. This dual cone element is comprised of two hollow, metal cones that are joined at the base with a shaft through the center of these driving cones that is supported by bearings. A carrier in which one end is connected to the input shaft supports this cone shaft, and a bearing supports the other. The cone shaft is mounted to this carrier at about a 20-degree angle, with the center of the cone shaft intersecting the transmission centerline (Fig. 2-7). Because of this angled arrangement, when the carrier rotates, the cone shaft "nutates" around the transmission axis. This compound motion is a result of the cone shaft being in rolling contact with the control rings. The output end of the cone shaft is connected to a gear, which contacts a ring gear connected to the output shaft of the transmission. The compound rotation of the cone shaft creates a motion analogous to that of the carrier of the planetary gear set, and the axial movement of the control rings changes the speed of the cone shaft, and hence the transmission ratio (Kluger and Fussner, 1997). 


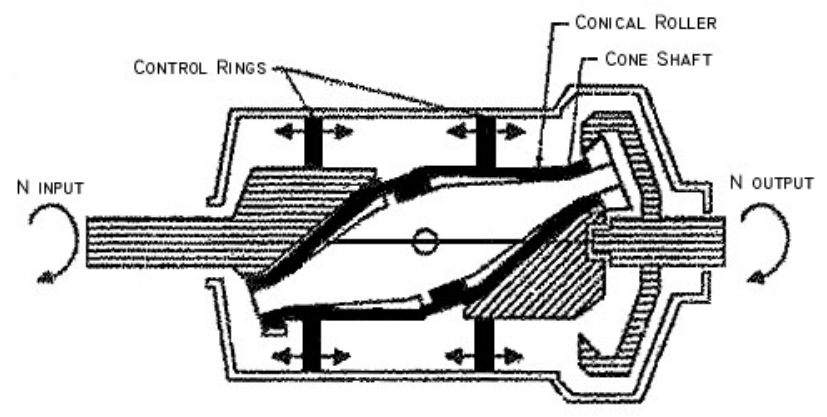

Figure 2-7. Nutating Traction Drive CVT (Kluger, 1997)

The nutating traction drive CVT was attractive to automobile and tractor manufacturers because its linear layout was superior to the parallel shaft layout of the Van Doorne design. This layout is better suited to the north-south layout of conventional cars and light trucks and rear wheel drive tractors. Vadetec Corporation developed this design for automotive use, but, to date, it has never been developed for series production (Hewko, 1986). The transmissions that were produced exhibited very good mechanical efficiency, with values of 90 to 96 percent being typical (Kluger and Long, 1999).

\section{Toric CVT}

The toric CVT is a transmission comprised of two toric races facing each other with three rollers equally spaced at 120 degrees inside of the toric cavity. The outside diameter of these rollers is equal to the transverse diameter of the torus, while the centers of the rollers are located on its pitch diameter (Hewko, 1986). This transmission transmits power into the input torus, which is in rolling contact with the rollers. These rollers then impart a rolling motion on the output torus. Changing the angle of the rollers relative to the transmission centerline effectively controls the speed ratio of the 
transmission (Fig. 2-8). When the roller planes are inline with the transmission axis, a 1:1 transmission ratio results. When the rollers are turned in either direction, either an under drive or overdrive condition results (Kluger and Fussner, 1997).

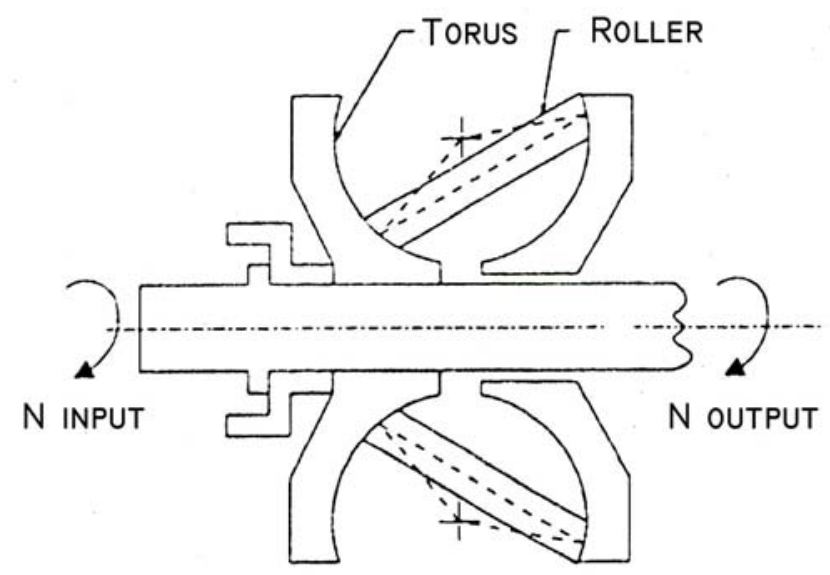

Figure 2-8. Half-toroidal Transmission (Kluger, 1997)

The toric CVT is one of the oldest traction CVT drive designs to be designed for use in passenger cars. The first toric CVT was manufactured by Hayes for the Austin automobile in the 1930's. Further development work on the toric design was pursued by General Motors off and on through the 1960's (Hewko, 1986). The Perbury gear emerged early 1970's with a toric design that could transmit $100 \mathrm{bhp}$ at 92 percent efficiency. This design was further developed and enhanced, and it culminated into the Torotrak transmission design (Fenton, 1996). The latest toroidal transmission design to reach the market was the Extroid transmission manufactured by Nissan Motors Corporation (Nissan). This transmission was mated to a 3.5 liter six cylinder engine, and it was designed for full-sized sedans (Nissan) in the Japanese market (Fig. 2-9) 


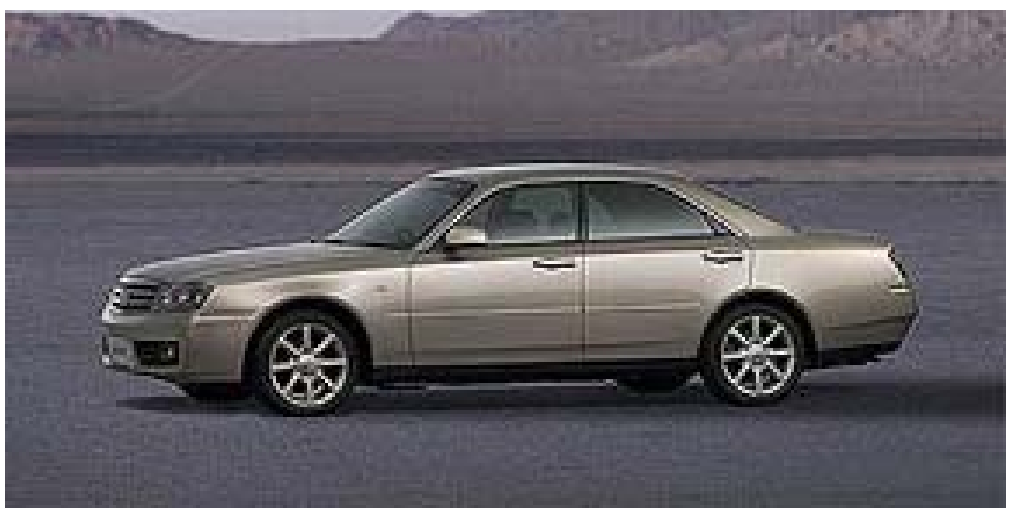

Figure 2-9. Nissan Gloria Equipped With the Extroid CVT (Nissan)

The modern toric CVT is approximately 91 percent efficient over the majority of its operating range with lowered efficiency in areas of low reduction ratio and input torque. This efficiency is superior to other continuously variable transmissions and standard automatic units, but toric transmissions are heavy and expensive compared to the other designs. In addition, the performance of the traction fluid is a limiting factor in the design because of its narrow temperature range (Wagner, 2001).

\subsubsection{Hydrostatic CVT}

A hydrostatic CVT is a transmission unit comprised of a hydrostatic pump and a hydrostatic motor. The pump input shaft is connected to the power source while the motor is connected to the output shaft; the pump and the motor are connected by a hydraulic circuit (Singh and Nair, 1992). The speed ratio change in these transmissions is performed by varying the displacements of the pump and motor while the overall system pressure limits the amount of torque that can be transmitted. The speed ratio change is stepless, and therefore continuously variable throughout the transmission operating range. The hydrostatic transmission differs from the hydrodynamic drives that are employed in common automotive torque converters. The hydrodynamic drive relies on fluid kinetic 
energy to derive power, while the hydrostatic drive is analogous to a column of liquid actuating a hydraulic unit attached to a load (Fenton, 1996).

The hydrostatic transmission has a lower mechanical efficiency than other continuously variable transmissions used in automotive applications (Singh and Nair, 1992). However, the hydrostatic transmission is successful in off-road vehicle applications where the vehicle operation is primarily in the low-speed, high-torque regime and the excess weight of the unit is not a liability (Fig. 2-10).

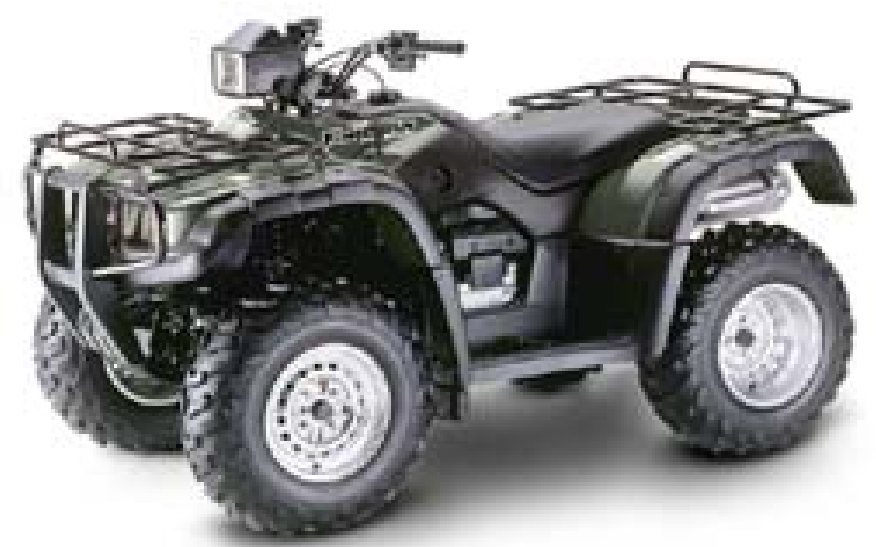

Figure 2-10. Honda Rubicon ATV with Hondamatic Hydrostatic Transmission (Honda)

\subsubsection{Electric CVT}

The electric CVT, or the series hybrid electric vehicle (HEV), is comprised of three to four main elements. These are the power source, the generator, the electric motor, and a battery pack (Fig. 2-11). The basic principle of the electric CVT is analogous to the hydrostatic CVT in that the power source drives an electric generator while the electric motor is connected to the output shaft; the generator and motor are connected by an electric circuit. Unlike the hydrostatic CVT, the addition of a battery pack can store excess power that would normally be wasted during vehicle operation (Kiuchi et al., 2001). 


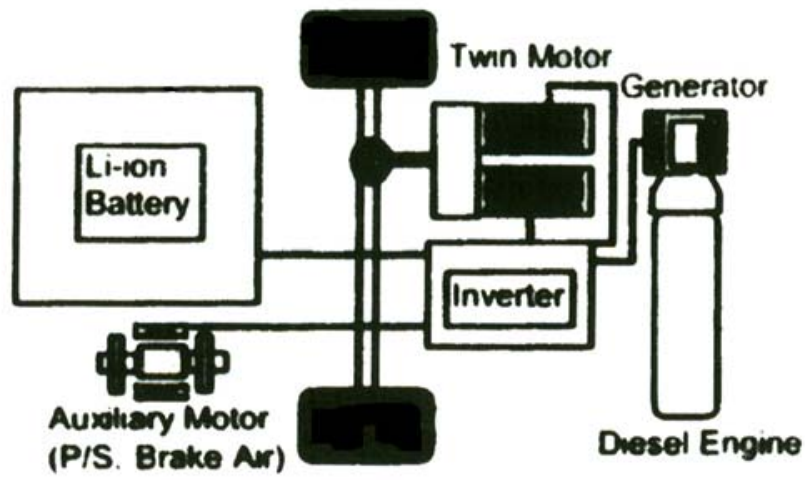

Figure 2-11. Layout of Series Hybrid for Heavy-Duty Buses (Kiuchi, et al., 2001)

The series hybrid has been used with limited success in the automotive field as parallel hybrid arrangements have proven to have superior performance and economy. Currently, only city buses have seen any success at volume production (Fenton, 1996). On the other hand, this series arrangement is the standard for such heavy vehicles as diesel locomotives and ultra-heavy-duty trucks (Fig. 2-12). The electric CVT serves well

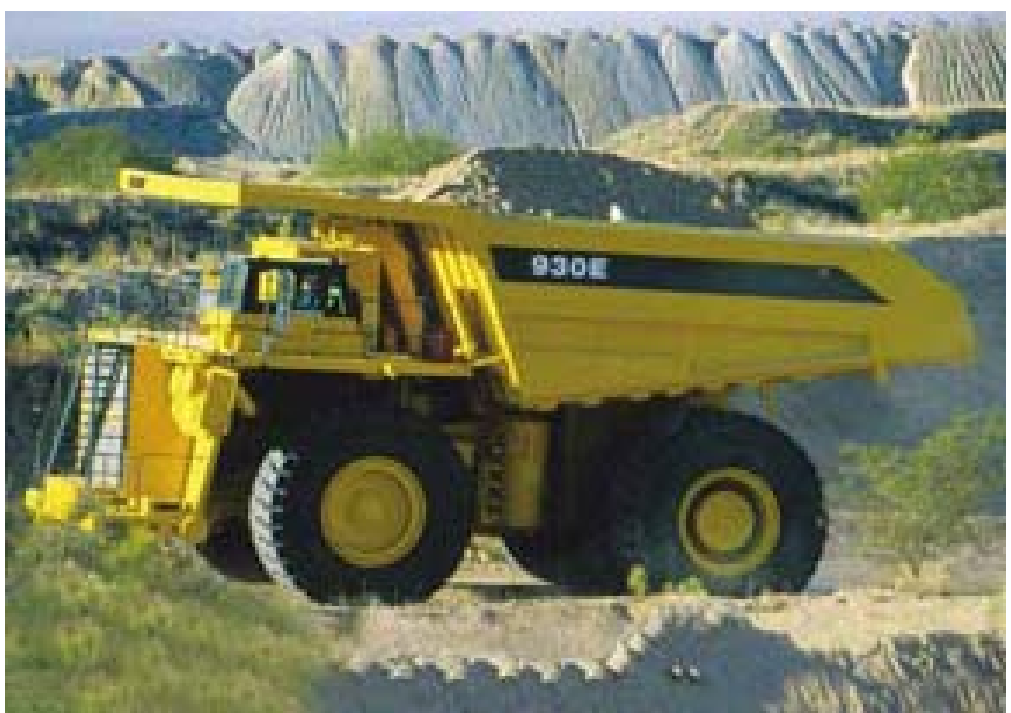

Figure 2-12. Komatsu 930E Heavy Diesel Truck with Electric Drive (Komatsu)

in situations where the power source and the load locations prohibit a direct mechanical drive and where accurate transmission of high power is necessary (Kiuchi et al. 2001). 


\subsubsection{Variable Geometry CVT}

\section{Epicyclic CVT}

The epicyclic CVT is a combination of a variable geometry sine wave generating mechanism and an epicyclic gear set. The sine wave generating mechanism consists of a crank arm carrier connected to the input shaft with four crank arms connected to a set of output gears. The crank ends fit into a slotted index plate. The index plate has a moveable center of rotation that can create a relative crank motion. This relative crank motion is translated to the output gears (Fig. 2-13). The epicyclic gear set then combines the input motion and one-way clutches in the output shafts add the forward motion from the output gears to form a new output gear ratio, which is a combination of the input and the positive sinusoidal output (Fitz and Pires, 1991). Compared to other CVT designs, this one does not allow gross slip in that there is a direct mechanical connection between the input and the output. Frictional losses do hurt efficiency at low speeds, but the peak efficiency of this mechanism is over 90 percent (Kluger and Fussner, 1997).

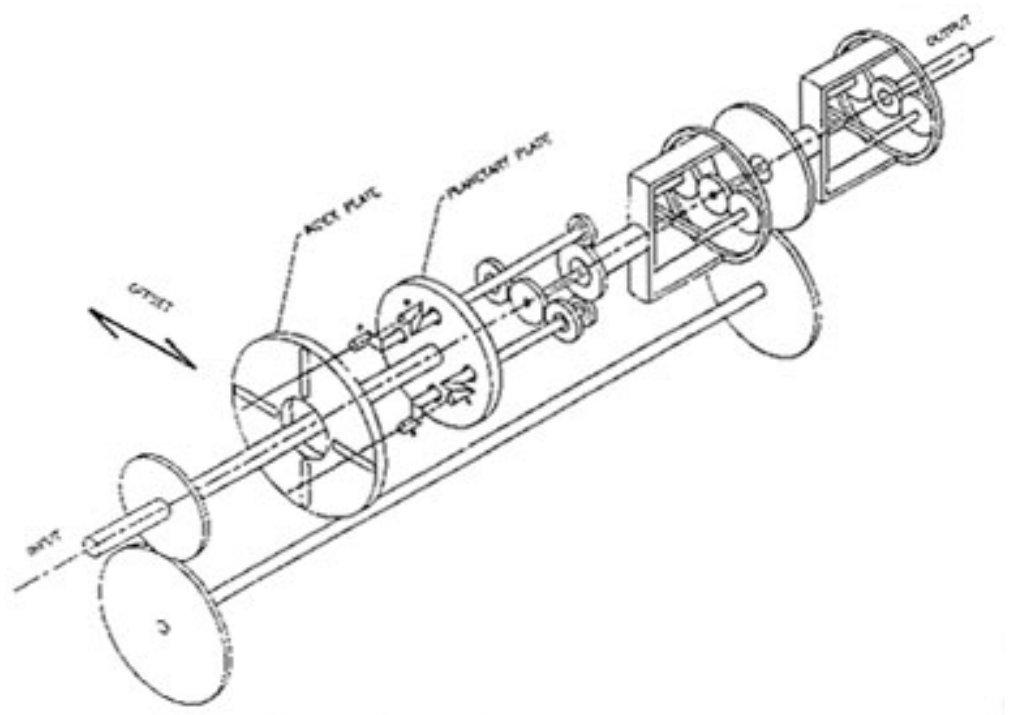

Figure 2-13. Epicyclic CVT (Fitz and Pires, 1991) 


\section{Other CVT Designs}

There are other purely mechanical designs listed in the literature that are too numerous to list here. One trait that is common to all of these designs is some sort of variable geometry which will change the input to output ratio. This variable geometry can be combined with an oscillating or rotating motion continuously for a stepless ratio change.

\subsection{Power-Split CVT Technology}

The CVT has distinct advantages over conventional fixed-ratio transmissions in many ways, but current CVT units suffer from limited torque capacity and ratio coverage when compared to conventional units (Vahabzadeh and Macey, 1990). There are two methods to overcome these limitations; either the CVT unit has to be redesigned or the CVT can be combined with an epicyclic gear set to change its operating characteristics. The first industry to recognize the advantages of combining the CVT and a differential gear set produced transmissions for agricultural equipment. These units combined a hydrostatic transmission with epicyclic gears. Kress (Kress, 1968) analyzed and classified these transmissions, but this analysis can be extended to any type of CVT by substituting it in place of the hydrostatic variator. These hybrid transmissions can be classified into two main categories; each with its own distinct characteristics. These are continuously variable power split transmissions (CVPST) and infinitely variable transmissions (IVT). 


\subsubsection{Continuously-Variable Power Split Transmissions}

The CVPST is a transmission system consisting of a variator and one or more sets of epicyclic gears. The CVPST operates in a three-branch power circuit where one of the branches is the output or input of the transmission, and the other two branches are connected by a variator, which is then connected to the input or output of the transmission. In the CVPST, the torque passing through the variator circuit is always less than the input torque. This quality is what has attracted engineers to this concept because a CVPST can extend the power envelope of current CVT mechanisms.

Interest in the CVPST has been around for the better part of the past century, but its development for automotive use has been limited. One CVPST designed especially for automotive use utilized a Van Doorne-type CVT connected to a planetary gear train (Fig. 2-14). This design minimized the torque input to the CVT at low speeds and increased the CVT load as the gear ratio decreased (Mucino et al., 1997). This arrangement was modified with a two-stage gearbox to extend the operational range of the transmission. This design never made it past the computer simulation, but the results of that simulation indicated that this design would give superior vehicle acceleration when compared to a conventional transmission while decreasing the load on the CVT unit (Lu, 1999).

Currently, the only development of the CVPST is in the academic arena. Most of the work is centered on deriving the operating characteristics of CVPST units in conjunction with other transmission arrangements (Fussner and Singh, 2002). The conclusions from this research are that the CVPST can be designed to extend the power envelope of any variator, but the overall transmission range will be reduced (Beccari and 
Cammalleri, 2001). The ideal CVPST will balance all of these design factors while producing a useable range of speed ratios.

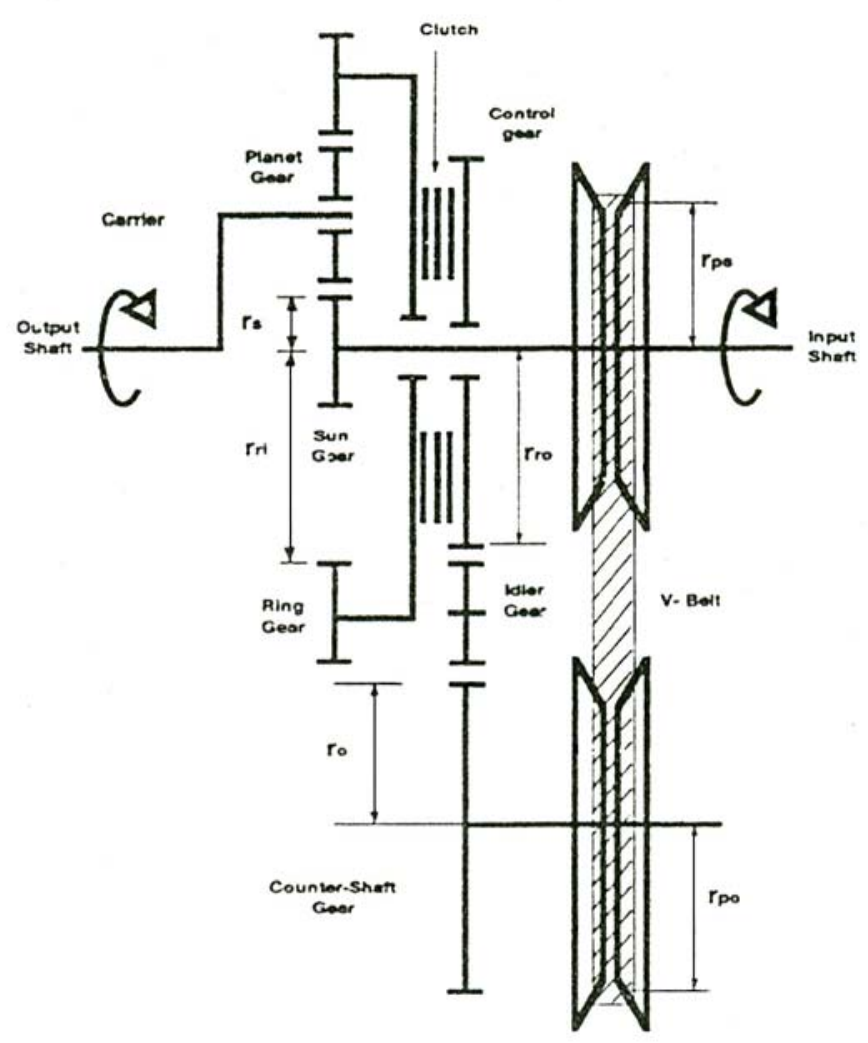

Figure 2-14. Continuously Variable Power Split Transmission (Mucino et al., 1997)

\subsubsection{Infinitely Variable Transmissions}

Infinitely variable transmissions share the same basic architecture with CVPST units in that they consist of some variator connected to one or more sets of epicyclic gears. The same three-branch system results from this arrangement, but the difference is in the power flows. In IVT units, there are two different power flows that can be encountered as the input power is recirculated through the branches instead of splitting between them. This power recirculation can cause either the variator or the epicyclic 
gears to operate under conditions that exceed the input power. These units are called infinitely variable transmissions because their arrangement actually extends the ratio of the variator to the point that the unit can reverse its output direction through the operating range of the transmission. This point of reversing is the geared neutral point (Macey and Vahabzadeh, 1987).

Initial work on IVT designs was directed toward use with hydrostatic transmissions. These transmissions were used in agricultural vehicles because their flexibility and performance were not degraded by their weight and cost (Kress, 1968). In 1987, General Motors patented an IVT design for automotive applications (Fig. 2-15). This design utilized a metal pushing belt CVT, a planetary gear set, and a set of clutches (Macey and Vahabzadeh, 1987). In this design, the transmission operated as an IVT for the lower portion of its driving range, while the CVT was the main transmission element through the higher portion of the driving range. This design was shown to have superior acceleration and economy to conventional transmissions, and the IVT design eliminated the need for a starting device and a reversing gear (Vahabzadeh, 1990). This work has been continued by the Torotrak Corporation, which has developed a dual-range transmission unit suitable for full-sized trucks with up to 5.4 liters of displacement.

The most recent work on IVT design is centered on the synthesis of components for maximum mechanical efficiency. Mantriota has designed and built a modular testing apparatus that can be used to test different IVT designs. With the validation of testing equipment, new expressions for the transmission overall efficiency have been validated (Mantriota, 2001). Other current works have been concerned with maximizing this 
efficiency in order to come up with a competitive design (Hong-Sen and Long-Chang, 1994).

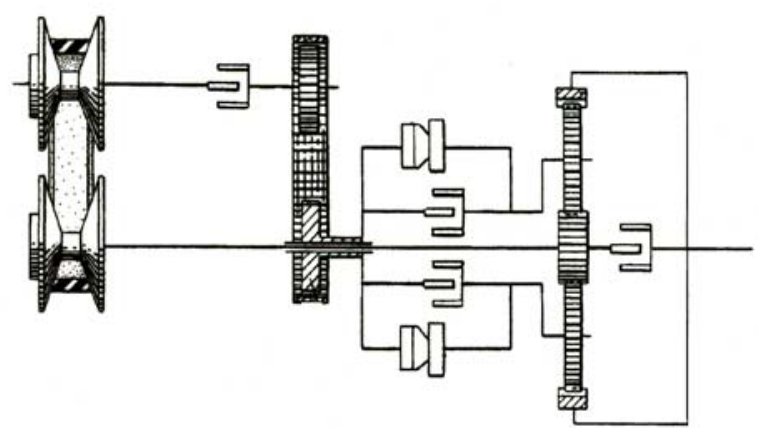

Figure 2-15. General Motors Infinitely Variable Transmission (Macey and Vahabzadeh, 1987) 


\section{Chapter 3 - Continuously Variable Power Split Transmissions - Definition and Analysis}

\subsection{Model of Study}

The transmission system evaluated in this study consists of a variable element and an epicyclic gear element. The variable element can be either a friction, traction, hydrostatic, electric, or mechanical CVT while the epicyclic gear element can consist of either differential or planetary gears. The central element in these transmissions is the epicyclic gear set. The epicyclic gear set consists of three shafts, and the motion of two of these shafts defines the motion of the third, which gives the system two degrees of freedom. In a transmission application where there is one input torque and speed that is passed to one output shaft, there is one degree of freedom. In epicyclic transmissions, one of the shafts is always moving at a defined speed, and the speeds of two of these shafts is constrained to each other to reduce the system to one degree of freedom. There are two levels of classification for this transmission system. The first level of classification is based on the physical layout of the transmission, which is either inputcoupled or output-coupled because variable element is either coupled to the input or output shaft of the transmission (Fig. 3-1).

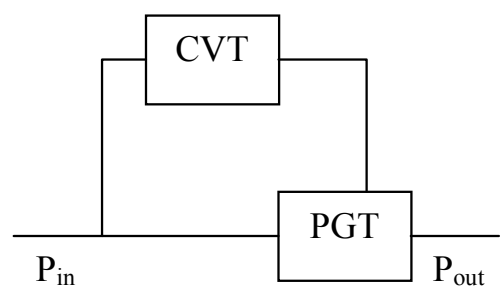

Input Coupled

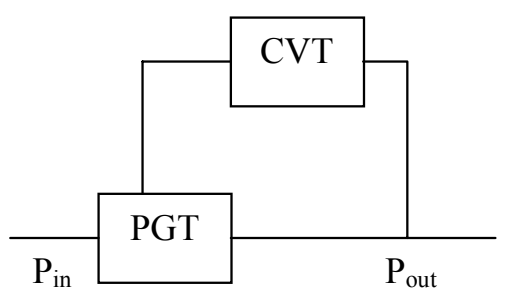

Output Coupled

Figure 3-1. Illustration of CVT Arrangements 
The second level of classification is based upon the direction of power flow between the components of the transmission. These are classified as a Type I, Type II, or Type III power flows for both the input-coupled and output-coupled arrangements (Figs. 3-2).
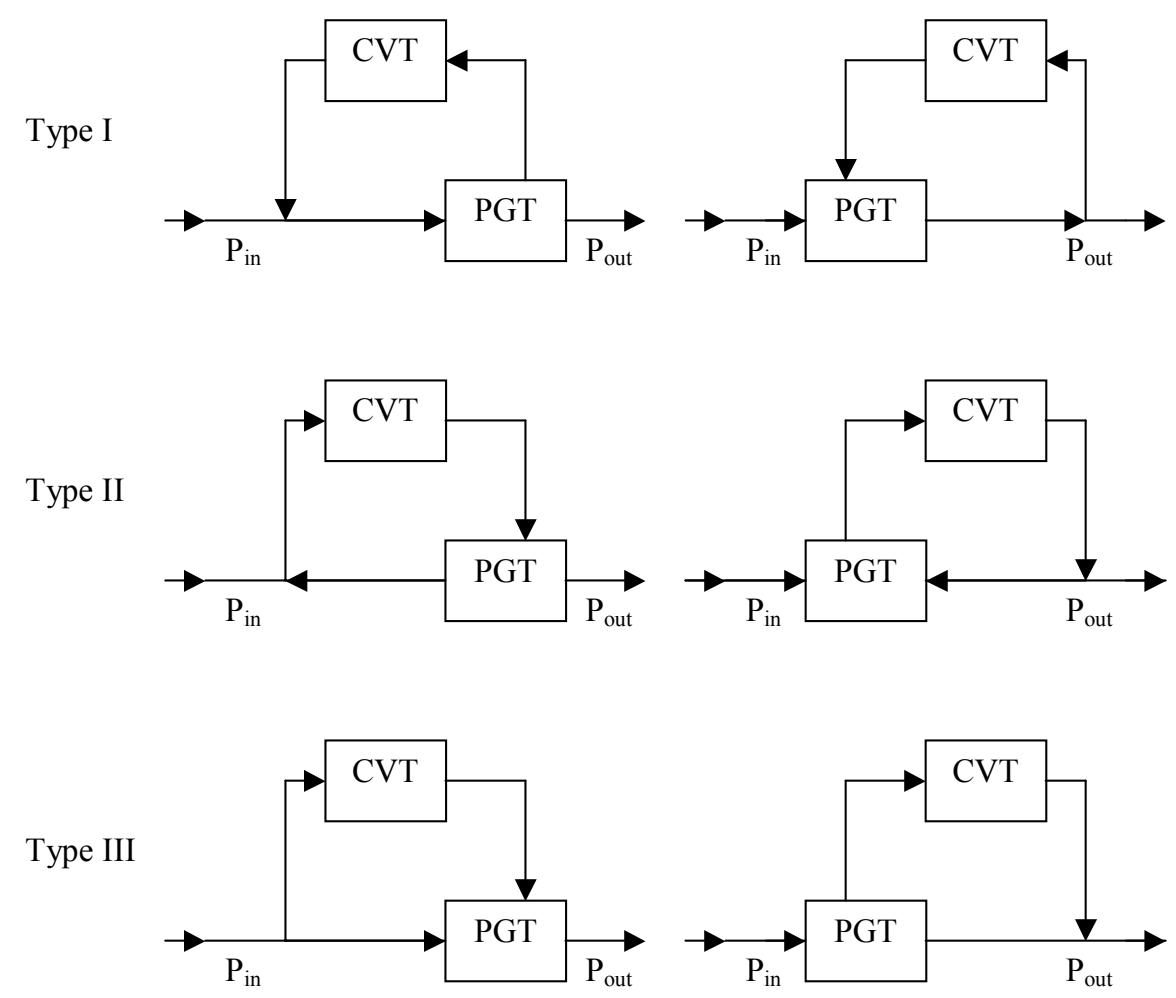

Figure 3-2. Illustration of Power Flows

Hsieh and Yan (1990) determined that the input-coupled transmission arrangement is the most efficient mechanically. In addition, the input-coupled transmission will connect the CVT to the input circuit of the transmission, which has a lower torque value than the output shaft for most of the transmission operating range. Also, the ratio of the CVT will be controlled in much the same manner as a conventional shaft-to-shaft CVT because it is connected to the input shaft of the transmission.

According to Figure 3-2, transmissions with a Type III power flow are more desirable because there is no power recirculation in the transmission circuit. In Type I 
and Type II power flows, certain transmission components are exposed to a power load greater than that of the input load. These loads can range from a factor of one to the hundreds, which can result in an undesirable design (Kress, 1968).

\subsection{Component Analysis}

The input-coupled CVPST is comprised of a planetary gear set, a variator, and one or more sets of conventional gears (Fig. 3-3). This particular system is designed to have a Type III power flow.

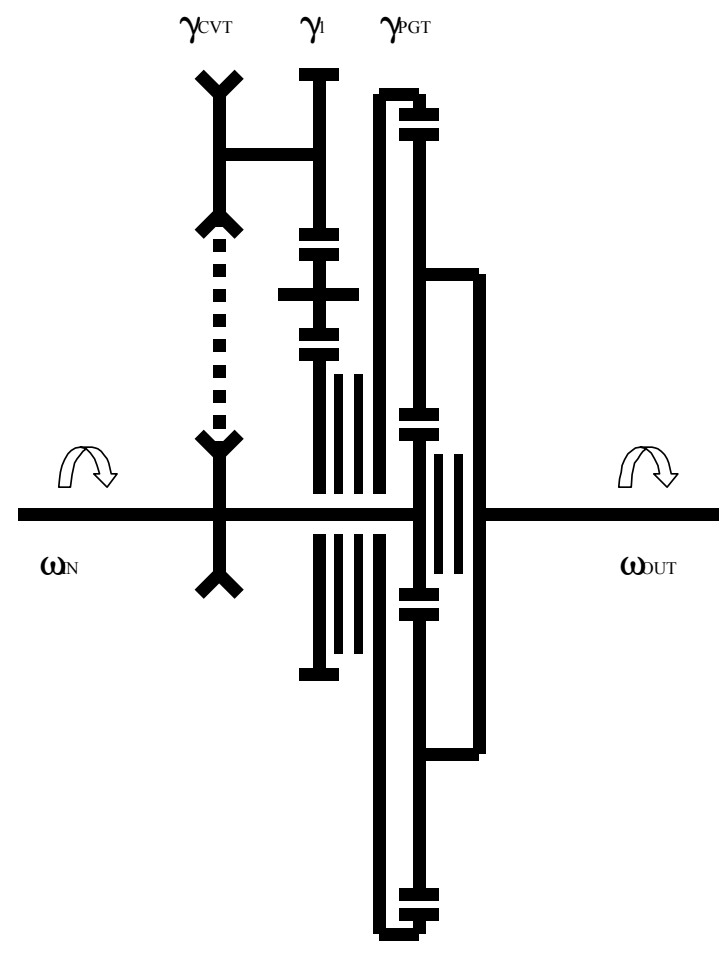

Figure 3-3. Layout of CVPST 


\subsubsection{Kinematic Analysis of Planetary Gears}

The heart of the CVPST is the planetary gear set. The planetary gear set is comprised of the sun gear, the ring gear, and the planet gears attached to a gear carrier (Fig. 3-4). The gear carrier allows the planetary gear to operate with a compound rotation where it can rotate around its own axis and rotate around the center axis of the transmission. The planetary gear system has two degrees of freedom, which can be proven with the relation:

$$
M=3(n-1)-2 f_{1}-f_{2} .
$$

In this equation, $M$ denotes the number of degrees of freedom, $n$ is the number of machine elements, and $f_{1}$ and $f_{\mathrm{f}}$ denote the number of one degree of freedom joints and two degree of freedom joints respectively (Mabie and Reinholtz, 1987). In the planetary gear set, there are five elements comprised of the gears, gear carrier, and the ground link. There are four revolute joints with one degree of freedom and two gear joints with two degrees of freedom:

$$
M=3(5-1)-2(4)-2=2 .
$$

Because there are two degrees of freedom, the motion of any two elements must be known in order to determine the motion of the third. As can be seen in the Kinematic Graph in Figure 3-4, the planetary system can be constrained to have one degree of freedom if the circuits between either elements 2 and 5 or elements 4 and 5 are coupled. The planetary system is fully constrained when both element pairs are coupled. Because of this design freedom, two planetary gear sets with the same ratio can produce different speed ratios dependent upon which components are coupled, and careful design must be performed so that the resulting transmission operates within all of its design parameters. 

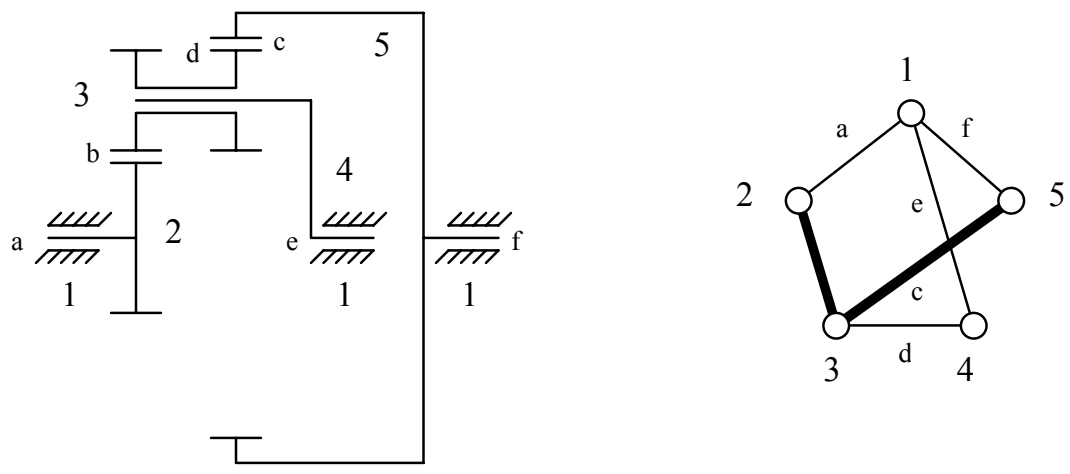

Figure 3-4. Skeleton and Kinematic Graph of Planetary Gear Set

\subsubsection{Motion Analysis of Planetary Gears}

The basic system for a planetary gear set consists of a sun gear, a planet gear, a rotating arm, and a ground link (Fig. 3-5). This system can be set up to derive the basic speed relations between the components so that an overall equation can be expressed.

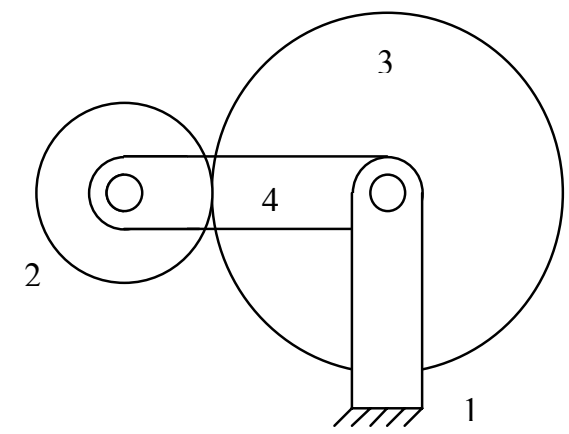

Figure 3-5. Basic Planetary Gear System
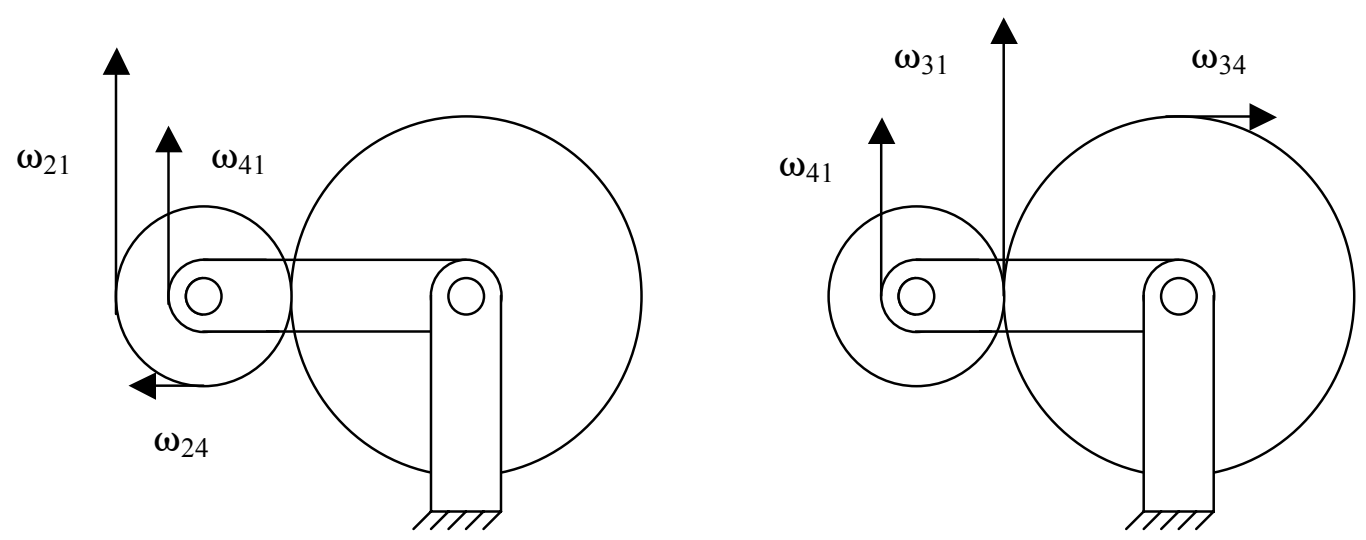

Figure 3-6. Complete Velocity Diagram for Basic Planetary System 
For the planetary gear system represented in Figure 3-6, two expressions can be derived from the velocity diagram (Mabie and Reinholtz, 1986):

$$
V_{24} r_{2}=V_{21} r_{2}-V_{41} r_{4}=\omega_{24}=\omega_{21}-\omega_{41}
$$

and,

$$
V_{34} r_{3}=V_{31} r_{3}-V_{41} r_{4}=\omega_{34}=\omega_{31}-\omega_{41},
$$

where $\omega$ denotes the angular velocities of the sun gear, planet gear, and arm with respect to the ground link and the angular velocities of the sun and planet gear in relation to the arm. The next step is to divide Eq. (3-3) by Eq. (3-4) to yield the velocity equation:

$$
\frac{\omega_{24}}{\omega_{34}}=\frac{\omega_{21}-\omega_{41}}{\omega_{31}-\omega_{41}}
$$

For the basic planetary system with a sun gear, ring gear, and planet gears, relations can be derived such that:

$$
\frac{\omega_{24}}{\omega_{34}}=-\frac{N_{R}}{N_{S}}=-\gamma_{P G T}
$$

where,

$$
\omega_{21}=\omega_{S},
$$$$
\omega_{31}=\omega_{R},
$$$$
\omega_{41}=\omega_{A},
$$

and where $\mathrm{N}$ denotes the number of teeth on the ring and sun gears, $\gamma$ denotes the velocity ratio between the sun and ring gears, and the subscripts $S, R$, and A stand for the sun, ring, and planetary gear carrier respectively. When Eq. (3-5) and Eqs. (3-6) are combined, the following relationship yields:

$$
-\gamma_{P G T}=\frac{\omega_{S}-\omega_{A}}{\omega_{R}-\omega_{A}},
$$

which can be used to calculate the angular velocities of all the components of the planetary gear set if the gear ratio and two of the velocities are known. 


\subsubsection{Torque and Power Analysis of Planetary Gears}

The key factor in analyzing a split-path transmission is determining the power split factor. With this power split factor, it can be determined whether a certain transmission design exhibits a Type I, II, or III power flow. The basic split-path system consists of three circuits. One circuit is connected to the output while the other circuit is connected to the input, and a third circuit is connected to either of the two. All of these circuits intersect at the differential gear set (Fig. 3-7).

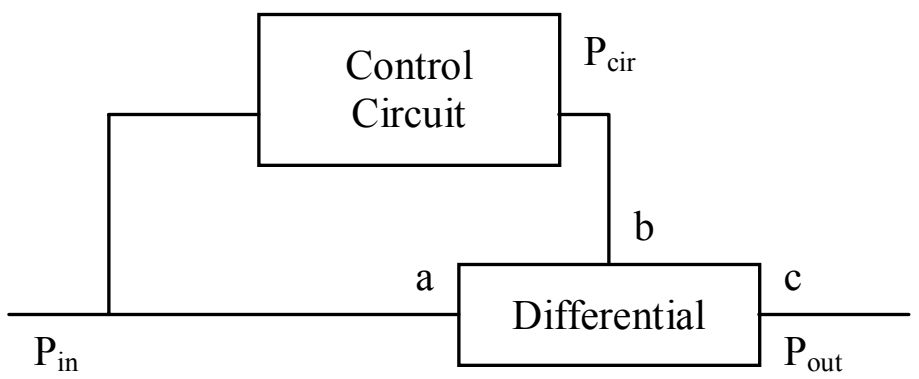

Figure 3-7. Layout of Power-Split Circuit

The power split factor is defined as the ratio of power circulating through the control circuit branch and the output power. The circulating power ratio is:

$$
\gamma=\frac{P_{c i r}}{P_{c}},
$$

where $\gamma$ is the circulating power ratio, $\mathrm{P}_{\text {cir }}$ is the circulating power through the control circuit, and $\mathrm{P}_{\mathrm{c}}$ is the output power. If the differential is considered as an isolated unit where branches $\mathrm{a}, \mathrm{b}$, and $\mathrm{c}$ intersect, then the scalar sums of powers and torques can be expressed as:

$$
\Sigma T=T_{a}+T_{b}+T_{c}=0
$$

and

$$
\Sigma P=T_{a} \omega_{a}+T_{b} \omega_{b}+T_{c} \omega_{c}=0 .
$$


It is noted that although these are scalar relations, the same relationship applies to vector components where the counter-clockwise direction is considered positive for torque and angular velocity. In this case, branch a is always the element connected to the branch control circuit and the differential, branch $b$ is always the branch control circuit that does not connect outside the system, and branch $\mathrm{c}$ is always the unit that projects directly from the differential to the input or output. With this arrangement, Eq. (3-5) and (3-6) can be solved simultaneously to give the relations (Mabie and Reinholtz, 1986):

$$
\gamma=\frac{\omega_{b}\left(\omega_{c}-\omega_{a}\right)}{\omega_{c}\left(\omega_{a}-\omega_{b}\right)}
$$

or

$$
\gamma=\frac{r(1-R)}{1-r}
$$

where

$$
r=\frac{\omega_{b}}{\omega_{a}} \quad \text { and } \quad R=\frac{\omega_{a}}{\omega_{c}} .
$$

The circulating power ratio defines the type of power flow exhibited by the transmission. When $\gamma$ is positive, the power flow in branches $\mathrm{b}$ and $\mathrm{c}$ are moving in the same direction either into or out of the differential. This is a Type I power flow where the power in the control branch is greater than the input power. When $\gamma$ is negative, the power flow in branches $\mathrm{b}$ and $\mathrm{c}$ are moving in opposite directions with respect to the differential. This is a Type II flow which exhibits power recirculation if $\gamma$ is greater than unity, or it is a Type III flow with the power split between the two branches if $\gamma$ is less than unity. 


\subsubsection{Component Efficiency}

\section{Gear Pair Efficiency}

The CVPST is made up of the planetary gear set, the CVT, a reduction gear set, clutches, and other supporting components. Each of these components exhibits some sort of power loss due to friction and other factors, so a comprehensive design must take all of these factors into account.

The efficiency for a gear pair is defined as:

$$
\eta_{\text {gear }}=-\frac{P_{\text {out }}}{P_{\text {in }}},
$$

where $\eta$ is the component efficiency and $\mathrm{P}$ is the power before and after the unit. The frictional power loss for a gear pair is defined:

$$
P_{\text {loss }}=P_{\text {in }}\left(1-\eta_{\text {gear }}\right) \text {. }
$$

\section{Planetary Gear Set Efficiency}

The planetary gear set is a system with two degrees of freedom, so the efficiency must be calculated for each branch of the system. The torques acting on the links and the power loss are independent of the observer's motion, so the power losses can be calculated in a moving reference frame in which one of the components appears fixed (Pennestri and Freudenstein, 1993). The conventional planetary gear set has six inversions in which one component is fixed in order to eliminate one degree of freedom. In an input-coupled CVPST, the power flows into the sun and ring gears and exits the gear carrier, so the two inversions of the system constrain either the sun or ring gears.

Table 3-1. Epicyclic Inversions for a Planetary Gear set

\begin{tabular}{|c|c|c|}
\hline & Case \#1 & Case \#2 \\
\hline Driver & $\mathrm{A}$ & $\mathrm{B}$ \\
\hline & $\mathrm{C}$ & $\mathrm{C}$ \\
\hline
\end{tabular}




\begin{tabular}{|c|c|c|}
\hline Fixed & $\mathrm{B}$ & $\mathrm{A}$ \\
\hline & &
\end{tabular}

The mechanical efficiency for the inversion in Case \#1 (Table 3-1) is defined by the expression:

$$
\eta_{B(A-C)}=\frac{r \eta_{1}-1}{r-1},
$$

where $\eta 1$ is the gear pair efficiency for the first gear pair and:

$$
r=-\frac{N_{A}}{N_{B}} .
$$

The mechanical efficiency for the inversion in Case \#2 (Table 1) is defined by the expression:

$$
\eta_{A(B-C)}=\frac{r-\eta_{2}}{r-1},
$$

where $\eta_{2}$ is the gear pair efficiency for the second gear pair. With the efficiencies of the individual components, the next step is to calculate the power flow through the planetary gear set. In the CVPST, the direction of power is positive at the sun and ring gear and negative at the gear carrier (Fig. 3-8).

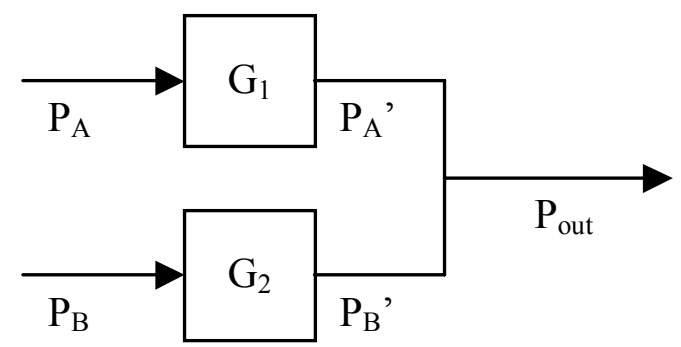

Figure 3-8. Power Flow in Planetary Gear Set 
The power balance for the system above can be expressed with the relations:

$$
\begin{gathered}
P_{\text {OUT }}=\left(P_{A}+P_{B}\right) \eta_{P G T}, \\
P_{A}{ }^{\prime}=P_{A} \eta_{B(A-C)}, \quad \text { and } \quad P_{B}^{\prime}=P_{B} \eta_{A(B-C)}
\end{gathered}
$$

where $P_{\text {OUT }}$ is the output power, $P_{A}$ is the power flowing into the ring gear, and $P_{B}$ is the power flowing into the sun gear. When Eq. (3-19) and Eqs. (3-20) are solved simultaneously, the resulting expression is:

$$
\eta_{P G T}=\frac{P_{O U T}}{\frac{P_{A}{ }^{\prime}}{\eta_{B(A-C)}}+\frac{P_{B}{ }^{\prime}}{\eta_{A(B-C)}}}
$$

The ratio of powers can be determined from the speed ratio and the power split factor $\gamma$ is introduced. The resulting expressions are:

$$
\gamma=\frac{P_{A}{ }^{\prime}}{P_{\text {OUT }}} \quad \text { and } \quad(1-\gamma)=\frac{P_{B}{ }^{\prime}}{P_{\text {OUT }}} .
$$

When Eq. (3-21) and Eqs. (3-22) are solved simultaneously, the resulting expression is:

$$
\eta_{P G T}=\frac{1}{\frac{\gamma}{\eta_{B(A-C)}}+\frac{1-\gamma}{\eta_{A(B-C)}}}
$$

Using Eq. (3-23) the mechanical efficiency of the planetary gear set can be calculated as long as the speeds of all the gear train elements are known.

\section{Variator Efficiency}

The variable element in this transmission is responsible for the greatest part of the mechanical losses because it is less efficient than conventional gears. The type of variable element chosen for this particular application was the metal pushing belt CVT because it offers acceptable efficiency values compared to other variable elements while 
being less costly and lighter than traction drives (Wagner, 2001). The mechanical efficiency of a metal pushing belt CVT is not a constant value, because it uses a combination of axial force to squeeze the metal blocks in the band to transmit torque and a compressive force in the blocks to transmit torque from one pulley to another. Changes to the torque and speed ratios of the CVT induce non-linear changes to the values of these force distributions, so the efficiency is dependent upon input torque and speed ratio (Kluger and Fussner, 1997). A method for estimating the efficiency of a metal pushing belt CVT was conceived that used efficiency values for varied metal pushing belt CVTs published in standard literature (Bothron, 1985). These values were normalized, and equations for the resultant curves were derived in a series of steps which accounted for efficiency variations due to input torque, speed ratio, and input speed respectively (Singh and Nair, 1992). The efficiency curves for the transmission (Bothron, 1985) were then duplicated with the resulting experimental equations.

The first step in this method is to compute the efficiency for a given input torque for the maximum and minimum speed ratios where the corrected speed ratio range is set from 2.5 to 0.4 . This is because it was recognized that there was a linear relationship between the natural logarithm of the speed ratio and the efficiency. The maximum and minimum speed ratios for the transmission were given a 2.5 and 0.4 respectively, and these were used as the bounding speed ratios for the torque and speed relationships. These efficiencies are calculated for the following set of boundary conditions from polynomial curves fitted to experimental data (Singh and Nair, 1992):

$$
\begin{array}{cc}
\text { if } t_{2.5} \leq 0.3, & \eta_{2.5}=0.616+3.84 t_{C V T}-16.4 t_{C V T}^{2}+24 t_{C V T}^{3}, \\
\text { if } t_{2.5}>0.3, & \eta_{2.5}=0.95,
\end{array}
$$


and:

if $t_{0.4} \leq 0.5$,

$$
\begin{aligned}
& \eta_{0.4}=-0.2145+13.87 t_{C V T}-76.01 t_{C V T}^{2} \\
& +218.4 t_{C V T}^{3}-318.4 t_{C V T}^{4}+185.4 t_{C V T}^{5}
\end{aligned}
$$

if $t_{0.4}>0.5$,

$$
\eta_{0.4}=0.92
$$

where:

$$
t_{C V T}=\frac{T_{C V T}}{T_{\left.C V T\right|_{M A X}}} \quad \text { and } \quad w_{C V T}=\frac{\omega_{C V T}}{\omega_{\left.C V T\right|_{M A X}}}
$$

The next step is to compute the efficiency with respect to the input torque and the speed ratio. In this relation, the linear relationship between speed ratio and efficiency is accounted for within the speed ratio boundaries (Singh and Nair, 1992). This is accomplished with the relation:

$$
\eta_{\gamma}=\eta_{2.5}+\left(\eta_{2.5}-\eta_{0.4}\right)\left[\frac{\log \left(\gamma_{C V T}\right)-0.9163}{1.8326}\right] .
$$

The final step is to compute the overall efficiency, which is in terms of input torque, input speed, and speed ratio. With this relation, the effect of input speed is accounted for. Using the information from Eqs. (3-24) to (3-29), the overall efficiency for the metal pushing belt CVT is (Singh and Nair, 1992):

$$
\eta_{C V T}=\eta_{\gamma}-0.04 w_{C V T}\left[\frac{0.067+0.46 t_{C V T}+0.47 t_{C V T}^{2}}{t_{C V T}^{2}}\right] .
$$

Eq. (3-30) can calculate the efficiency for a metal pushing belt CVT under all operating conditions as long as the maximum rated torque and input speed are known. 


\subsection{CVPST System Design}

The complete CVPST has to account for the velocity ratios, power flows, and overall efficiency of the transmission system. In order to do so, the relations for all of these factors must be derived with emphasis on the optimal design. Also, in order to accommodate variator disengagement, the angular velocity ratio of the variable element in relation to the overall transmission ratio must be manipulated.

\subsubsection{CVPST Speed Ratio}

The speed ratio of the CVPST is dependent upon the fixed ratios of the fixed gear pair and the planetary gear set and the variable ratio of the variable element. When the transmission layout in Fig. (3-9) is used to assign angular velocities to the planetary gear train components, Eq. (3-7) becomes:

$$
-\gamma_{P G T}=\frac{\omega_{I N}-\omega_{O U T}}{\omega_{R}-\omega_{O U T}} .
$$

The ring gear in this transmission is connected to the variable circuit where its speed is controlled by the ratios of the CVT element and the gear pair. The relations that determine these speeds are:

$$
\omega_{b}=\omega_{a} \gamma_{C V T} \quad \text { and } \quad \omega_{e}=\omega_{c} \gamma_{1},
$$

where $\omega_{b}=\omega_{c}, \omega_{e}=\omega_{R}$ and $\gamma_{\mathrm{CVT}}$ and $\gamma_{1}$ are the speed ratios of the variator and the gear pair respectively. 


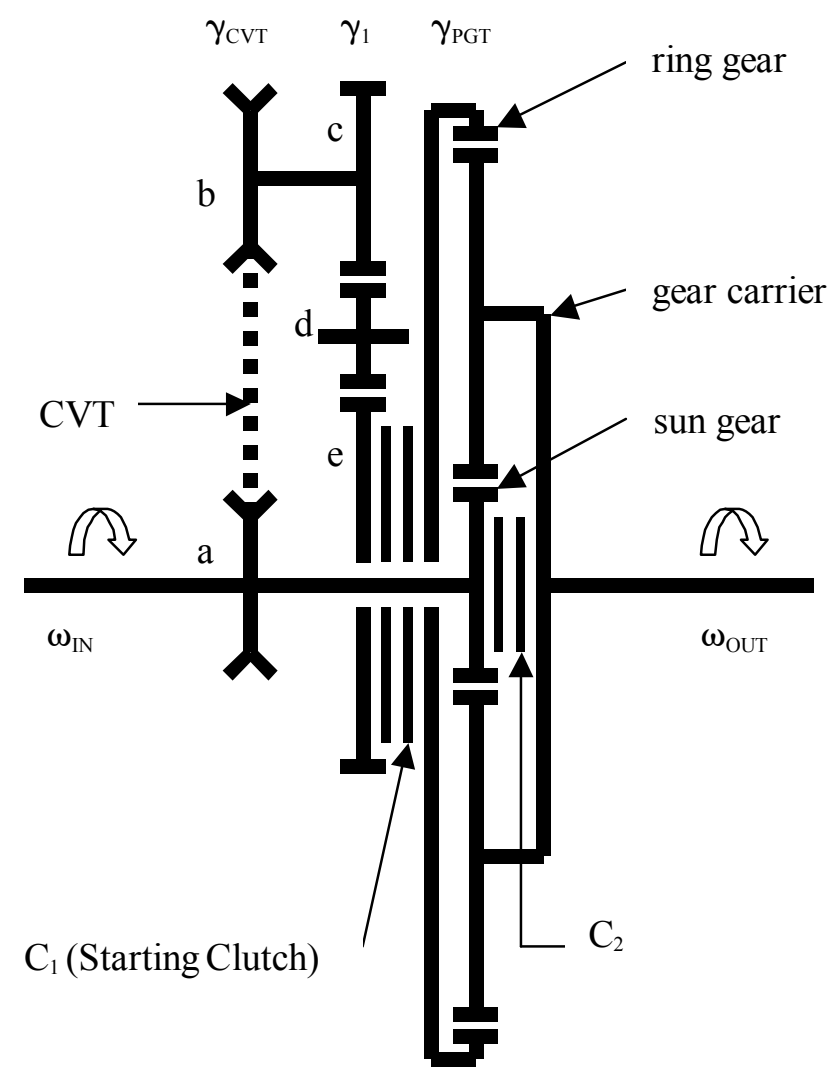

Figure 3-9. Skeleton Diagram of CVPST

When Eq. (3-31) and Eqs. (3-32) are combined, the relation for the overall speed ratio becomes:

$$
\frac{\omega_{I N}}{\omega_{O U T}}=\frac{1+\gamma_{P G T}}{1+\gamma_{P G T} \gamma_{1} \gamma_{C V T}} .
$$

In this design, there are two modes of operation. During the drive mode, $\mathrm{C}_{1}$ is engaged and $\mathrm{C}_{2}$ is disengaged so that the transmission speed ratio varies in proportion to the CVT. In cruise mode, $\mathrm{C}_{1}$ is disengaged while $\mathrm{C}_{2}$ is engaged. In this mode, the planetary gear set is fully constrained so that $\omega_{R}=\omega_{S}=\omega_{A}, \omega_{I N}=\omega_{O U T}$, and there is no power passing through the control circuit (Table 3-2). 
Table 3-2. Modes of Operation for CVPST

(Shading Indicates Clutch Engagement)

\begin{tabular}{|c|c|c|}
\hline Drive Mode & $\mathrm{C}_{1}$ & $\mathrm{C}_{2}$ \\
\hline Drive & & \\
\hline Cruise & & \\
\hline Neutral & & \\
\hline Park & & \\
\hline
\end{tabular}

In order to fully constrain the planetary gear set for the cruise mode, the speeds of all the planetary members must be synchronized, or the clutch cannot engage them all smoothly. The "synchronous point" of the planetary gear set only occurs when all three members are moving at the same angular velocity and in the same direction. A CVT can be overdriven where the output velocity is twice the input velocity while the CVPST is limited to a 1:1 speed ratio at its minimum, so the transmission must be designed to use the entire useful range of the CVT. This is accomplished with the equation:

$$
\left(\gamma_{\left.C V T\right|_{M A X}}\right)\left(\gamma_{1}\right)=1 .
$$

In this equation, the maximum value for $\gamma_{\mathrm{CVT}}$ is in terms of output to input value. In the Modified CVPST, the maximum speed ratio is $1: 1$, so the ratio range for this entire transmission is:

$$
\phi_{T}=\frac{\gamma_{\left.T\right|_{M A X}}}{\gamma_{\left.T\right|_{M N}}}=\frac{\frac{1+\gamma_{P G T} \gamma_{1} \gamma_{\left.C V T\right|_{M A X}}}{1+\gamma_{P G T}}}{\frac{1+\gamma_{P G T} \gamma_{1} \gamma_{\left.C V T\right|_{M N}}}{1+\gamma_{P G T}}}=\frac{1}{\gamma_{\left.T\right|_{M I N}}}=\frac{1+\gamma_{P G T}}{1+\gamma_{P G T} \gamma_{1} \gamma_{\left.C V T\right|_{M I N}}} .
$$

The ratio range of the CVT and the CVPST differ because of the split power path associated with the planetary gear set. The value of this difference is: 


$$
\% \text { Diff }=1-\frac{\phi_{T}}{\phi_{C V T}}
$$

where $\phi_{\mathrm{CVT}}$ is the ratio range of the variable element. A positive value indicates that the CVT range is increased by the CVPST, which would also indicate a Type I or Type II power flow. A negative value indicates that the CVT range is decreased by the CVPST, but the power flow is a Type III.

\subsubsection{CVPST Torque and Power Analysis}

The power splitting factor can be used to determine the performance of the transmission because the branch control circuit contains the CVT, which is the least efficient component in the transmission. The relation for the power splitting factor for the transmission in Fig. (3-9) is:

$$
\gamma=\left(\frac{\gamma_{1} \gamma_{C V T}}{\gamma_{1} \gamma_{C V T}-1}\right)\left(\frac{\gamma_{P G T}-\gamma_{P G T} \gamma_{1} \gamma_{C V T}}{1+\gamma_{P G T} \gamma_{1} \gamma_{C V T}}\right) .
$$

The torque splitting factor between the output torque and the branch control circuit torque is derived by combining Eqs. (3-9), (3-10), (3-32), and (3-33) to get the relation:

$$
\frac{T_{B R}}{T_{O U T}}=\left(\frac{1}{\gamma_{1} \gamma_{C V T}-1}\right)\left(1-\frac{1+\gamma_{P G T} \gamma_{1} \gamma_{C V T}}{1+\gamma_{P G T}}\right) .
$$

Equation (3-38) would also be used to calculate the torque split at the entrance of the branch control circuit in the absence of mechanical losses. The torques through the other circuits and their respective powers can be calculated with Eqs. (3-9) and (3-10) if the torque and power ratio through one branch is known.

\subsubsection{CVPST Efficiency Analysis}

The CVPST system efficiency is a function of the individual component efficiencies and the ratio of power flowing through the individual branches of the system 
(Fig. 3-10). For simplicity, the clutches $\mathrm{C}_{1}$ and $\mathrm{C}_{2}$ have been omitted. In order to include them in the analysis, the component efficiency of $\mathrm{C}_{1}$ would be placed at (4) in Figure (310) and the component efficiency of $\mathrm{C}_{2}$ would be evaluated within the PGT.

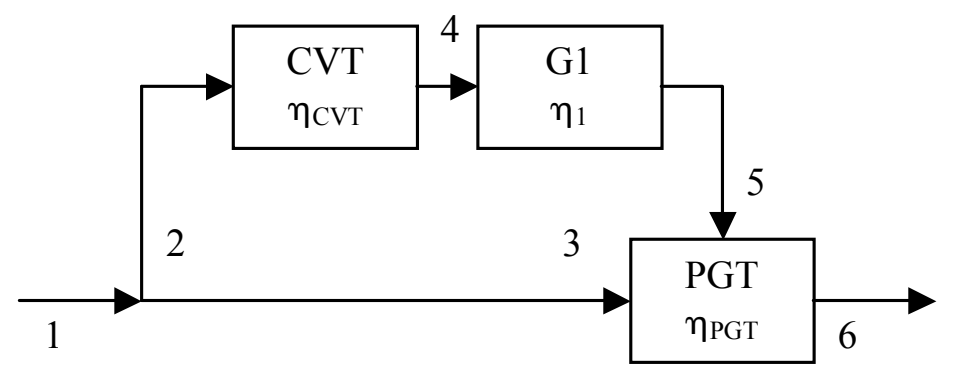

Figure 3-10. The Interaction of Components and Their Efficiencies in the CVPST

The first step in calculating the efficiency of the transmission is to apply the conservation of energy, or rate-based energy (Power), equations at the two branch intersections:

$$
P_{1}+P_{2}+P_{3}=0,
$$

and

$$
P_{3}+P_{5}+P_{6}=0,
$$

where $P_{I}=P_{I N}$ and $P_{6} \eta_{P G T}=P_{O U T}$. The power relationship on both sides of the branch control circuit can be calculated with the equation:

$$
P_{2} \eta_{C V T} \eta_{1}=P_{5} .
$$

An equation for the overall transmission efficiency can be calculated by combining Eqs. (3-39), (3-40), and (3-41) to produce the relation:

$$
\frac{P_{6}}{P_{1}}=\frac{1}{\frac{P_{5}}{P_{6}}-\frac{P_{5}}{P_{6} \eta_{1} \eta_{C V T}}+1} .
$$

This can be simplified to form the relation: 


$$
\eta_{T}=\frac{\eta_{P G T}}{\gamma-\frac{\gamma}{\eta_{1} \eta_{C V T}}+1}
$$

Eq. (3-43) can compute the global efficiency for the CVPST in terms of its individual components. In the cruise mode of operation, the power flow through the branch control circuit is interrupted (Fig. 3-11), so the power flow is simplified to one circuit which transmits power while the only power required by the branch control circuit is that to overcome frictional losses. When the efficiency of $\mathrm{C} 2$ is estimated to be unity, the power flow becomes:

$$
P_{1}-P_{\text {LOSS }}=P_{6} \quad \text { or } \quad P_{I N}-P_{\text {LOSS }}=P_{\text {OUT }} .
$$

The resulting efficiency for the transmission is also unity because:

$$
\frac{P_{\text {OUT }}}{P_{I N}}=\eta_{T} .
$$

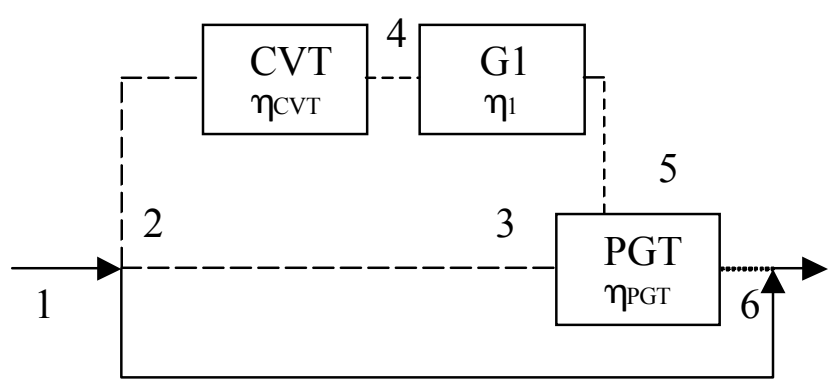

Figure 3-11. Transmission Power Path in Cruise Mode 


\section{Chapter 4 - Continuously Variable Power Split Transmission Simulation Design}

A thorough evaluation of different CVPST configurations would include such factors as the mechanical efficiency of individual elements along with the basic factors of speed and torque ratios. In the CVPST, the power in the branch control circuit varies with overall transmission ratio, and the power loss in the variable element varies in a nonlinear fashion according to its instantaneous speed ratio, torque, and operating speed. In addition, the torque losses associated with gear friction and bearing friction have to be addressed. Because of the complexity of this system, no single equation can be derived to predict the transmission output torque and speed, so a computer simulation that can solve the system of equations for each component must be used. For this study, three separate simulations were produced to evaluate the different operating conditions.

These simulations were designed and operated with the Matlab Simulink software package. All three simulations were designed using the same methodology, where function blocks represent physical components of the transmission. The simulations follow the same physical hierarchy of a physical system where the global system is the transmission with an input, output, and operating conditions, and the subassemblies that perform specific functions are contained within the global system. The modularity of these simulations allows for the replacement of individual components in the system for greater flexibility (Rubin et al., 1997)

\subsection{CVPST Simulation Program}

The CVPST simulation is modeled after the common CVPST described in the literature (Mucino et al., 1997). In this system, the power flow is a type III in which the 
power splits at the input of the CVT and recombines at the planetary gear set. This system is comprised of three subsystems, which include the variator, the conventional gear pair, and the planetary gear set (Fig. 4-1). In this arrangement, all of the subsystems are mechanically connected to the input shaft, and all of the subsystems transmit power.

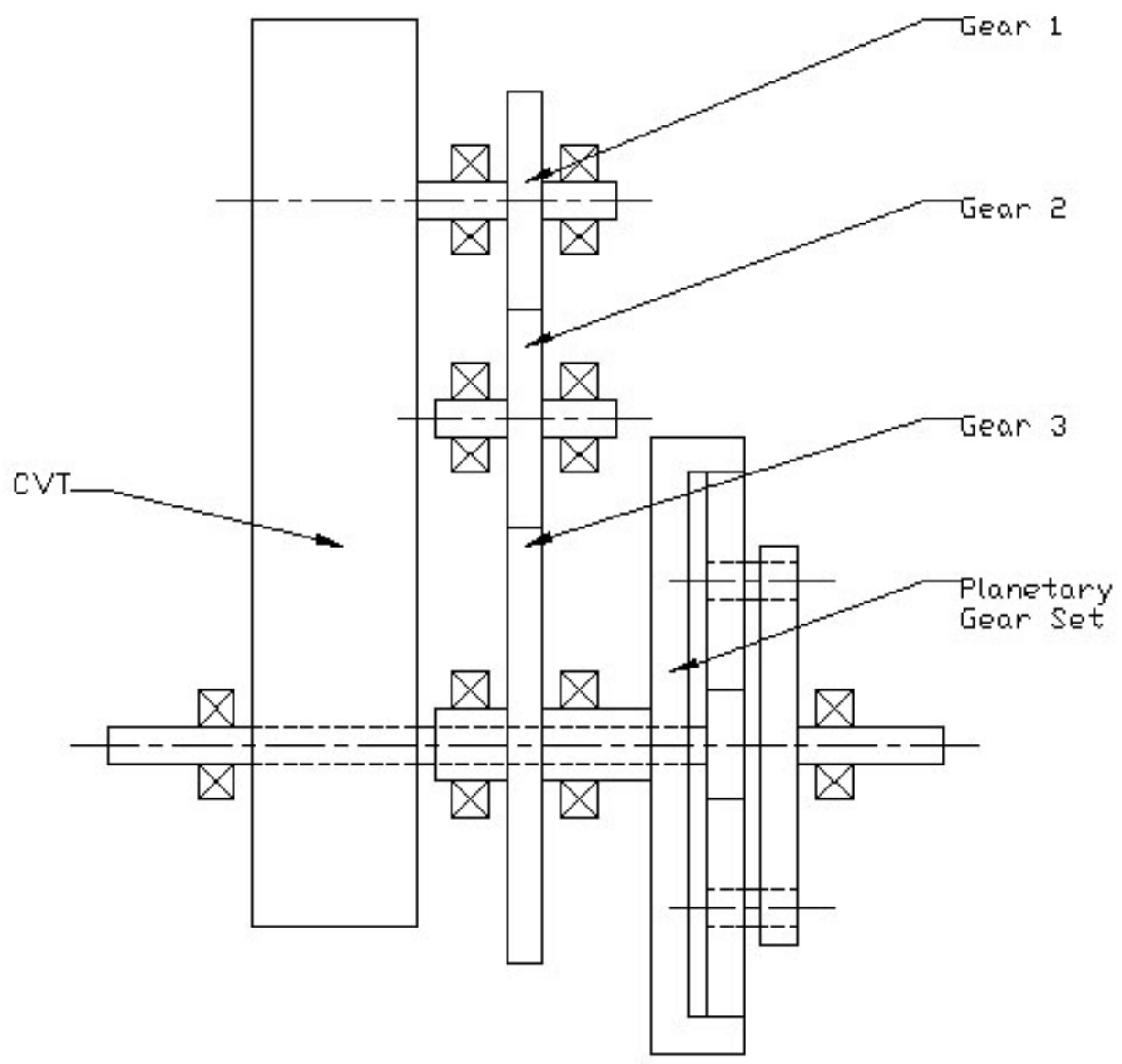

Figure 4-1. CVPST Model

\subsubsection{Simulation Hierarchy}

The global transmission model calculates the transmission output torque and speed based upon the input speed, torque, and CVT ratio (Fig. 4-2). This "black box" model simulates the performance of the transmission for discrete values of speed, torque, 
and CVT ratios, and the input and output variables are the same as in the actual, physical model. Within this global model are the subsystems that represent the physical components of the transmission and how they interact with one another. These subsystems operate within the global system with each individual subsystem simulating the operation of its physical counterpart. The gearing subsystem computes the speed and torque ratio between the input and output shafts of the gears while the bearing subsystem computes the frictional loss in bearings depending upon the operating conditions. The global system is comprised of the following hierarchy of subsystems:

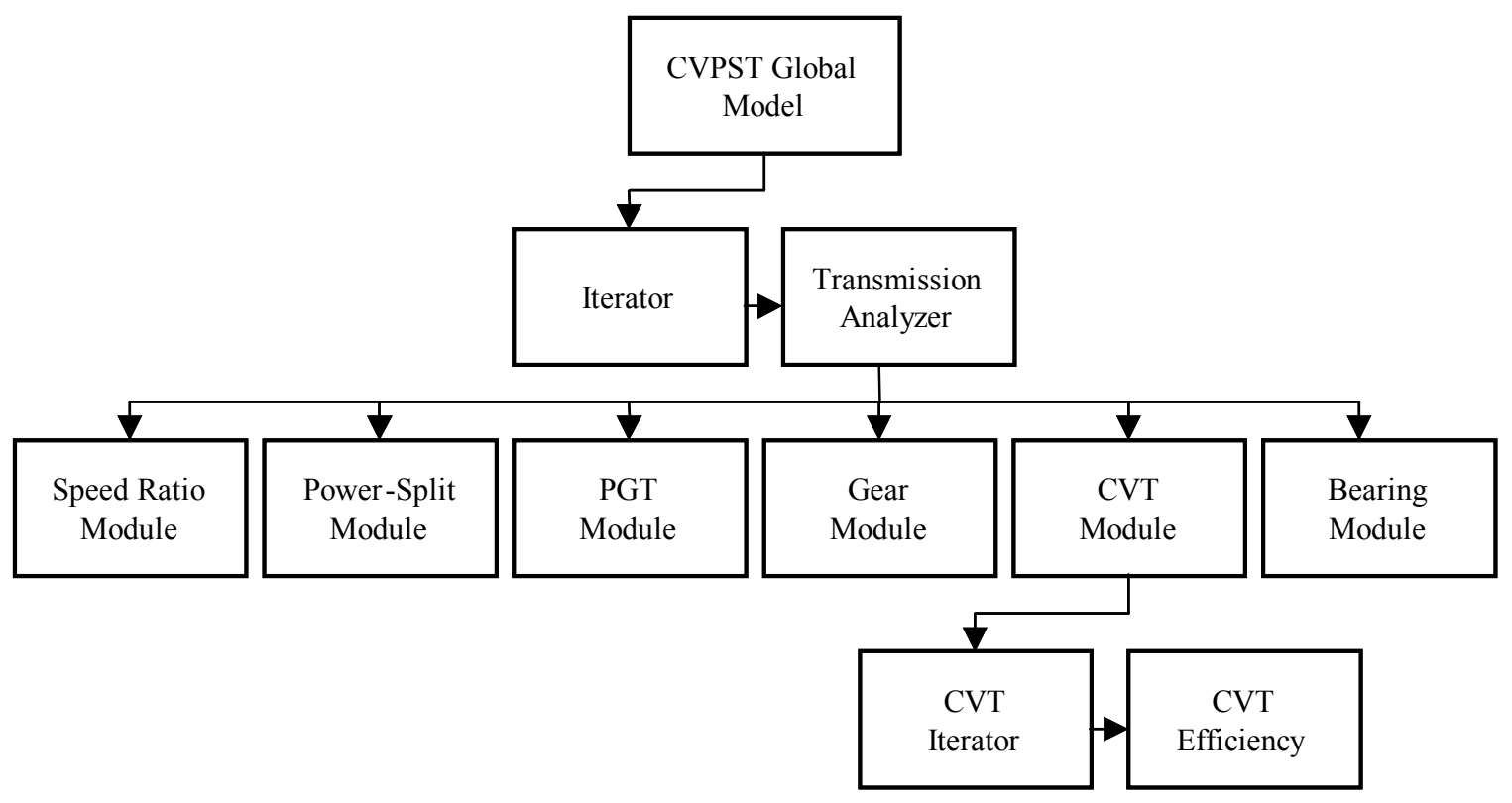

Figure 4-2. CVPST Transmission Simulation Model Hierarchy

\subsubsection{Transmission Analyzer Subsystem}

The transmission analyzer subsystem is similar to the global transmission model in that the input signals are torque, speed, and speed ratio, and the output signals are torque and speed. The difference is that the input signal for torque is the actual output 
torque for the transmission. This is because the output torque of the transmission is based on two factors: the overall speed ratio of the transmission and the combined torque loss due to frictional losses of the transmission components. This torque loss is based directly upon the power split between the branch control circuit and the main circuit of the transmission. According to Eq. (3-38), the power flow in the branch control circuit is proportional to the output torque. The torque loss through the two branches of the transmission are then solved in a "backwards" fashion by starting with the output torque and solving for torque losses through the branches of the transmission toward the input. The torque losses are added at each component location, and the solution is an input torque that would produce the specified output torque for the transmission speed ratio and input speed. For this simulation, gross slip in the CVT is neglected so that the speed efficiency is unity.

\subsubsection{Iterator Subsystem}

The CVPST Global Model has the input torque as an input signal to the model while the transmission analyzer has the input torque as an output signal. This discrepancy is rectified with the iterator subsystem that solves for the input torque through a conditional loop. In this loop, the input torque for the global model is the condition that must be satisfied. The relation to solve for input torque is:

$$
T_{O U T_{K-1}} \gamma_{T} \eta_{K}=T_{I N_{K}}
$$

where

$$
T_{O U T_{K-1}}=\gamma_{T} \eta_{K-1} T_{I N_{G L O B A L}}
$$

This relation is solved iteratively until the instantaneous condition $T_{I N_{G L O B A L}}=T_{I N_{K}}$ is satisfied. At this point, the loop is broken, and the input torque and its respective output torque are known. 


\subsubsection{Speed Ratio Module}

The speed ratio module has the inputs of the input speed and CVT speed ratio from the global transmission module. Also, the constant values for planetary gear ratio and the fixed gear ratio are input signals to the module. The speed ratio module performs the calculations outlined in Eqs. (3-33) and (3-34), and the output signals are the instantaneous angular velocities of all the transmission components.

\subsubsection{Power Split Module}

The power split module has the inputs of the input speed and CVT speed ratio from the global transmission module. Constant values for the fixed speed ratios are also input signals. The power split module performs the calculations outlined in Eqs. (3-38) and (3-39), and the output signals are the instantaneous power split ratio and torque split ratio for the transmission.

\subsubsection{PGT Module}

The PGT (Planetary Gear Train) module has the inputs of the output torque from the transmission analyzer subsystem and the instantaneous power split ratio from the power split module. These signals are used to perform the calculations in Eqs. (3-17) through (3-24). Inside this module, the output torque is then divided by the resulting efficiency to get the corrected torque in the PGT.

\subsubsection{Gear Module}

The gear module has the inputs of the corrected torque from the PGT module which has been multiplied by the torque split ratio from the power split module, the fixed gear ratio, and the mechanical efficiency of the gear pair. This module corrects for the 
torque loss due to gear friction with Eq. (3-15) and the output signal is the corrected torque at the CVT outlet.

\subsubsection{CVT Module}

The CVT Module is similar in operation to the global transmission model in that the type of input and output signals is the same. This is because the CVT is also a power transmission device; it is just embedded in the larger model. The CVT module lies in the chain of solving for torques from the output of the transmission to the input, so the input signals to the module consist of the speed ratio, the CVT input speed, and the CVT output torque. The output signals of the module consist of the input torque and the output speed.

\subsubsection{CVT Iterator}

The CVT Iterator Module operates like the main iterator module on the global model. The need for this model is to solve for the input torque from a known output torque. The efficiency of the CVT can be calculated from Eqs. (3-25) to (3-31) in terms of input torque, speed, and speed ratio, but input speed, output torque, and speed ratio are the available signals. The input and output torques are bounded by the relation for dynamic equilibrium:

$$
T_{O U T_{C V T}} \gamma_{T} \eta=T_{I N_{C V T}}
$$

In order to solve this problem for a known output torque, the torque in the CVT is increased by 0.001 Newton-meter increments until its resulting torque is equal to the value of the input signal. 


\subsubsection{CVT Efficiency Module}

The CVT Efficiency module is used to determine the efficiency of the CVT for a given set of operating conditions. The input signals consist of the input torque, input speed, and speed ratio of the CVT. The module then solves Eqs. (3-25) to (3-31) to determine the efficiency of the CVT. The output signals consist of the output torque and speed.

\subsubsection{Bearing Module}

The bearing module is used to determine the bearing moments due to friction for all of the bearings in the transmission. The input signals to the bearing module consist of the torque at each shaft location. The module then calculates the torque loss due to friction with the relation:

$$
T_{\text {LOSS }_{n}}=F_{n} d \mu
$$

where $T_{\text {LOSSn }}$ is the torque loss in bearing $n, F_{n}$ is the force on bearing $n$, and $\mu$ is the bearing coefficient of friction. Fn is calculated from the force analysis on the shaft due to tangential gear forces and component weight. The bearing module solves this relation for each bearing location, and the output signals consist of the torque loss at each bearing location. These torque losses are then added to the reversed torque path in the transmission analyzer to attain a cumulative bearing loss.

\subsection{Modified CVPST Simulation Program}

The modified CVPST simulation is modeled after the common CVPST described in the previous section with two differences. The modified CVPST has the branch control circuit disconnected from the split power path right before its connection to the 
ring gear, and the sun, ring, and gear carrier of the planetary gear set are constrained. The resulting transmission has a 1:1 ratio direct-drive with an idling CVT. In this arrangement, all of the subsystems are mechanically connected to the input shaft, but not all of the components transmit power.

The global transmission model calculates the transmission output torque and speed based upon the input speed, torque, and CVT ratio. This model performs the same function as the previous model, but it is for a different physical system. Within this global model are subsystems that represent the same physical components as the previous system. Because of this similarity, the same modules programmed for one module can be used in another. The modified global system is comprised of the following hierarchy of subsystems:

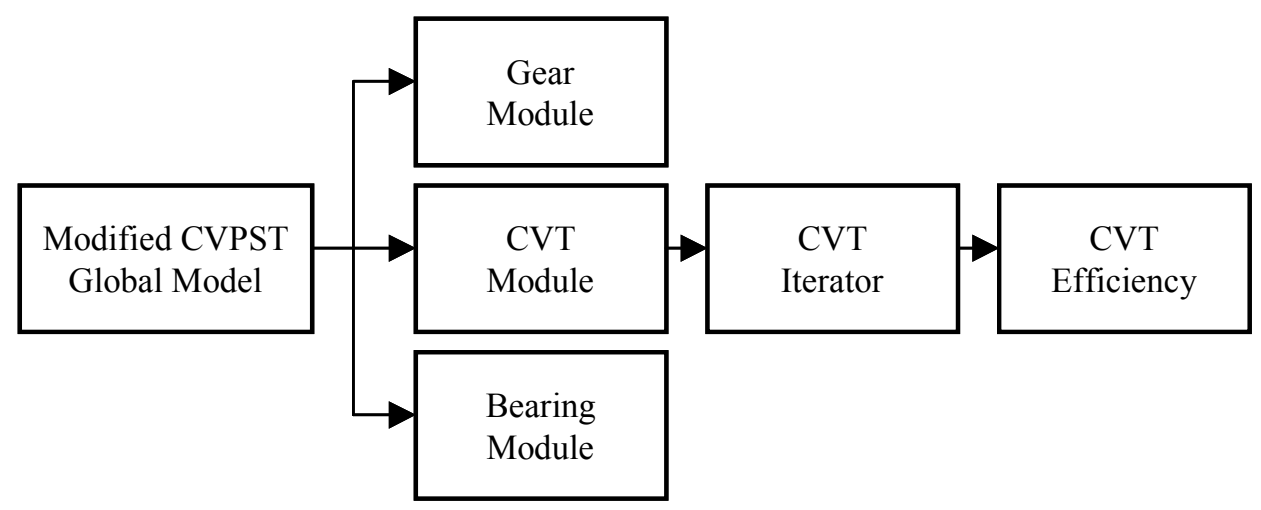

Figure 4-3. Modified CVPST Transmission Simulation Hierarchy

The same modules from the previous case were used in the simulation to calculate the performance of the CVT, gears, and bearings. Because the branch control circuit was disconnected at the ring gear, the planetary gear set was modeled as a constrained, lumped mass (Fig. 4-3). 


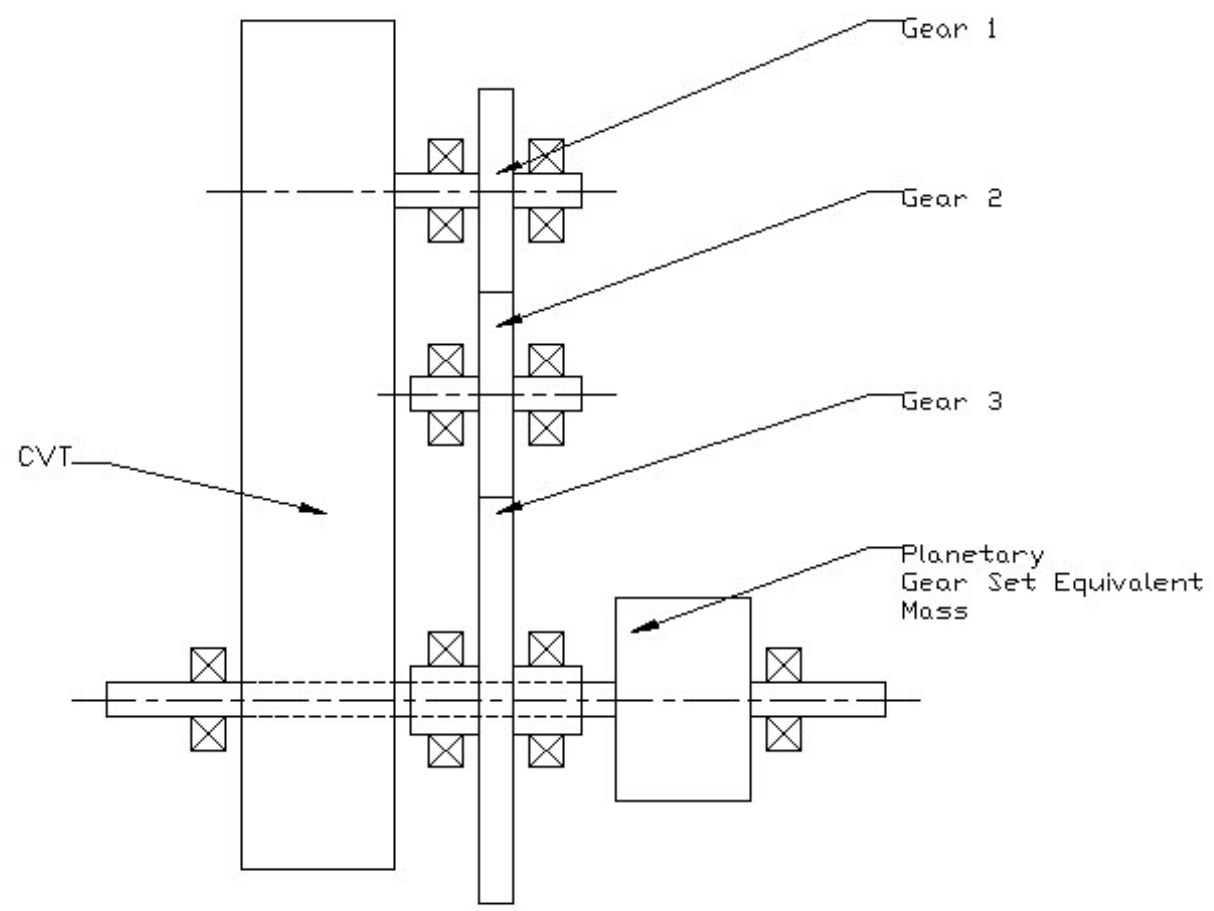

Figure 4-4. Modified CVPST Model

\subsection{Direct-Drive CVPST Simulation Program}

The direct-drive CVPST simulation is modeled with the same components as the previous two transmission layouts, but the CVT is disconnected from the input shaft and the planetary gear set fully constrained. In this arrangement, none of the branch control circuit elements are mechanically connected to the input shaft, and the power path moves directly from the input to the output shaft (Fig. 4-4). 


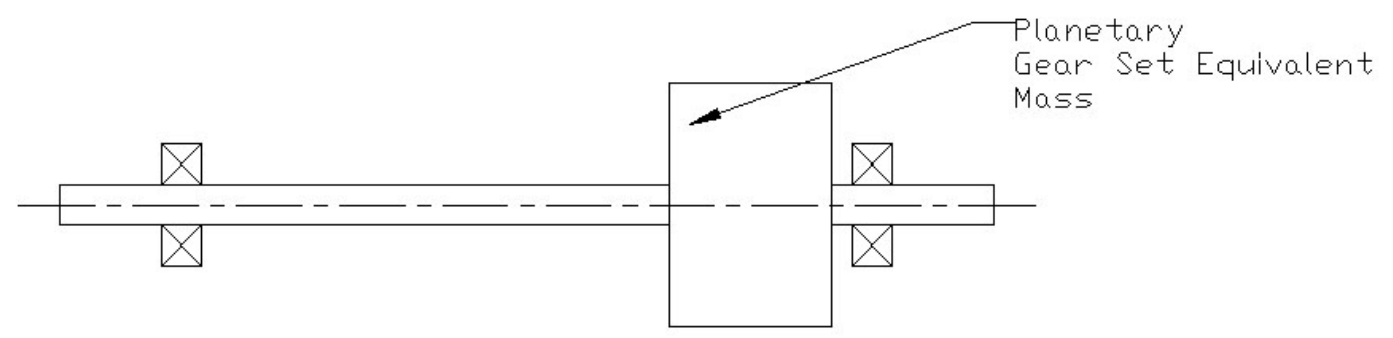

Figure 4-5. Direct-Drive CVPST Model

The global transmission model calculates the transmission output torque and speed based upon the input speed and torque. This model performs the same function as the previous models, but it is for a different physical system. Within this global model are subsystems that represent the same physical components as the previous system. The modified global system is comprised of the following hierarchy of subsystems:

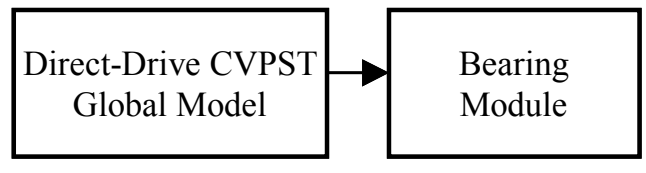

Figure 4-6. Direct-Drive CVPST Simulation Block Diagram

The same module used in the previous sections was used. The CVT, gear, and PGT modules were not used because the CVT and gears were completely disconnected from the system and the physical system was modeled as a solid shaft supported by bearings. 


\section{Chapter 5 - Continuously Variable Power Split Simulation Results and Analysis}

A computer program developed from the framework in the previous chapter simulates the performance of a CVPST for three different modes of operation. This program can be used to determine overall transmission efficiency in order to determine which kinematic arrangement is most efficient. Another task for this program is to identify which parameters affect transmission efficiency in order to optimize the design. The program used for this simulation is Simulink, which is part of the Matlab 6.1 release. This software is a graphical package that can be used to model physical systems quickly while retaining the computation capabilities of Matlab 6.1. It is also a modular program in which subsystems can be copied from one simulation into another. In addition, Simulink has input modules that allow simulations to run from data files and output modules which can write data to new files, graph the information, or place the data in Matlab for post-processing. Because this is a graphical program, there is no program code that had to be produced. A glossary of the function blocks used in the simulation is given in Appendix A while the Simulink model diagrams for the three simulations are given in Appendix B.

\subsection{Simulation Overview}

\subsubsection{Overall Model}

In order to simulate the performance of a modified CVPST, a representative physical model had to be constructed. This is a simplified conceptual model that is meant to study the performance of the three kinematic arrangements and illustrate the problem- 
solving method for that study. Because of this, the design process for the model is less thorough than that for a transmission entering volume production. This model is the basis for all three simulation conditions so that the data could be compared directly. The model consists of a CVT, a set of conventional gears, and a planetary gear set (Fig. 5-1). Using Eqs. (3-34) and (3-35), this transmission is designed to have a maximum speed ratio of $3: 1$ and a minimum speed ratio of 1:1.

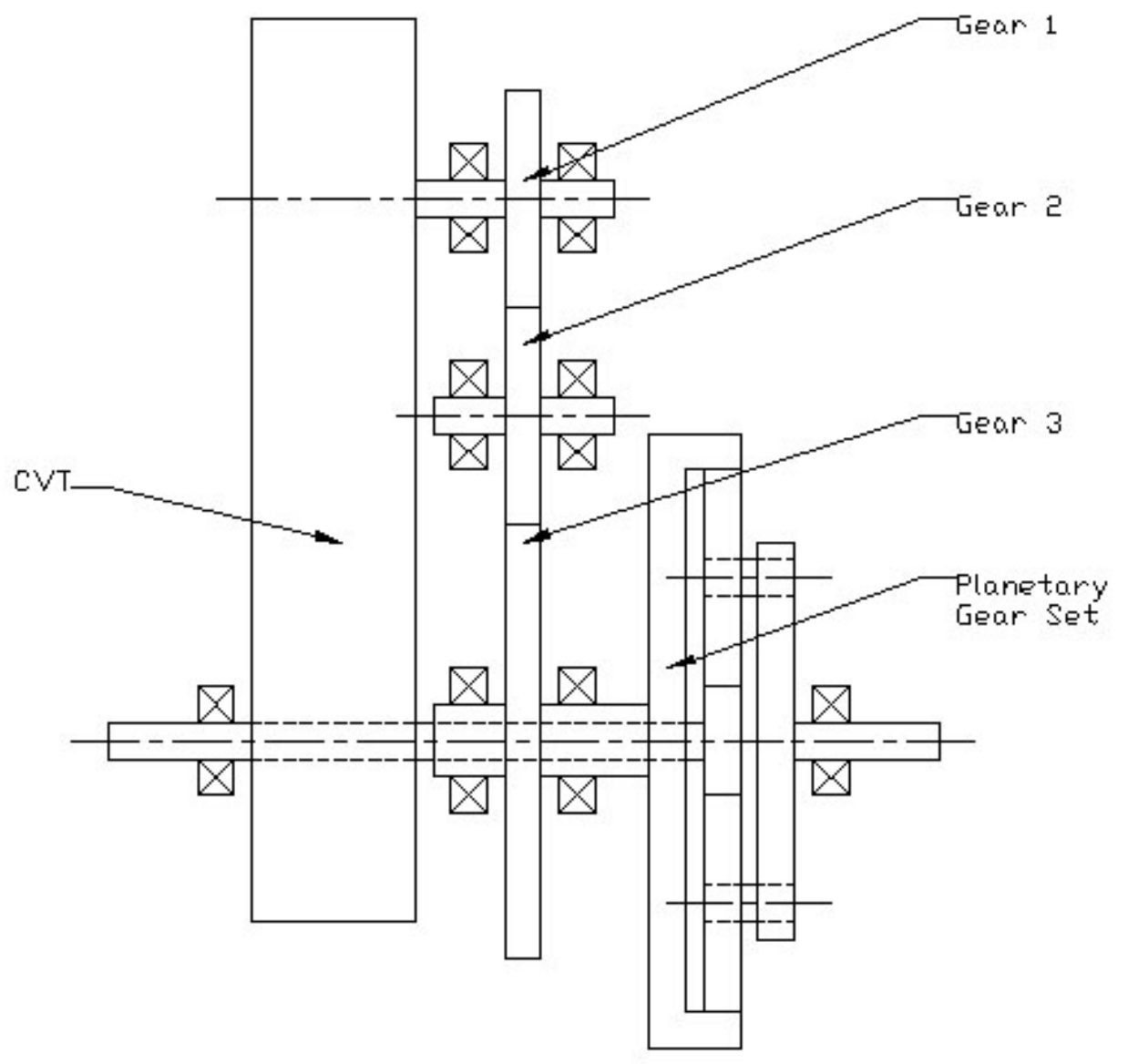

Figure 5-1. Diagram of Transmission Model 


\subsubsection{CVT Model}

In this model, a block with one input and two output shafts represents the CVT. The CVT model is based upon a Volvo Components Corporation design (Bonthron, 1985). This CVT is a metal pushing belt friction CVT with a ratio range from $2.5: 1$ to 0.5:1. The maximum input torque for this CVT is $120 \mathrm{~N}-\mathrm{m}$. This CVT is microprocessor controlled, but a hydraulic actuator controls the sheave movement and applies the belt clamping loads. The hydraulic losses were estimated to be $250 \mathrm{~W}$ while running at constant speed, $300 \mathrm{~W}$ while accelerating with constant input speed, and $420 \mathrm{~W}$ while changing input speed (Bothron, 1985). A mathematical model of the efficiency of this mechanism was constructed for all of its operating conditions (Singh and Nair, 1992), and this model is represented by Eqs. (3-24) to (3-30). Because the transmission efficiency was measured in terms of the entire transmission mechanism complete with bearings, hydraulic components, and control mechanisms, the CVT is represented as a "black box" model where the only inputs and outputs are torque and speed as the exact geometry and material of all the transmission components were not available in the literature. In addition, the shaft center distance between the CVT input and output shafts was set at $300 \mathrm{~mm}$. The true shaft center distance was not apparent in the literature (Bothron, 1985), so the CVT black box model is combined with a set of 1:1 ratio gears to relocate the output shaft for analysis. These output gears have an efficiency of unity, so their influence is negligible within the CVT model.

\subsubsection{Gear Train Model}

The gear train model is represented by four components, which are gear one, gear two, gear three, and the planetary gear set. Gears one, two, and three were designed for a 
2:1 gear reduction with the gear sizes satisfying the $300 \mathrm{~mm}$ center distance, and the planetary gear set was designed to have a 5:1 ratio. The bearings used in this transmission are tapered roller bearings that were assumed to have a constant coefficient of friction.

Because this was a conceptual design, only the static loading was used to determine the gear sizes, and a load factor of 1.5 was used. The gear loads were calculated with a simulation model at the greatest loading condition, which occurs at the maximum 3:1 gear ratio at a maximum input torque of $120 \mathrm{~N}-\mathrm{m}$. The gear loading was simulated in another Simulink model that calculated the stresses on gear teeth using the Lewis formula, and a common face width was used for all gears to simplify the analysis. The complete Simulink model is given in Appendix C, and the resulting gear components are shown in Table 5-1.

Table 5-1. Gear Sizes for Transmission Model

\begin{tabular}{|c|c|c|c|c|c|c|}
\hline Gear & $\begin{array}{c}\text { Pitch Dia. } \\
(\mathbf{m m})\end{array}$ & $\begin{array}{c}\text { Module } \\
(\mathbf{m m})\end{array}$ & $\begin{array}{c}\text { No. of } \\
\text { Teeth }\end{array}$ & $\begin{array}{c}\text { Face Width } \\
(\mathbf{m m})\end{array}$ & Material & $\begin{array}{c}\text { Unit } \\
\text { Weight (N) }\end{array}$ \\
\hline Gear 1 & 120 & 3 & 40 & 20 & SAE 1020 Steel & 17.30 \\
\hline Gear 2 & 120 & 3 & 40 & 20 & SAE 1020 Steel & 17.30 \\
\hline Gear 3 & 240 & 3 & 80 & 20 & SAE 1020 Steel & 69.22 \\
\hline Sun Gear & 60 & 3 & 20 & 20 & SAE 1020 Steel & 4.33 \\
\hline Ring Gear & 300 & 3 & 100 & 20 & SAE 1020 Steel & 112.96 \\
\hline $\begin{array}{c}\text { Planet } \\
\text { Gears (4) }\end{array}$ & 120 & 3 & 40 & 20 & SAE 1020 Steel & 69.20 \\
(all 4)
\end{tabular}

The other components of the physical system such as shafts, seals, and clutches were considered to have no mass and be frictionless to simplify the model and eliminate design time for components where the design practices are well-established (Table 5-2). 
Table 5-2. Transmission Model Components

\begin{tabular}{|c|c|}
\hline Shaft & Diameter \\
\hline Main Input and Output Shaft & $20 \mathrm{~mm}$ \\
\hline Parallel Shaft out of CVT & $20 \mathrm{~mm}$ \\
\hline Gear 2 Shaft & $20 \mathrm{~mm}$ \\
\hline Gear 3 Shaft & $40 \mathrm{~mm}$ \\
\hline Bearing Type & Coefficient of Friction \\
\hline Tapered-Roller & 0.0018 \\
\hline
\end{tabular}

\subsection{Simulation Conditions}

\subsubsection{Simulation of the CVSPT}

The first kinematic arrangement to be simulated was the common PSCVT. The common PSCVT is modeled with the same model depicted in Figure (5-1). The operating condition that is modeled is the 1:1 input to output ratio, where all elements of the planetary gear set are rotating at the same angular velocity. Because of this "synchronous" condition, the power split cannot be determined. Recalling Eqs. (3-10) and (3-11):

$$
\Sigma T=T_{a}+T_{b}+T_{c}=0,
$$

and

$$
\Sigma P=T_{a} \omega_{a}+T_{b} \omega_{b}+T_{c} \omega_{c}=0 .
$$

which are solved simultaneously to yield Eq. (3-12)

$$
\gamma=\frac{\omega_{b}\left(\omega_{c}-\omega_{a}\right)}{\omega_{c}\left(\omega_{a}-\omega_{b}\right)},
$$

where $\mathrm{S}, \mathrm{R}$, and $\mathrm{A}$ denote the angular speeds of the sun, ring, and planetary arm respectively. At the synchronous point, Eq. (3-12) reduces to:

$$
\gamma=\frac{(1-1)}{(1-1)}=\frac{0}{0}=\text { undefined }
$$


which is a singularity point in the function. This singularity occurs because the derivation of Eq. (3-12) is a solution of the system of equations in Eqs. (3-10) and (3-11) which become equal when the speeds are synchronized where a singularity is defined as an algebraic relation divided by zero which is undefined. This is due to the fact that all of the angular velocities are equal, so when Eq. (3-11) is reduced, Eqs. (3-10) and (3-11) are equal and the system of equations form a singular matrix which cannot be solved by a computer program. In the physical system, the power split is still present even if it cannot be calculated with Eq. (3-12) because a power split exists on both sides of that synchronous point, so it must exist in the discontinuity, or power would be instantaneously transferred from one power transmitting member to another on each side of the synchronous point.

As can be seen in Figure (5-2), the power split factor has a linear relationship with respect to speed ratio. The discontinuity at the $1: 1$ speed ratio is shown to be a point discontinuity in the linear function. It is a point discontinuity because power split exists as a linear function of speed ratio for smaller and smaller increments of speed ratio as it approaches the 1:1 synchronous value. Because of this singularity, the power split factor at the synchronous ratio is calculated for the model with Eq. (3-38) in the limit:

$$
\gamma=\lim _{\gamma_{1} \gamma_{C V T} \rightarrow 1}\left(\frac{\gamma_{1} \gamma_{C V T}}{\gamma_{1} \gamma_{C V T}-1}\right)\left(\frac{\gamma_{P G T}-\gamma_{P G T} \gamma_{1} \gamma_{C V T}}{1+\gamma_{P G T} \gamma_{1} \gamma_{C V T}}\right) .
$$

The solution to this relation is the power split ratio at the synchronous point. 


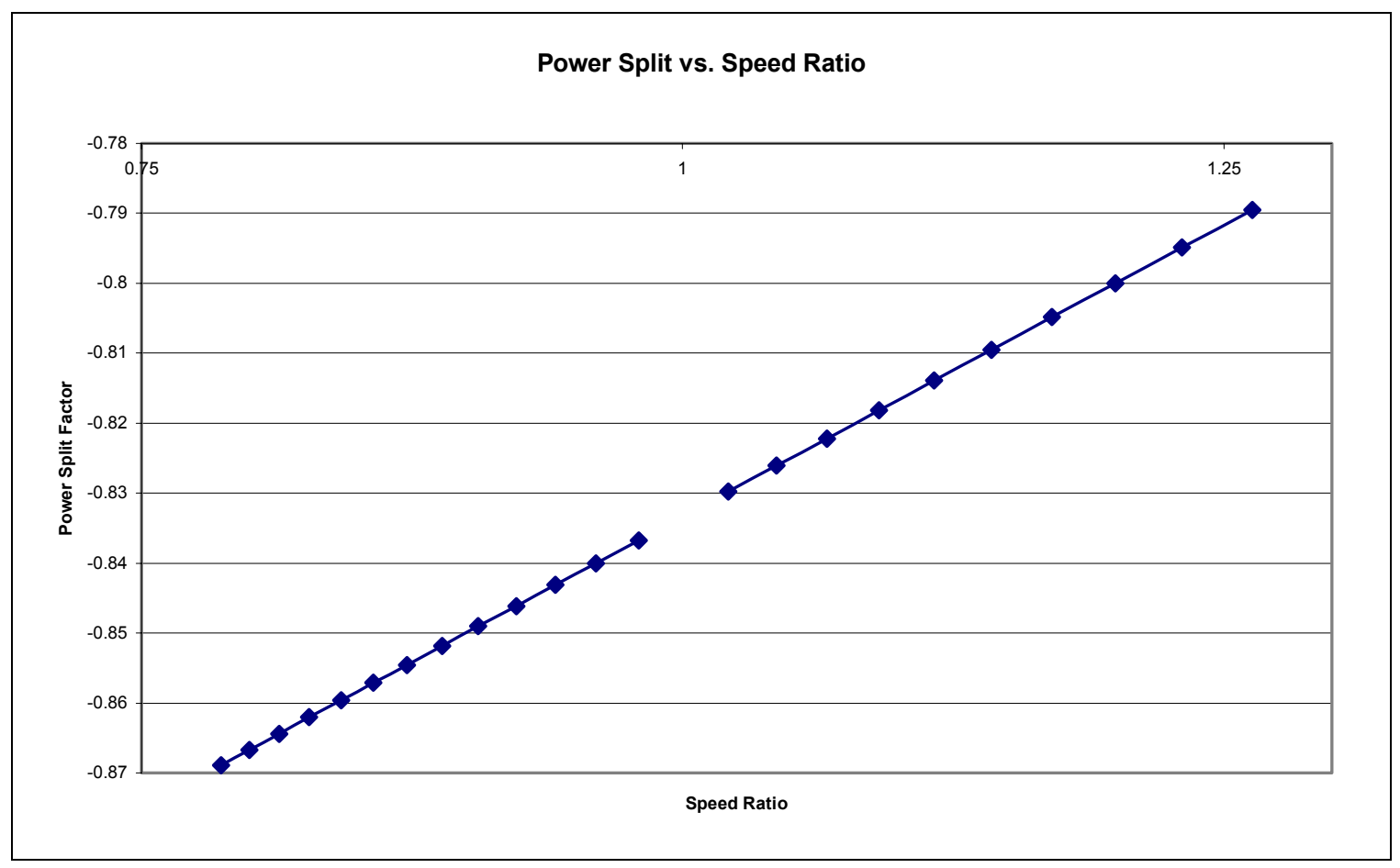

Figure 5-2. Graph of the Power Split Factor around the Synchronous Point

In this simulation, all of the components are in the power path. The sources of loss include the frictional and hydraulic losses in the CVT and the frictional losses in the gears. The frictional losses in the planetary gear set are not present at the 1:1 ratio because there is no relative velocity between the sun, ring, and planet gears. The only other source of loss simulated was that in the bearings. These losses are frictional losses due to radial loads on the bearing shafts. These radial loads are a combination of the weight loads of the components and the tangential forces on the gear teeth.

\subsubsection{Simulation of the Modified CVPST}

The second kinematic arrangement to be simulated was the modified CVPST. The modified PSCVT is modeled at the 1:1 input to output ratio in the cruise mode, so the ring gear of the planetary gear set is disconnected from gear 3 in the model. The resulting system is modeled as a direct-drive shaft with an idling CVT driving gear 1, 
gear 2, and gear 3 (Fig. 5-3). In this model, the planetary gear set is represented by an equivalent mass with a fixed input and output shaft to simulate a fixed planetary gear that has been engaged by a clutch. The CVT is the same black box model used in the previous simulation, but its load is determined by the frictional moment in the bearings and gears instead of the load specified by the power split factor. In this arrangement, the losses are due to the frictional and hydraulic losses in the CVT, the mechanical losses in the gears, and the frictional losses in the bearings due to radial loads on the bearing shafts.

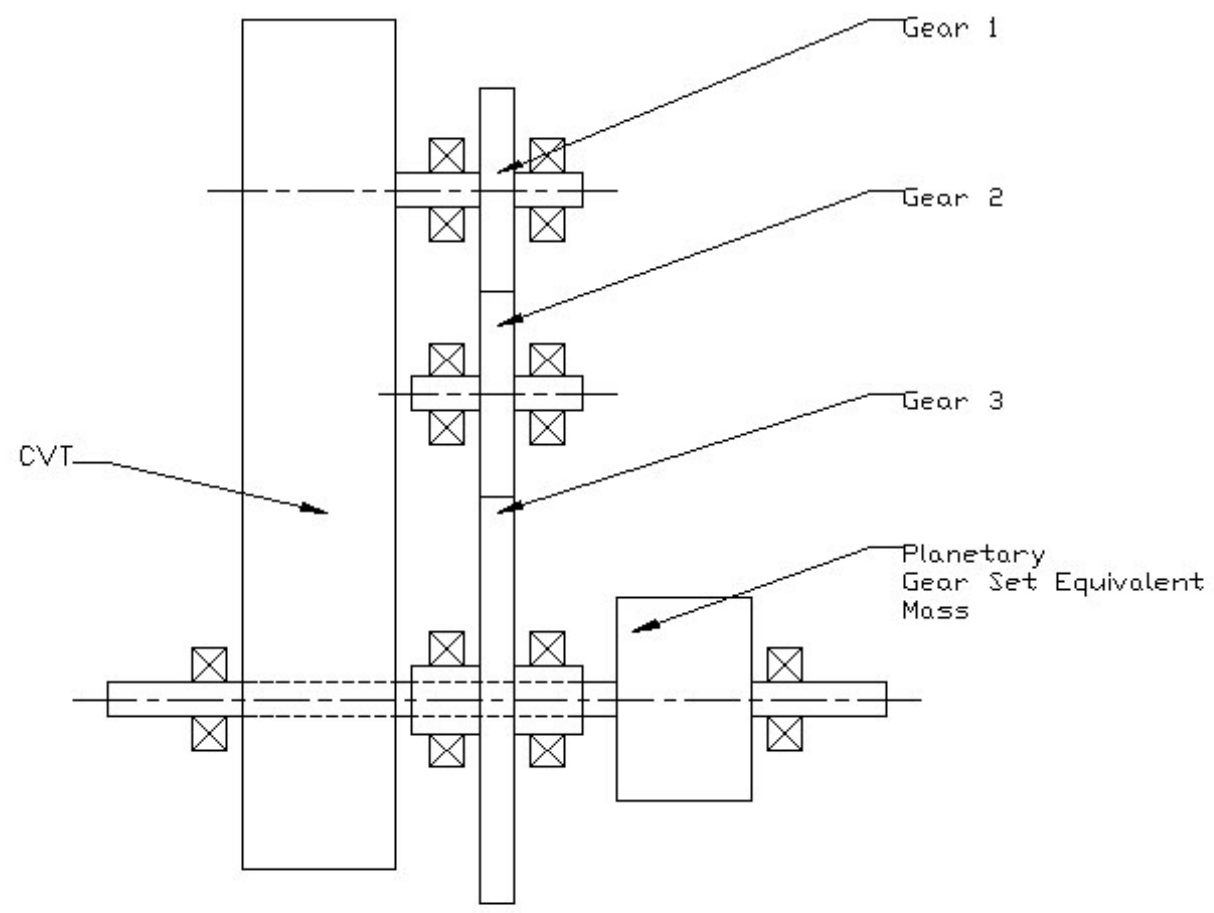

Figure 5-3. Simulation Model for Modified Power Split CVPST

\subsubsection{Direct-Drive CVPST Simulation}

The final kinematic arrangement to be simulated was the direct-drive CVSPT. As in the previous cases, the direct-drive transmission is simulated at the 1:1 input to output 
ratio for direct comparison to the other kinematic arrangements. In the direct-drive model, the CVT is mechanically disconnected from the input shaft and gear 3 is disconnected from the ring gear. The equivalent transmission model is simply a solid shaft with an equivalent mass representing the constrained planetary gear set (Fig. 5-4). In this arrangement, the only losses are due to frictional losses in the bearings because the branch control circuit is completely disconnected and the planetary gear set is constrained.

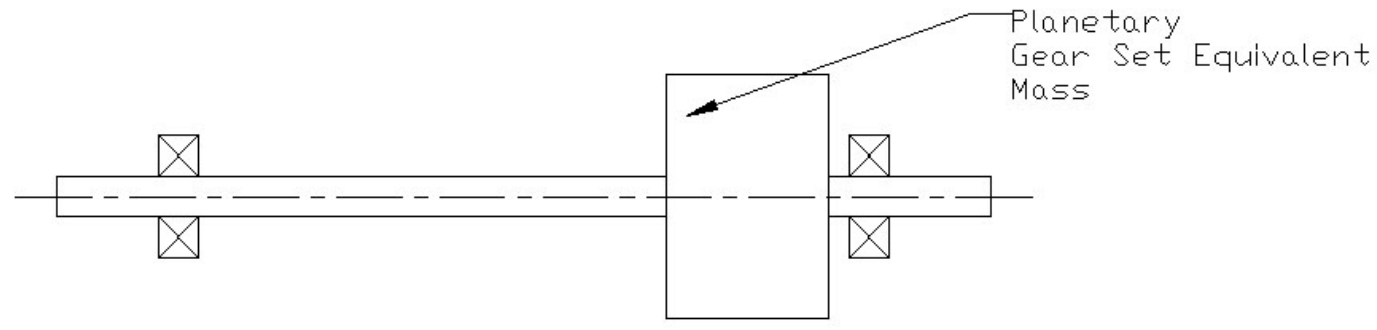

Figure 5-4. Simulation Model for the Direct-Drive PSCVT

\subsection{Simulation of CVPST at Constant Speed}

The CVPST simulation at constant speed is intended to simulate the performance of all three CVSPT arrangements for a given range of torques. The maximum tested speed for the CVT in the transmission is 4000 RPM (Bonthron, 1985) and the maximum torque is $120 \mathrm{~N}-\mathrm{m}$. The simulation was performed for all three transmission arrangements in 1000-RPM increments from 1000 RPM to the 4000-RPM maximum. In these simulations, the input speed is considered constant for each data point so that inertial effects do not show up in the data. The following figures show the results of the simulations. 


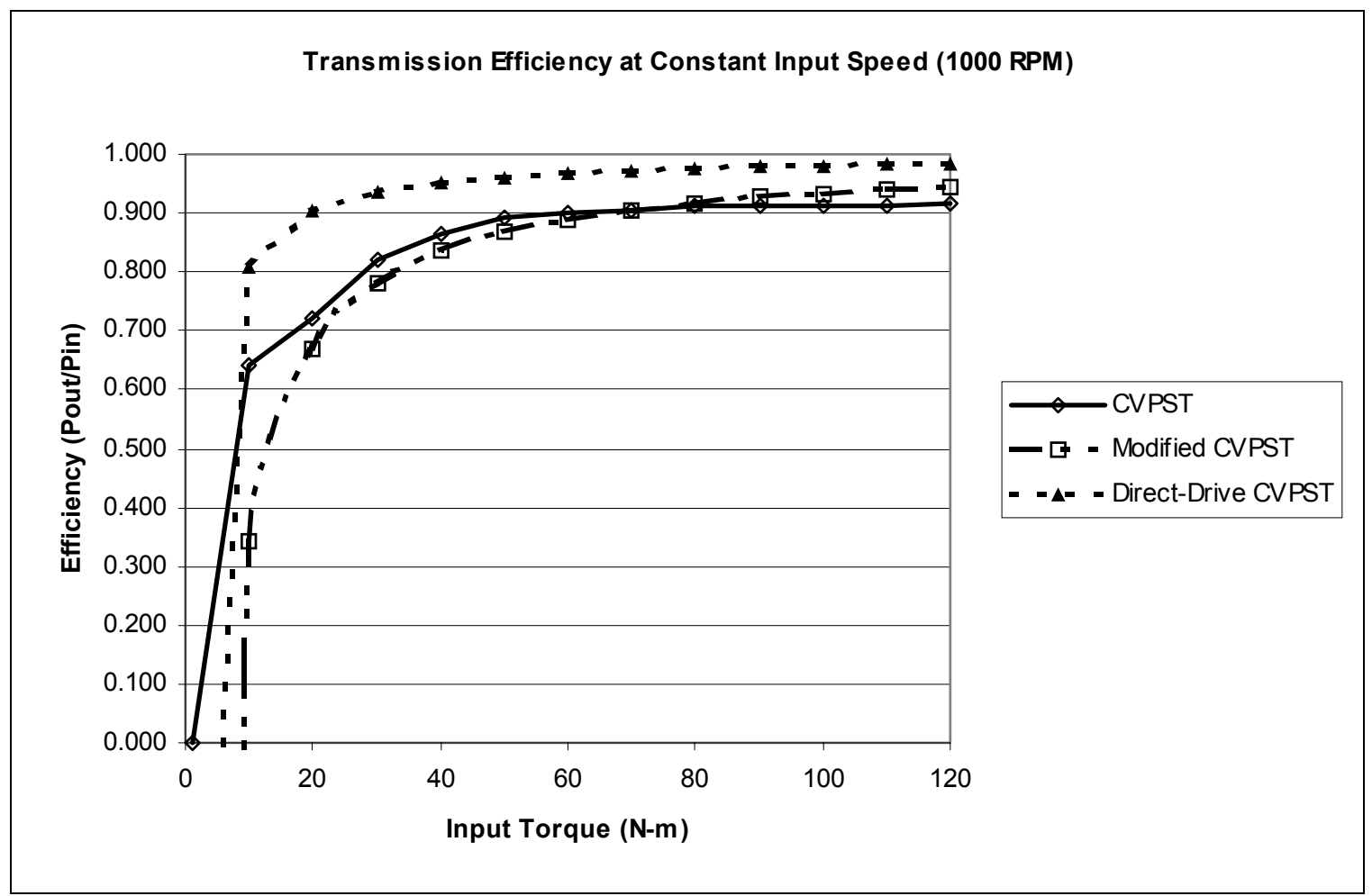

Figure 5-5. Comparison of Total Transmission Efficiency for Varying Torques at 1000 RPM Input Speed

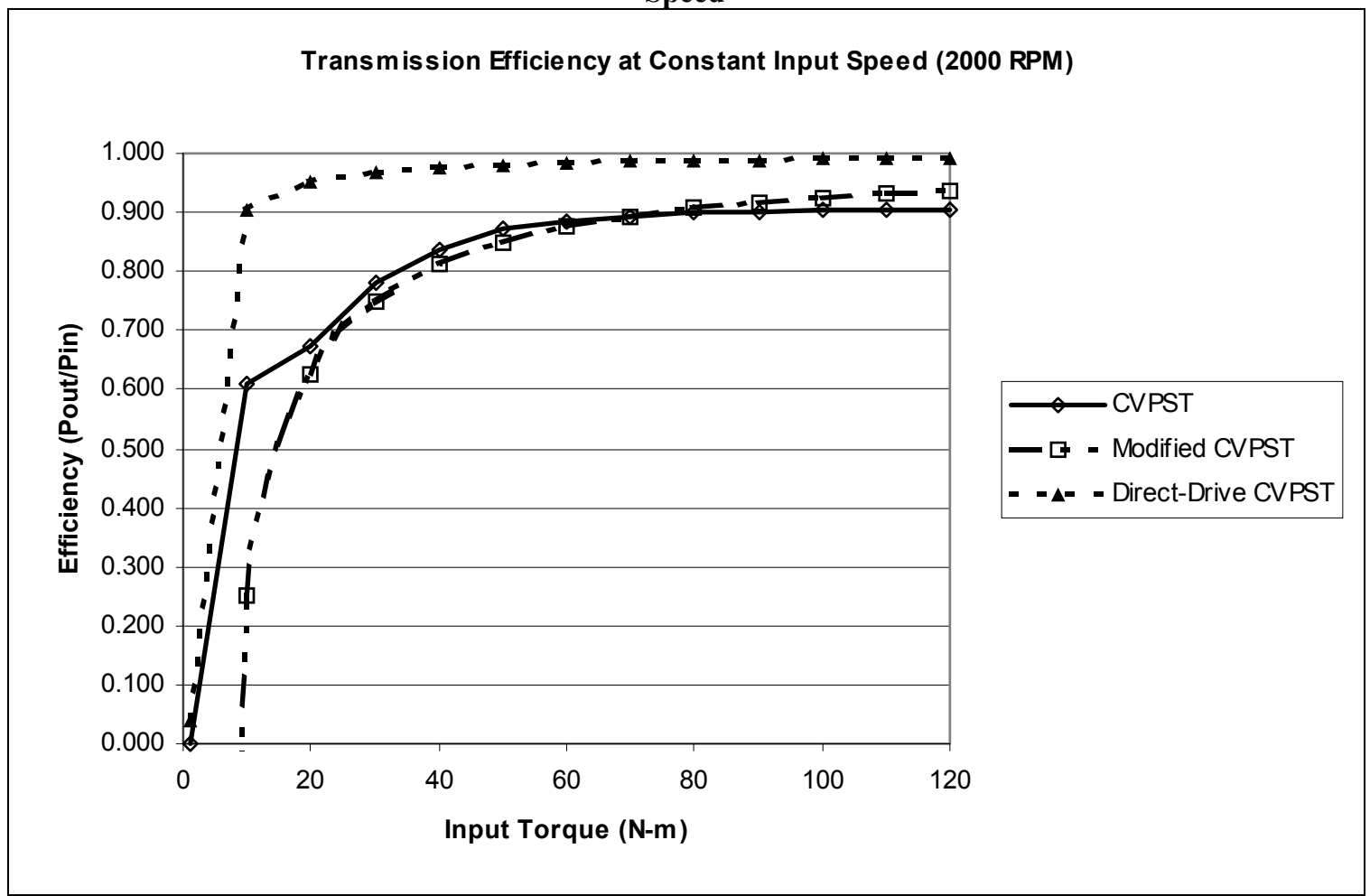

Figure 5-6. Comparison of Total Transmission Efficiency for Varying Torques at 2000 RPM Input Speed 


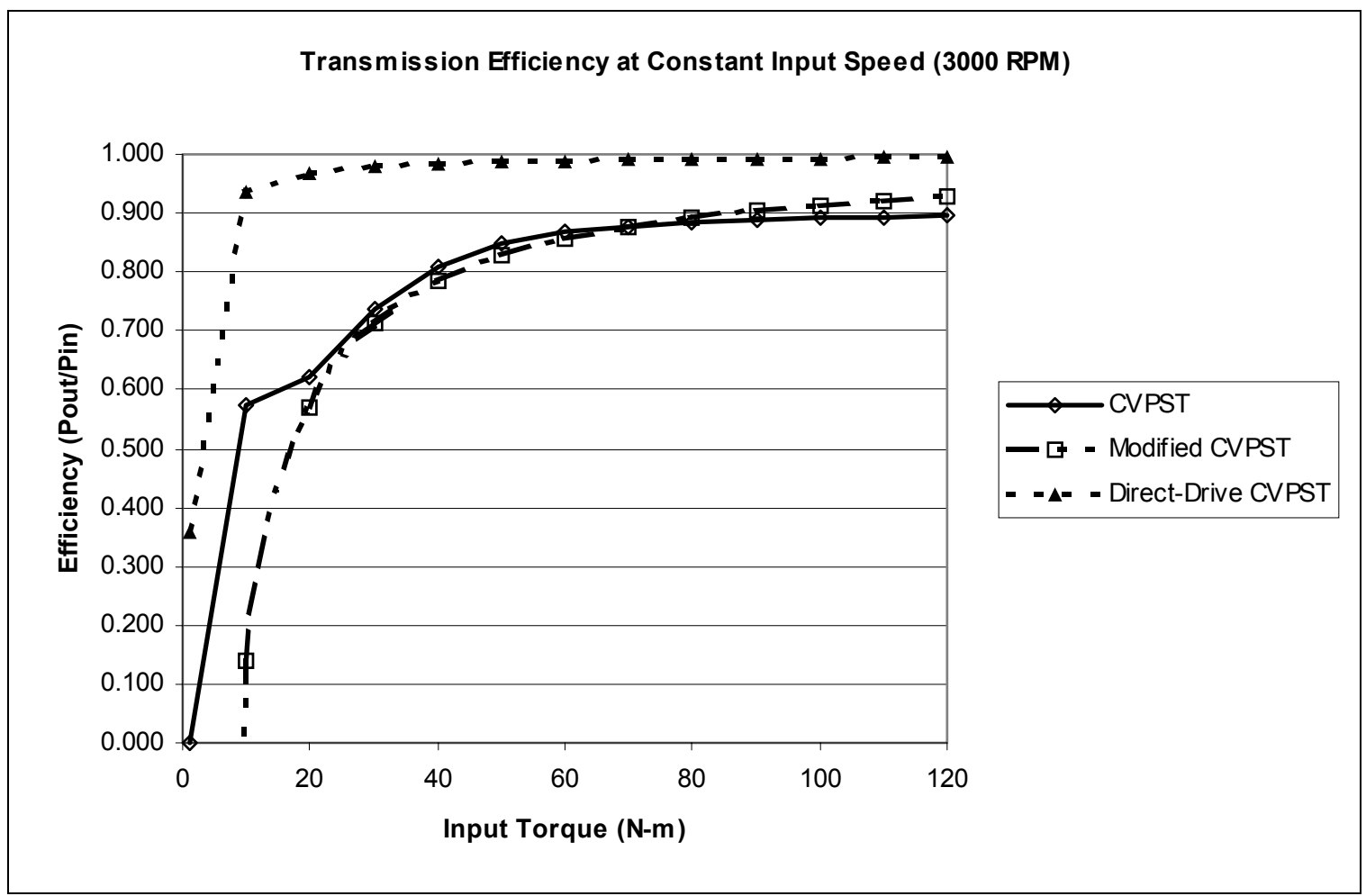

Figure 5-7. Comparison of Total Transmission Efficiency for Varying Torques at 3000 RPM Input Speed

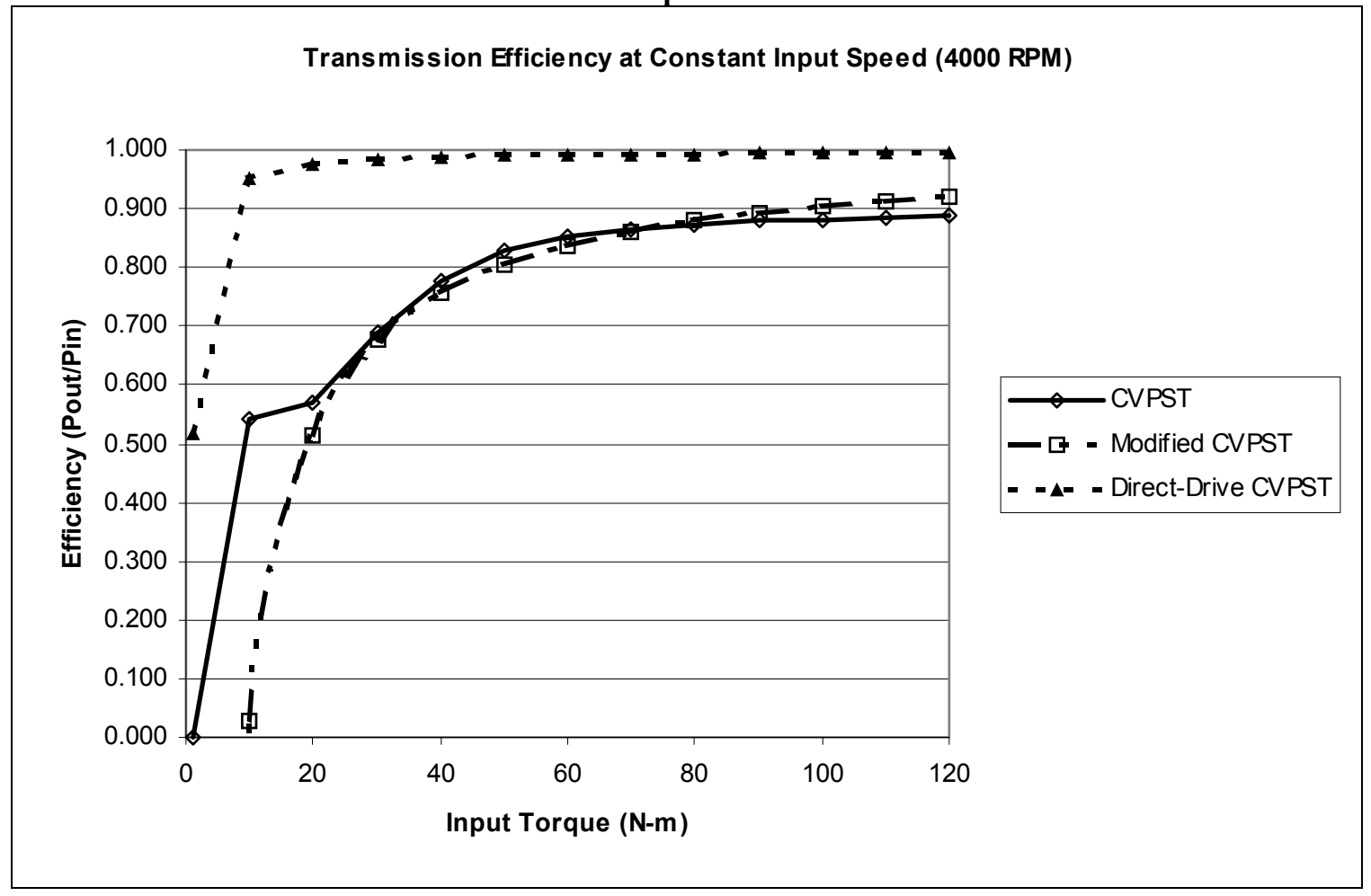

Figure 5-8. Comparison of Total Transmission Efficiency for Varying Torques at 4000 RPM Input Speed 
The results of the CVPST simulation at constant input speeds indicate that the direct-drive arrangement is the most efficient throughout the transmission operating range. It can also be seen that the efficiencies of the unmodified CVPST and the modified CVPST are almost identical for ranges above $25 \mathrm{Nm}$ for all of the speeds.

\subsection{Simulation of CVPST at Constant Torque}

The CVPST simulation at constant torque is intended to simulate the performance of all three CVSPT arrangements for a given range of speeds. The simulation was performed for all three transmission arrangements in 10 and $20 \mathrm{~N}-\mathrm{m}$ increments to the $120 \mathrm{~N}-\mathrm{m}$ maximum. The following figures show the results of these simulations.

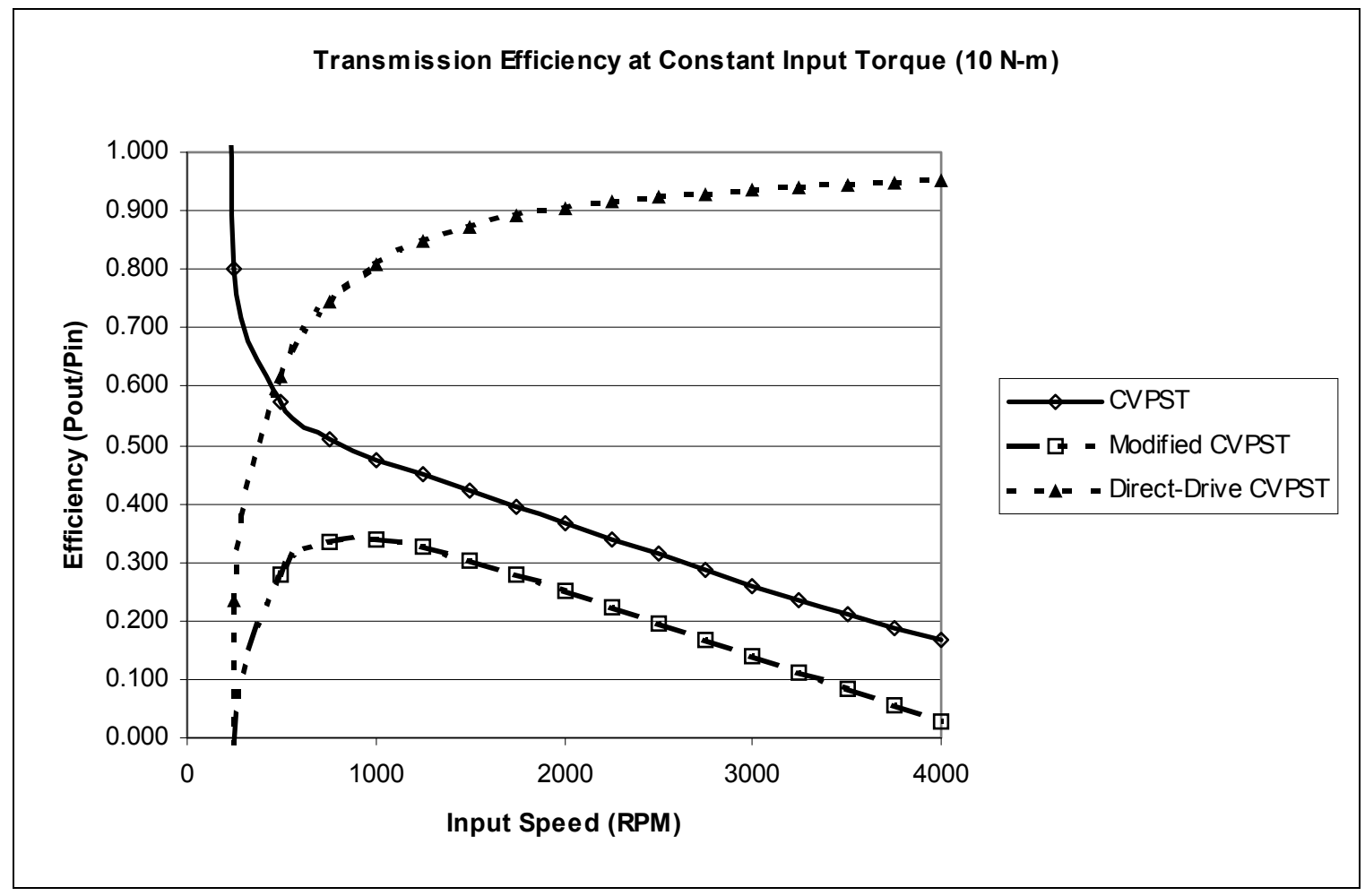

Figure 5-9. Comparison of Total Transmission Efficiency for Varying Speeds at a Constant Input Torque of $10 \mathrm{~N}-\mathrm{m}$ 


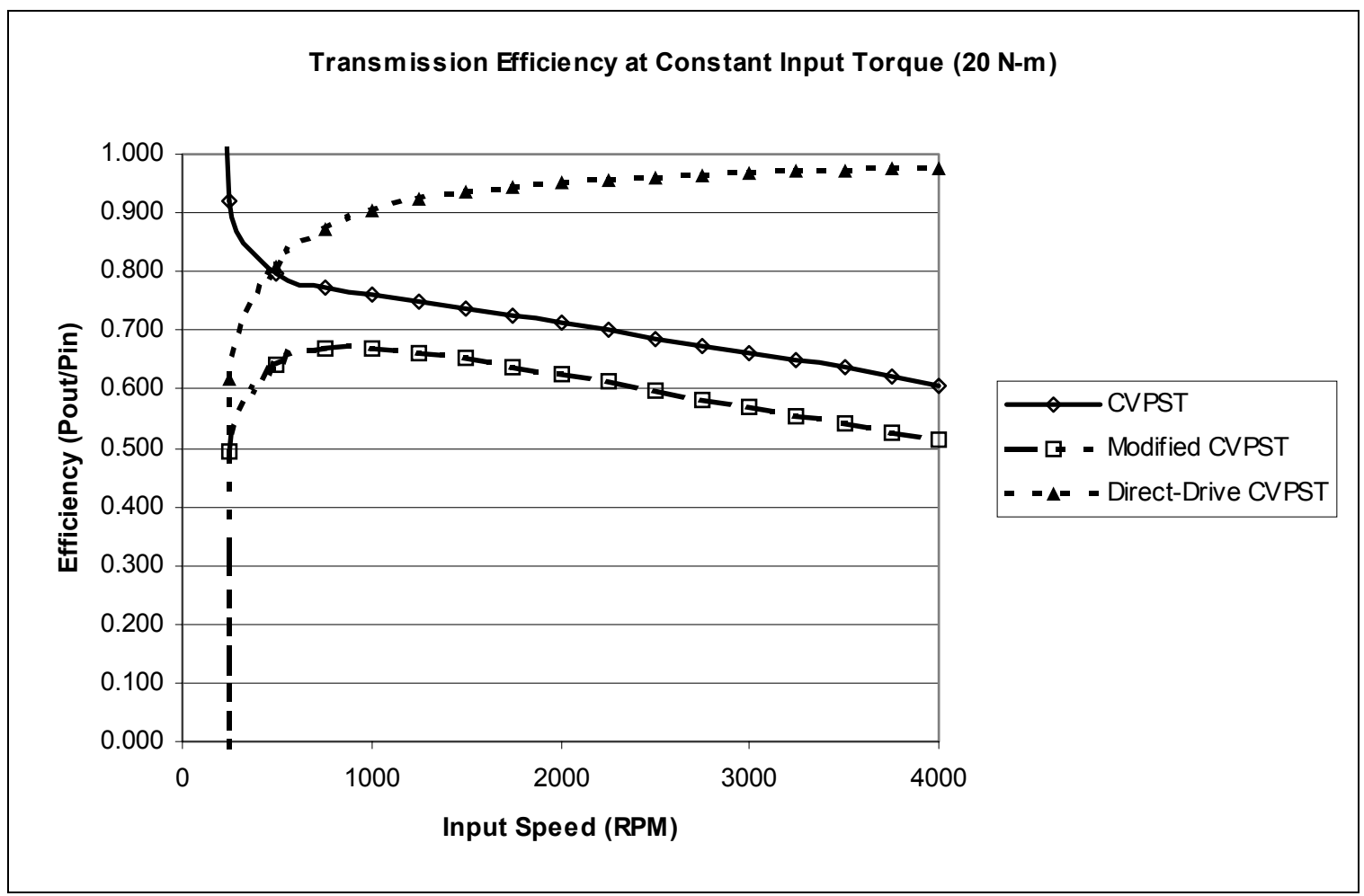

Figure 5-10. Comparison of Total Transmission Efficiency for Varying Speeds at a Constant Input Torque of $20 \mathrm{~N}-\mathrm{m}$

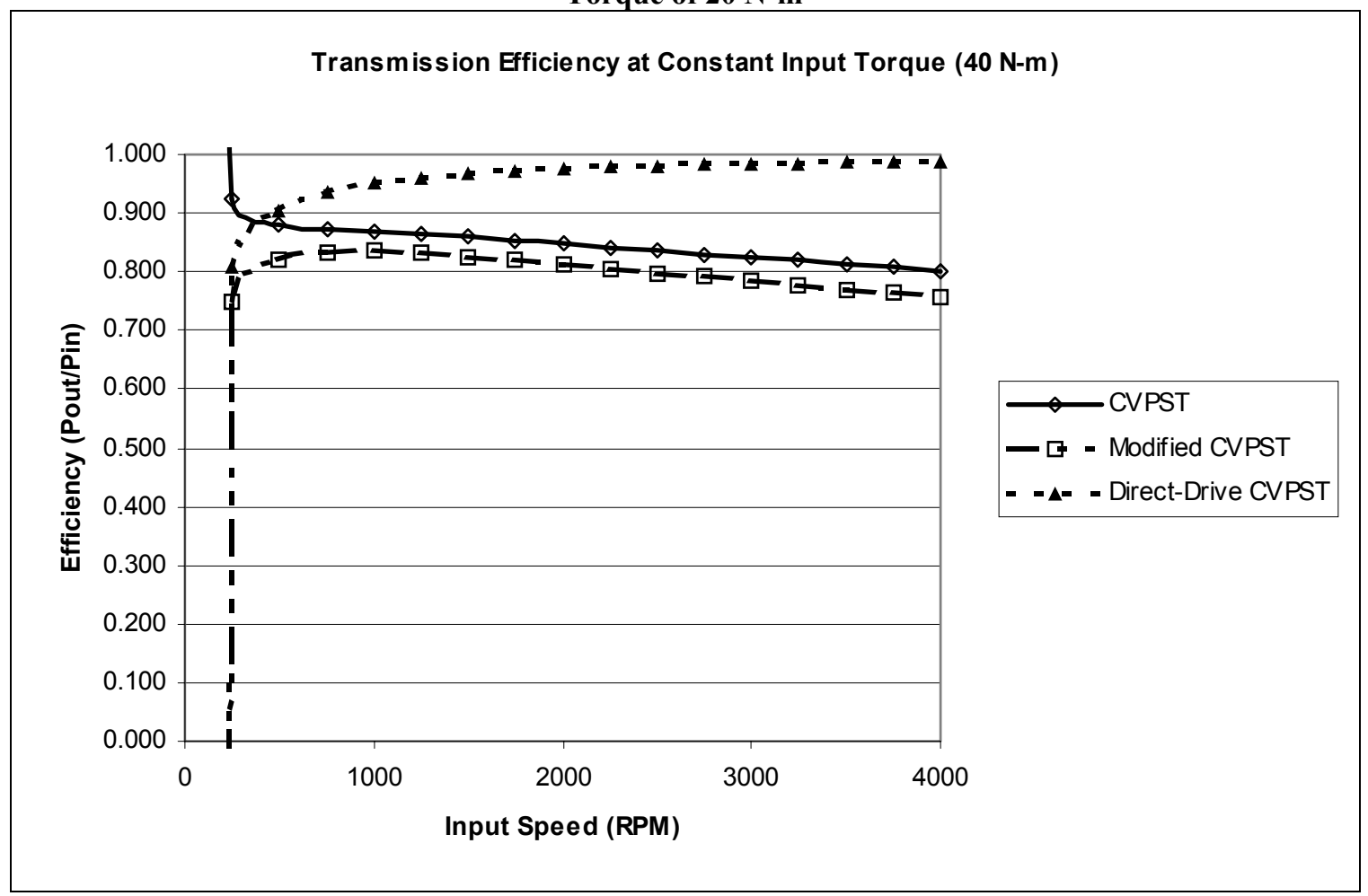

Figure 5-11. Comparison of Total Transmission Efficiency for Varying Speeds at a Constant Input Torque of $40 \mathrm{~N}-\mathrm{m}$ 


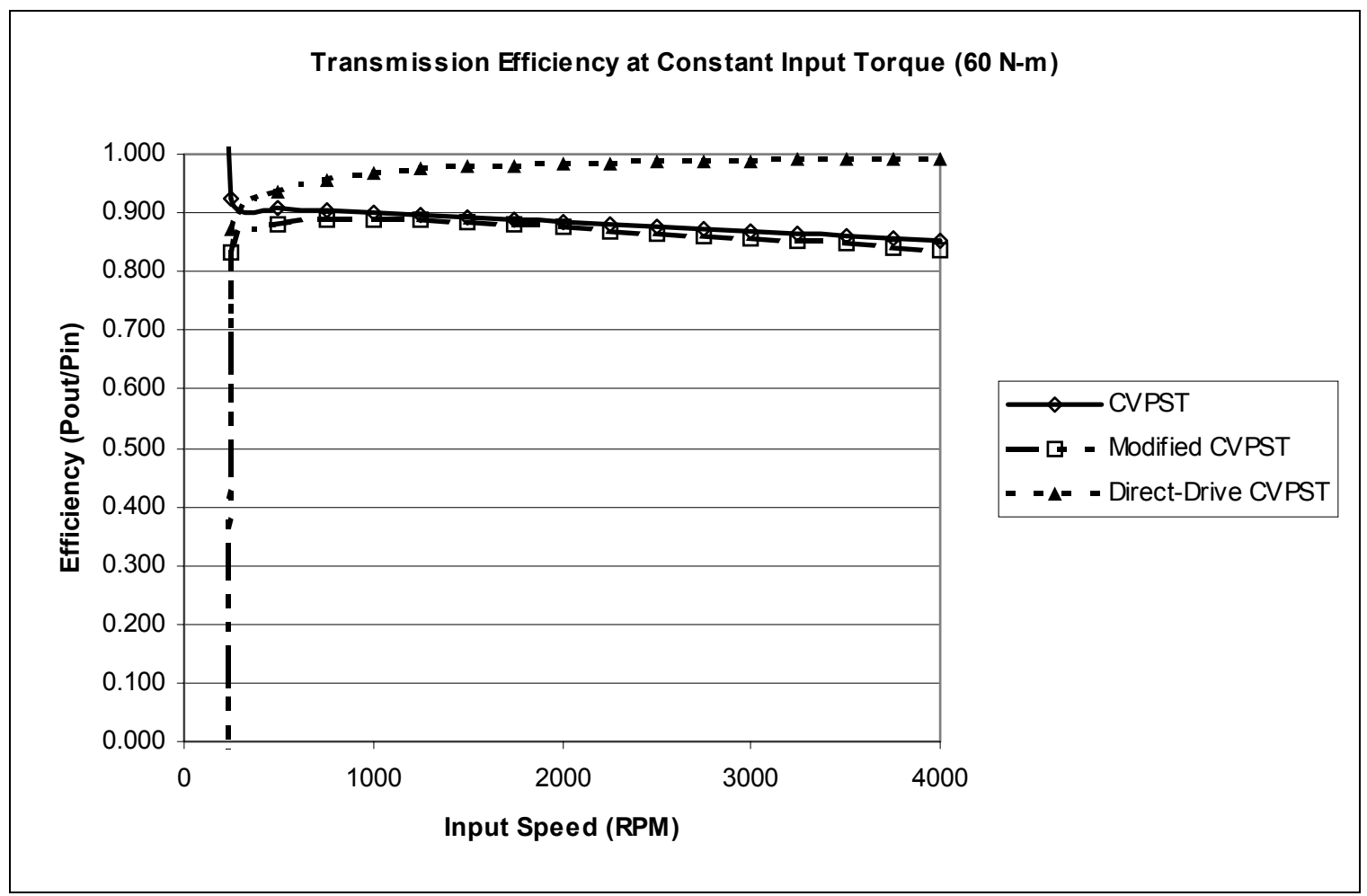

Figure 5-12. Comparison of Total Transmission Efficiency for Varying Speeds at a Constant Input Torque of $60 \mathrm{~N}-\mathrm{m}$

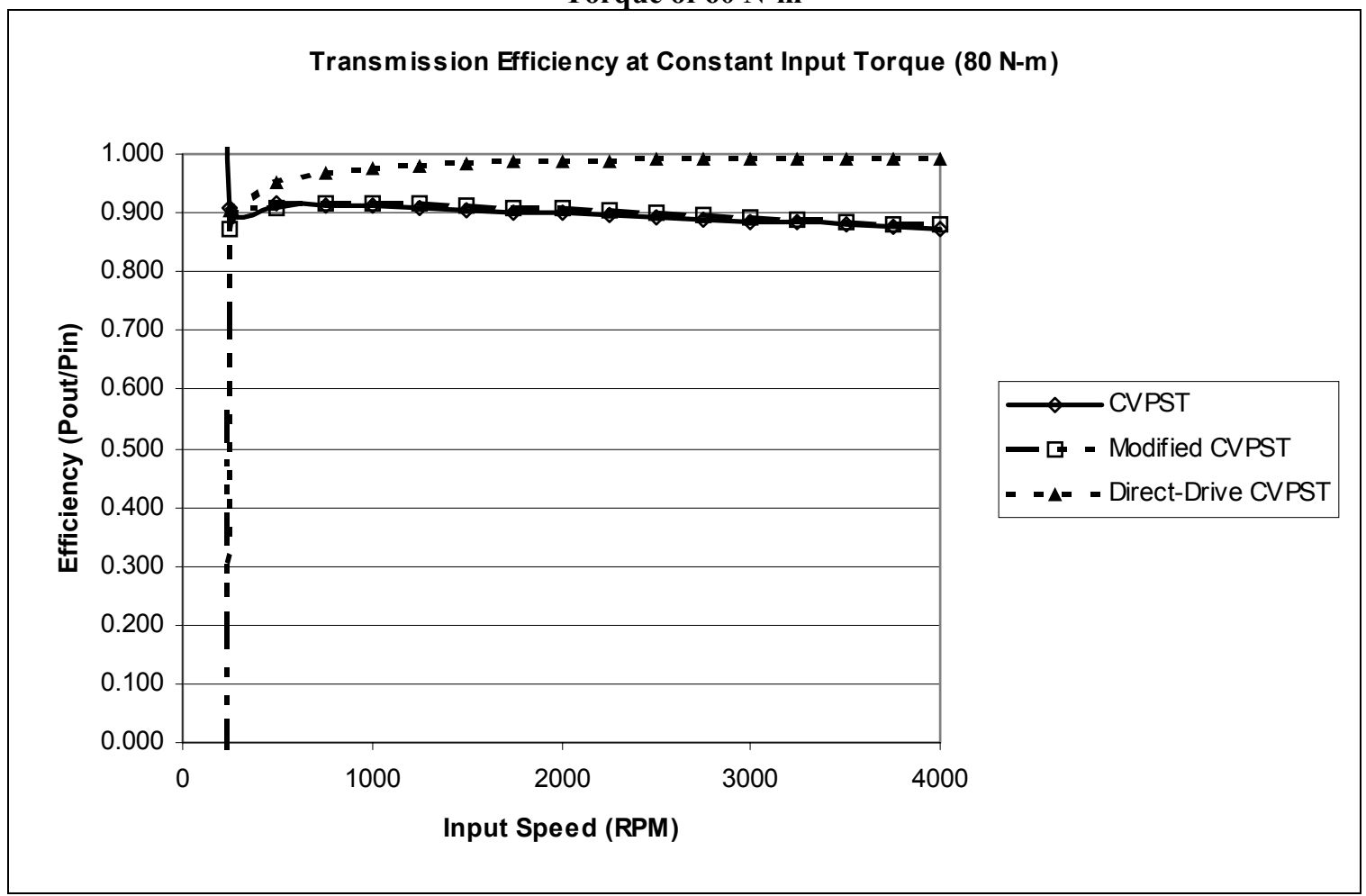

Figure 5-13. Comparison of Total Transmission Efficiency for Varying Speeds at a Constant Input Torque of $80 \mathrm{~N}-\mathrm{m}$ 


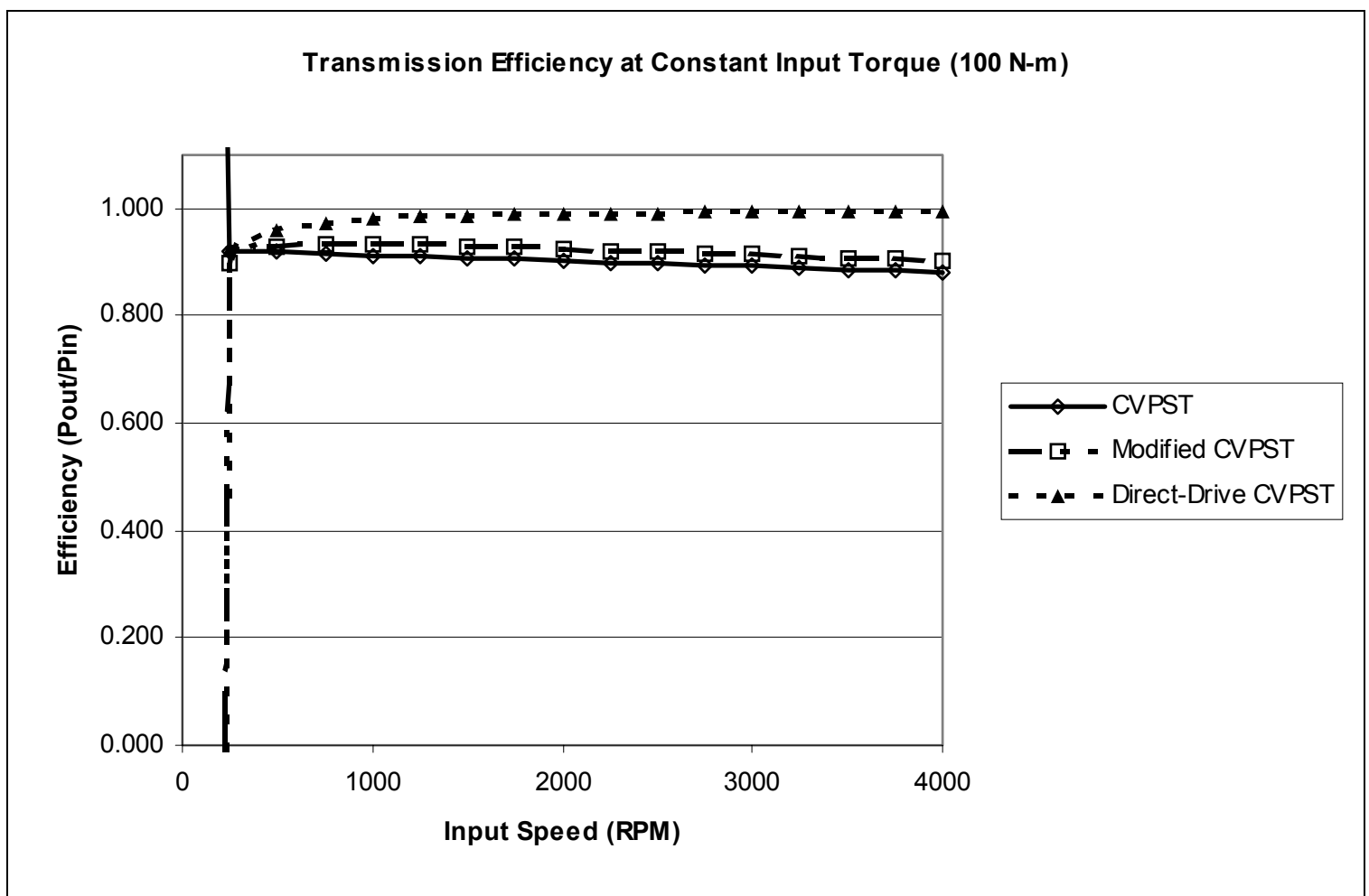

Figure 5-14. Comparison of Total Transmission Efficiency for Varying Speeds at a Constant Input Torque of $100 \mathrm{~N}-\mathrm{m}$

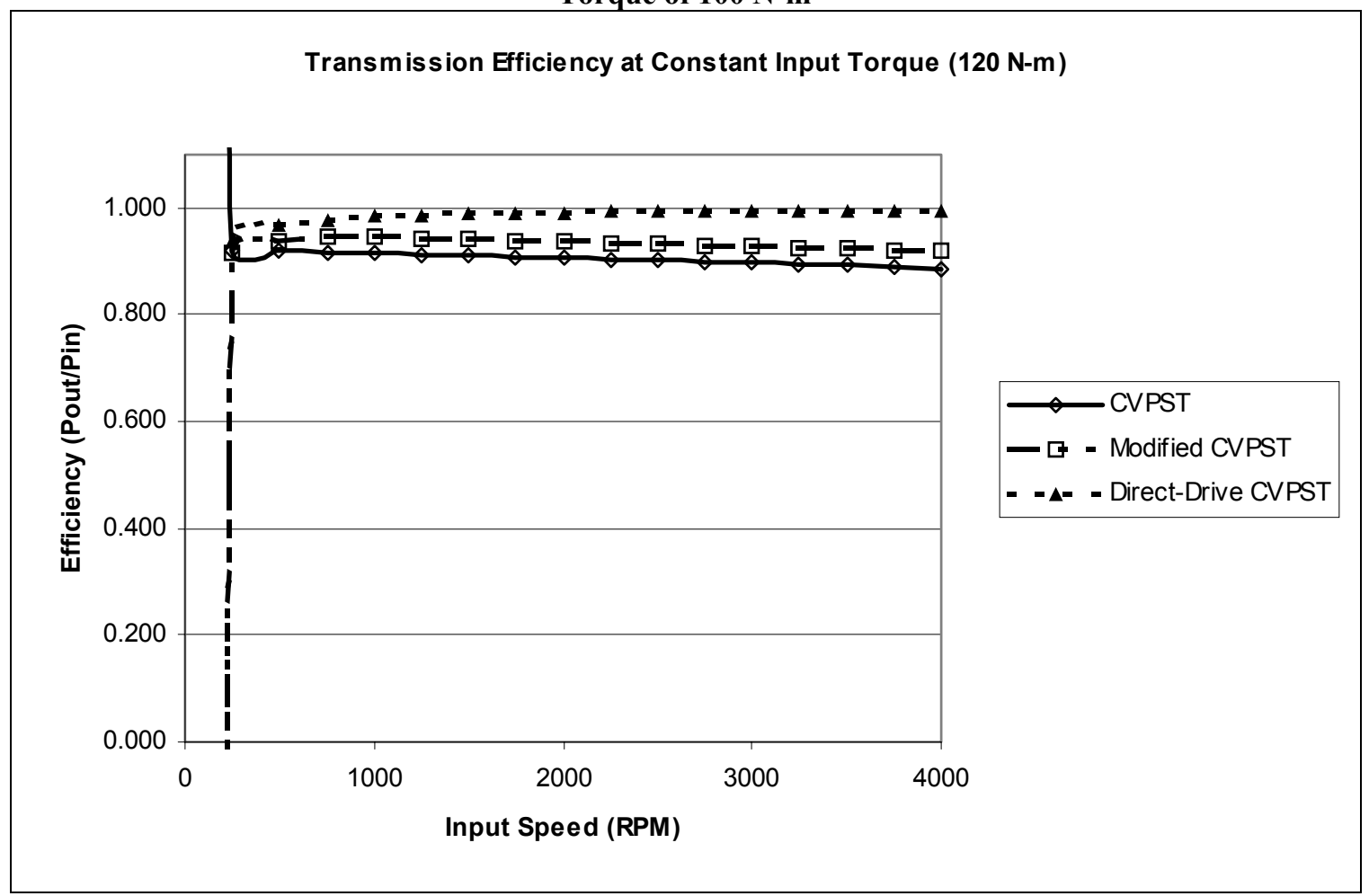

Figure 5-15. Comparison of Total Transmission Efficiency for Varying Speeds at a Constant Input Torque of $120 \mathrm{~N}-\mathrm{m}$ 
In Figs. (5-9) through (5-13) it can be seen that the direct-drive CVPST is the most efficient throughout the operating range. At low torques, the CVPST has a higher efficiency than the modified CVPST in the lower half of the RPM range. It can also be seen in all of these figures that the simulation model fails at low speeds because the CVT model efficiency does not converge to zero efficiency at zero input speed. When all of the data is compiled from the preceding figures, geometric representations of the efficiencies of the three transmissions can be produced. The following figures show the resulting surfaces.

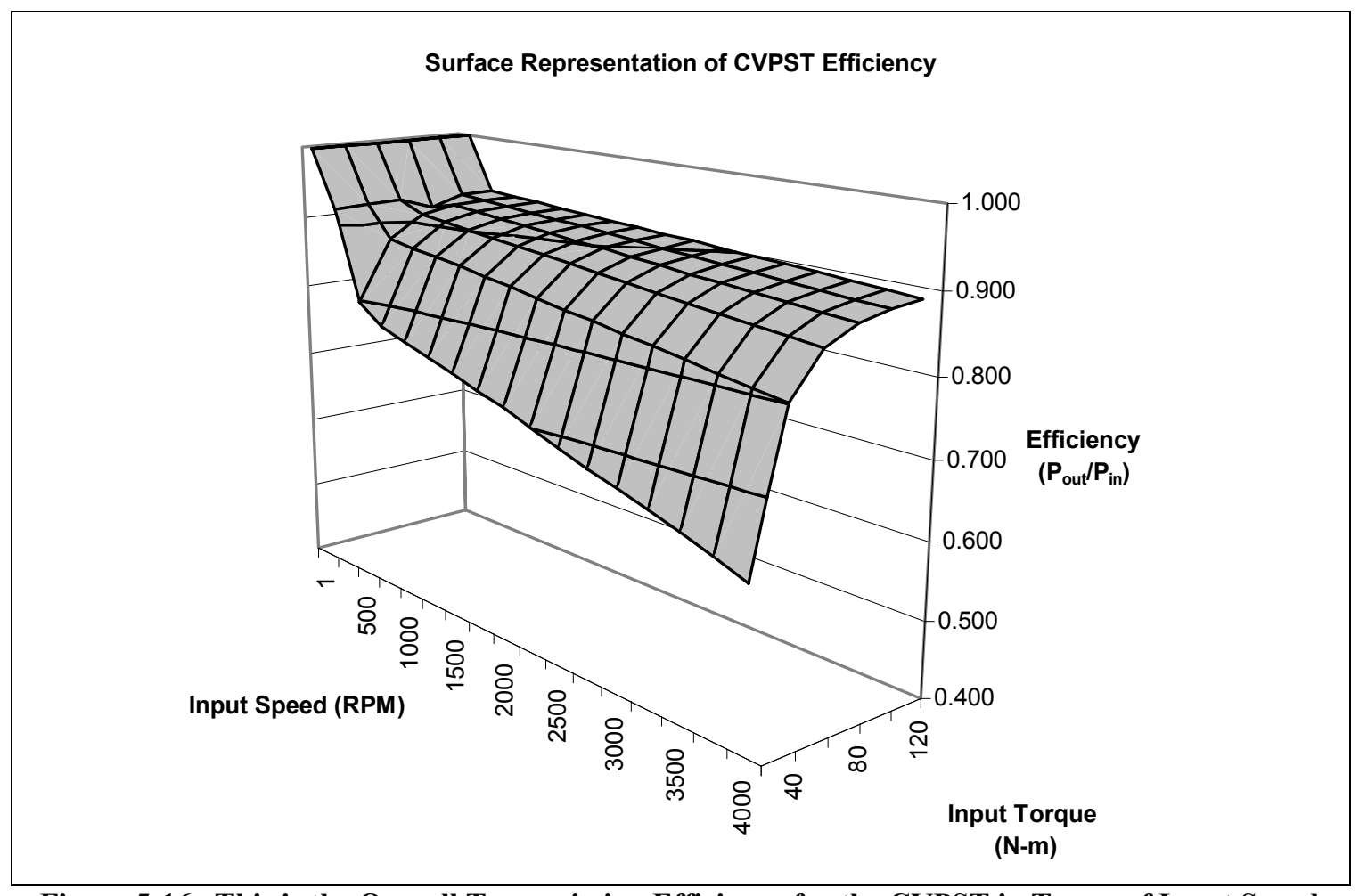

Figure 5-16. This is the Overall Transmission Efficiency for the CVPST in Terms of Input Speed and Input Torque 


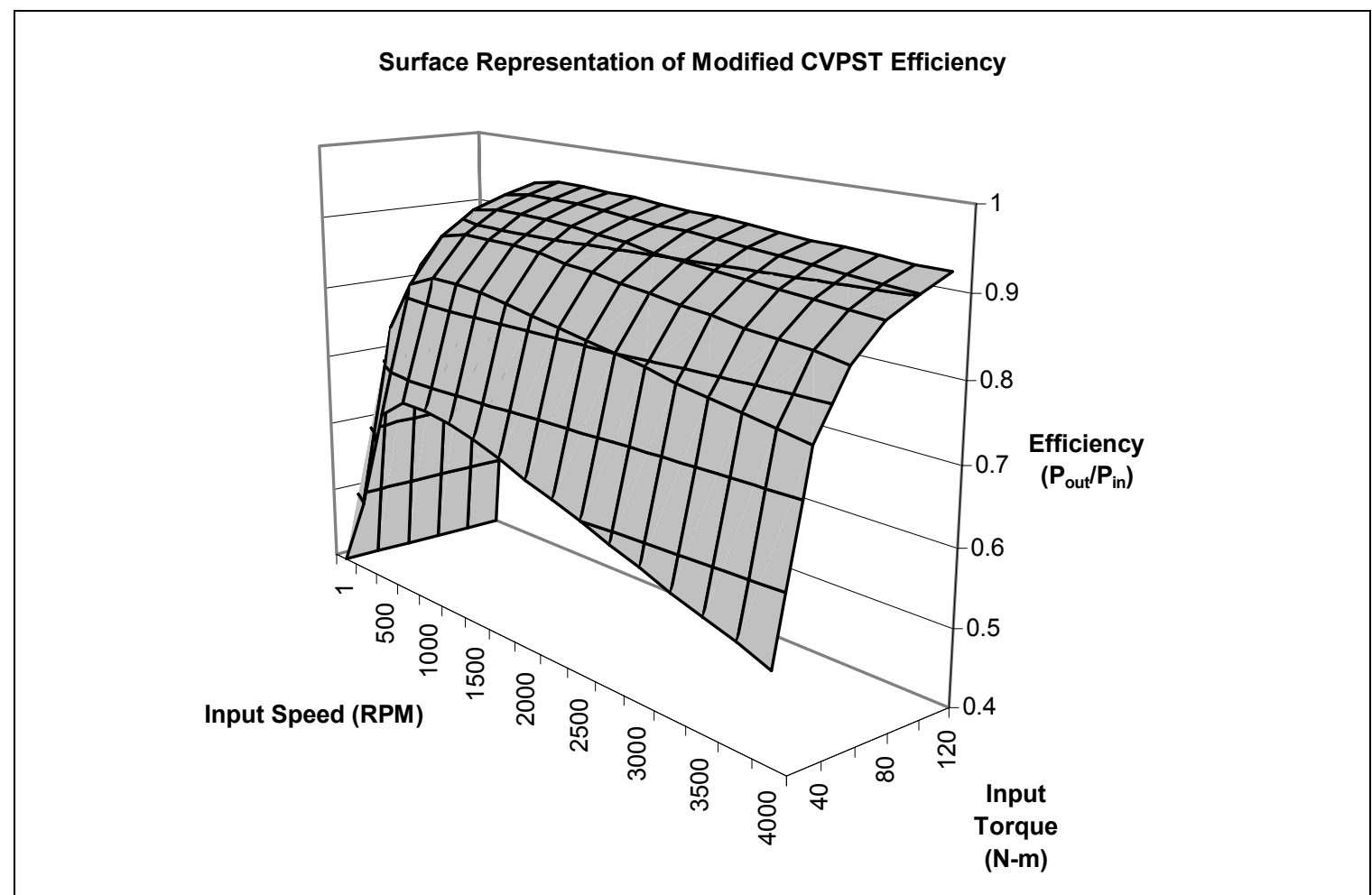

Figure 5-17. This is the Overall Transmission Efficiency for the Modified CVPST in Terms of Input Speed and Input Torque

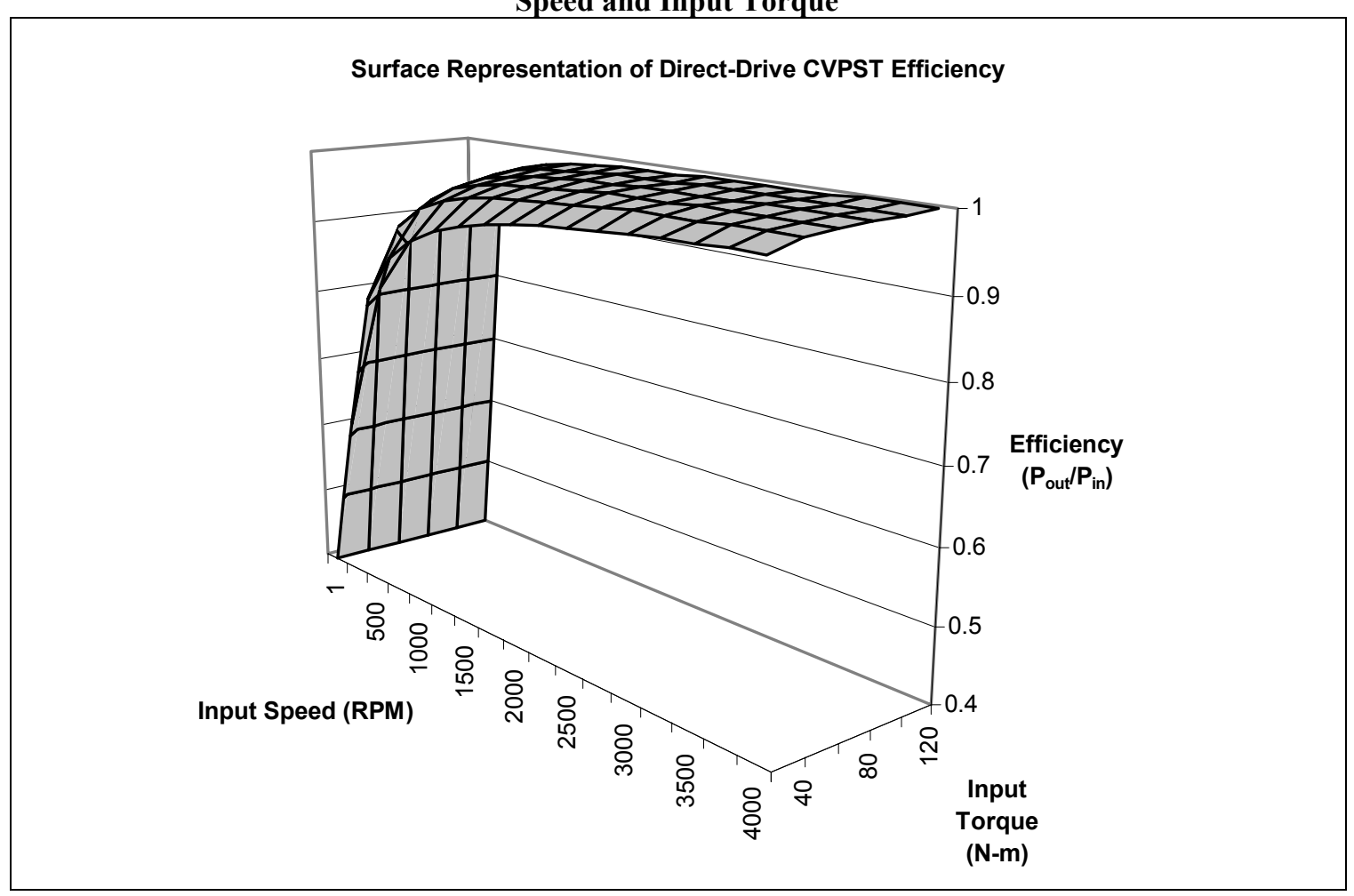

Figure 5-18. This is the Overall Transmission Efficiency for the Direct-Drive CVPST in Terms of Input Speed and Input Torque 
It is evident in all of the preceding figures that there is an error in calculation at input speeds below 250 RPM. In these regions, the efficiency is either above unity or negative, and both cases do not occur in physical systems due to conservation of energy laws. This error can be traced to the CVT model, where the efficiency curve does not intersect with zero at the origin, so there are cases where a negative efficiency is indicated.

\subsection{Comparison of CVPST to CVT}

In order to gain an overall perspective on the transmission performance, the efficiency of the three CVPST designs were compared to the CVT component efficiency for the median value of the two simulation conditions. The following figures show the results of this simulation.

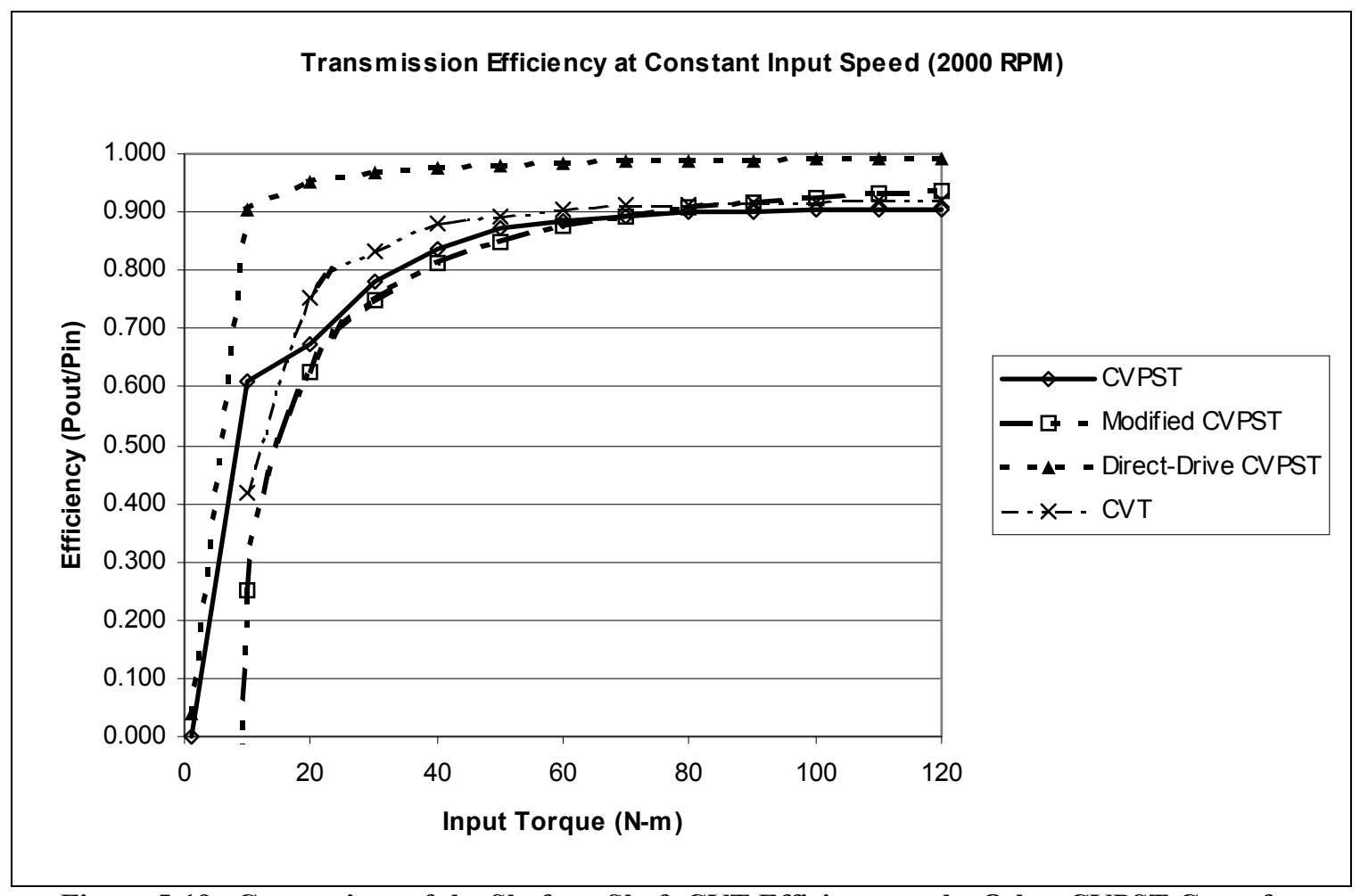

Figure 5-19. Comparison of the Shaft-to-Shaft CVT Efficiency to the Other CVPST Cases for Varying Torques and a Constant 2000 RPM Input Speed 


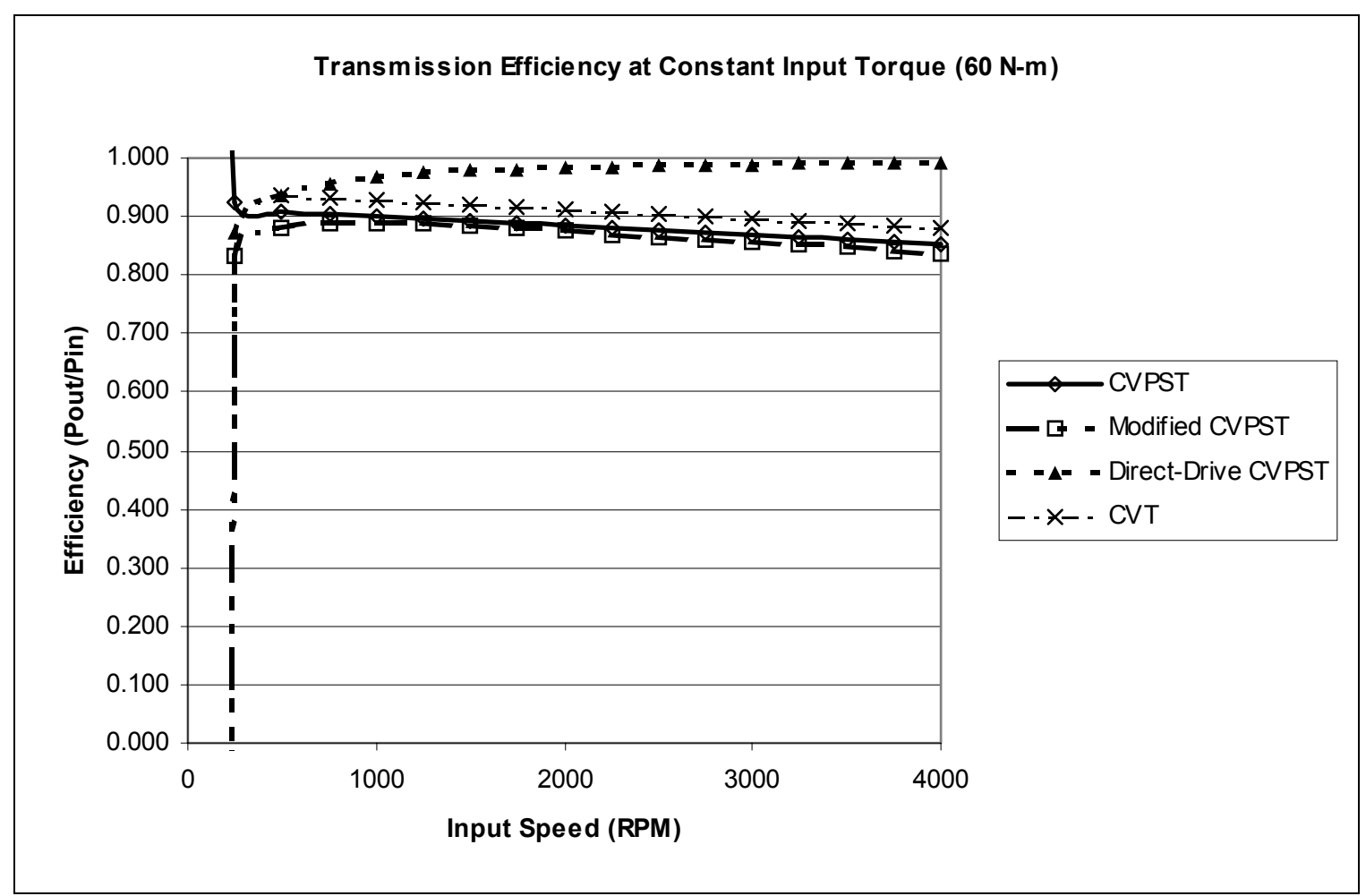

Figure 5-20. Comparison of the Shaft-to-Shaft CVT Efficiency to the Other CVPST Cases for Varying Input Speeds and a Constant $60 \mathrm{~N}-\mathrm{m}$ Input Torque

\subsection{Discussion of Results}

The results of the simulation clearly indicate that the direct-drive CVPST is superior to the other two designs in terms of mechanical efficiency. The results for the CVPST and the modified CVPST are similar above $25 \mathrm{~N}-\mathrm{m}$, but there is a large difference between the two values below that torque. The average efficiency for each transmission was calculated for the entire operating range above $250 \mathrm{RPM}$ and $20 \mathrm{~N}-\mathrm{m}$ in order to eliminate data where the efficiency was either negative or above unity so that the average efficiency values were not influenced by those values (Table 5-3).

Table 5-3. Comparison of Average Efficiencies for Each Simulation Model

\begin{tabular}{|c|c|c|}
\hline CVPST & Modified CVPST & Direct-Drive CVPST \\
\hline $85.8 \%$ & $83.6 \%$ & $96.7 \%$ \\
\hline
\end{tabular}


This difference is attributed to the CVT always being under load in the CVPSVT. In the modified CVPST, the only CVT load is that to overcome bearing friction, so the CVT operates in an extremely low efficiency region of less than one percent. In order to drive this load at such a low efficiency, the CVT requires a large amount of torque, which is nearly a constant value. This explains the extremely low mechanical efficiency at low torques, and the efficiency increase, as that constant torque value becomes a smaller and smaller proportion of the input torque. In contrast, in the CVPST the CVT receives a load torque in constant proportion to the output torque, so it operates in a more efficient range. In all three applications, it is apparent that the ideal operating range is at higher torque. The direct-drive CVPST is more efficient at higher input velocities because the speed-dependent losses in the CVT are eliminated. The shaft-to-shaft CVT is more efficient than the common and modified CVPST for most of the operating ranges, but it is less efficient than the common CVPST at the extremes of the speed range where speeddependent losses are not mitigated by the torque-split. In all three cases, the $200 \mathrm{~W}$ required by the pump affected the simulation where the input to the transmission was less than $200 \mathrm{~W}$ due to low speed or torque.

\subsection{Conclusion}

The complete performance of a transmission must be studied in order to determine whether or not it is a viable alternative to established designs. In the modified PSCVT, the efficiency values are higher than the common CVPST only in the higher torque and speed values where the parasitic losses are a smaller proportion of the input torque. For low input torques, the modified CVPST parasitic losses can consume over 75 percent of the input torque while the CVPST loses less than half. The narrow range of 
efficiency advantage in the modified CVPST does not justify the added complexity of components if its parasitic loss can exceed that of the common CVPST for some operating conditions. Improvements to the modified and direct-drive CVPST could be realized by minimizing the pump load because the CVT would not need an actuating force on the sheaves in a no-load condition. Because this improvement would apply to both arrangements, the best dual-mode design would still employ a pure direct-drive where the parasitic losses are minimized even though the modified CVPST could be made as efficient at the common CVPST.

\subsection{Future Recommendations}

This study was based upon a complete metal pushing belt CVT transmission, which was designed as a stand-alone unit. In order to have a more effective model, a dynamometer test of the individual CVT belt and sheaves should be performed in order to get a better understanding of the mechanism. In addition, development of theoretical models of the metal pushing belt and its contact phenomena could yield theoretical equations for CVT losses which would be generalized to belt and sheave CVTs in general. In addition, a truly accurate model would be designed for real-world conditions where gear, bearing, and shaft sizes are appropriate to a particular application. It is that kind of detailed analysis that will determine the utility of different kinematic arrangements. 


\section{References}

Beccari, A. and Cammalleri, M., 2001, "Implicit Regulation for Automotive Variators," Proc. Instn. Mech. Engrs. Vol. 215, Part D, pp. 697-708.

Birch, S., "Audi Takes CVT From $15^{\text {th }}$ Century to $21^{\text {st }}$ Century," Automotive Engineering International Online: Tech Briefs, January 2000, http://www.aeionline.sae.org/automag/techbriefs_01-00/03.htm (Accessed April 2, 2003).

Bonthron, A., 1985, "CVT-Efficiency Measured Under Dynamic Running Conditions," SAE Technical Paper No. 850569.

Brockbank, C. and Heumann, H., 2002, "Delivery of IVT for a 5 litre SUV: Addressing the Concerns of Geared Neutral," Innovative Fahrzeug-Getriebe C1143 20-21.

Chan, C., Omitsu, T., Yang, D., Volz, T., Breitweiser, D., Jamzadeh, F. S., and Frank, A., 1984, "System Design and Control Considerations of Automotive Continuously Variable Transmissions," SAE Technical Paper No. 840048.

Csere, C., "Audi A4," 10 Best Cars 2002. January 2002. Car and Driver. http://www.caranddriver.com/xp/Caranddriver/10best/2002/2002_10best_cars

audi_a4.xml (Accessed December 30, 2002).

Fenton, J., 1996, "Handbook of Vehicle Design Analysis," Society of Automotive Engineers, Inc., Warrendale, PA, Ch. 19.

Fitz, Frank A. and Pires, Paul B., 1991, "A Geared Neutral Infinitely Variable Transmission for Automotive Applications," SAE Technical Paper No. 910407.

Fussner, D. and Singh, Y., 2002, "Development of Single Stage Input Coupled Split Power Transmission Arrangements and Their Characteristics," SAE Technical Paper No. 2002-01-1294.

Hewko, L., 1986, “Automotive Traction Drive CVTs - An Overview," SAE Technical Paper No. 861355.

Honda Fourtrax Foreman. Honda Motorcycles Website. 2002, American Honda Motor Co., Inc-Motorcycle Division. Torrance, CA

http://www.hondamotorcycles.com/atvs/utility/model.asp?ModelName=FourTrax+Forem an+Rubicon\&ModelYear=2003\&ModelId=TRX500FA3\&bhcp (Accessed April 2, 2003).

Hong-Sen, Y. and Long-Chang, H., 1994, "Maximum Mechanical Efficiency of Infinitely Variable Transmissions," Mech. Mach. Theory, Vol. 29, No. 5, pp. 777-784. 
Kluger, M. and Fussner, D., 1997, "An Overview of Current CVT Mechanisms, Forces, and Efficiencies," SAE Technical Paper No. 970688.

Kluger, M. and Long, D., 1999, “An Overview of Current Automatic, Manual and Continuously Variable Transmission Efficiencies and Their Projected Future Improvements," SAE Technical Paper No. 1999-01-1259.

Kress, J., 1968, "Hydrostatic Power-Splitting Transmissions for Wheeled Vehicles Classification and Theory of Operation," SAE Technical Paper No. 680549.

Kiuchi, T., Ogata, M., Iizawa, M. Yanase, T., Susuki, Y., Takeda, N., and Kumagai, N., 2001, "A Report on Advantage of a Heavy-Duty Hybrid Electric Vehicle," SAE Technical Paper No. 2001-01-2777.

Komatsu 930E-3 Full Specifications. 2003, Komatsu North America. Vernon Hills, IL. http://www.komatsuamerica.com/index.cfm?resource id=113 (Accessed April 2, 2003).

Long-Chang, H. and Hong-Sen, Y., 1990, "On the Mechanical Efficiency of Continuously Variable Transmissions With Planetary Gear Trains," Int. J. of Vehicle Design, Vol. 11, No. 2, pp. 176-187.

Lu, Z., 1998, "Acceleration Simulation of a Vehicle with a Continuously Variable Power Split Transmission,” Master's Thesis, West Virginia University.

Mabie, H., Reinholtz, C., 1986, "Mechanisms and Dynamics of Machinery," John Wiley \& Sons, Inc, New York, NY, Ch. 7.

Macey, J. and Vahabzadeh, H., "Geared-Neutral Continuously Variable Transmission," U.S. Patent No. 4,644,820, Feb. 24, 1987.

Mantriota, G., 2001, “Infinitely Variable Transmissions With Automatic Regulation,“Proc. Instn. Mech. Engrs. Vol. 215, Part D, pp. 1267-1279.

Mantriota, G., 2001, “Theoretical and Experimental Study of a Power Split Continuously Variable Transmission System, Part 1," Proc. Instn. Mech. Engrs. Vol. 215, Part D, pp. 837-850.

Mantriota, G., 2001, “Theoretical and Experimental Study of a Power Split Continuously Variable Transmission System, Part 2," Proc. Instn. Mech. Engrs. Vol. 215, Part D, pp. 851-864.

Mucino, V., Smith, J., Cowan, B., and Kmicikiewicz, M., 1997, “A Continuously Variable Power Split Transmission for Automotive Applications," SAE Technical Paper No. 970687. 
Nissan Gloria Lineup. Nissan Official Website. 2003, Nissan Motors Corp. Tokyo, Japan. http://www.nissan.co.jp/GLORIA/Y34/0112/LINEUP/index.html. （Accessed April 2, 2003).

Pennestri, E. and Freudenstein, F., 1993, "The Mechanical Efficiency of Epicyclic Gear Trains," Journal of Mechanical Design, September, 1993, Vol. 115, pp. 645-651.

Ritzinger, A., "DAF Cars," March 31, $2003 . \quad$ Ritzsite. http://www.ritzsite.demon.nl/DAF/DAF_cars_p9.htm (Accessed April 2, 2003).

"Rubber Band Cars Are Coming Back," Mechanical Engineering, December 1984, pp. 34-38.

Singh, T. and Nair, S., 1992, "A Mathematical Review and Comparison of Continuously Variable Transmissions,” SAE Technical Paper No. 922107.

"SKF Interactive Engineering Catalog," Products and Services. 2003, SKF Corporation. Goteborg, Sweden. http://iec.skf.com/4e.htm (Accessed April 2, 2003).

Vahabzadeh, H., Macey, J., and Dittrich, O., 1990, "A Split-Torque, Geared-Neutral Infinitely Variable Transmission Mechanism,” SAE Technical Paper No. 905089.

"Using Simulink," Help Documentation, Matlab Release 12.1, 2001, The Mathworks, Inc. Natick, MA

Wagner, G., 2001, "Application of Transmission Systems for Different Driveline Configurations in Passenger Cars, "SAE Technical Paper No. 2001-01-0882. 


\section{Appendix A - Glossary of Function Blocks}

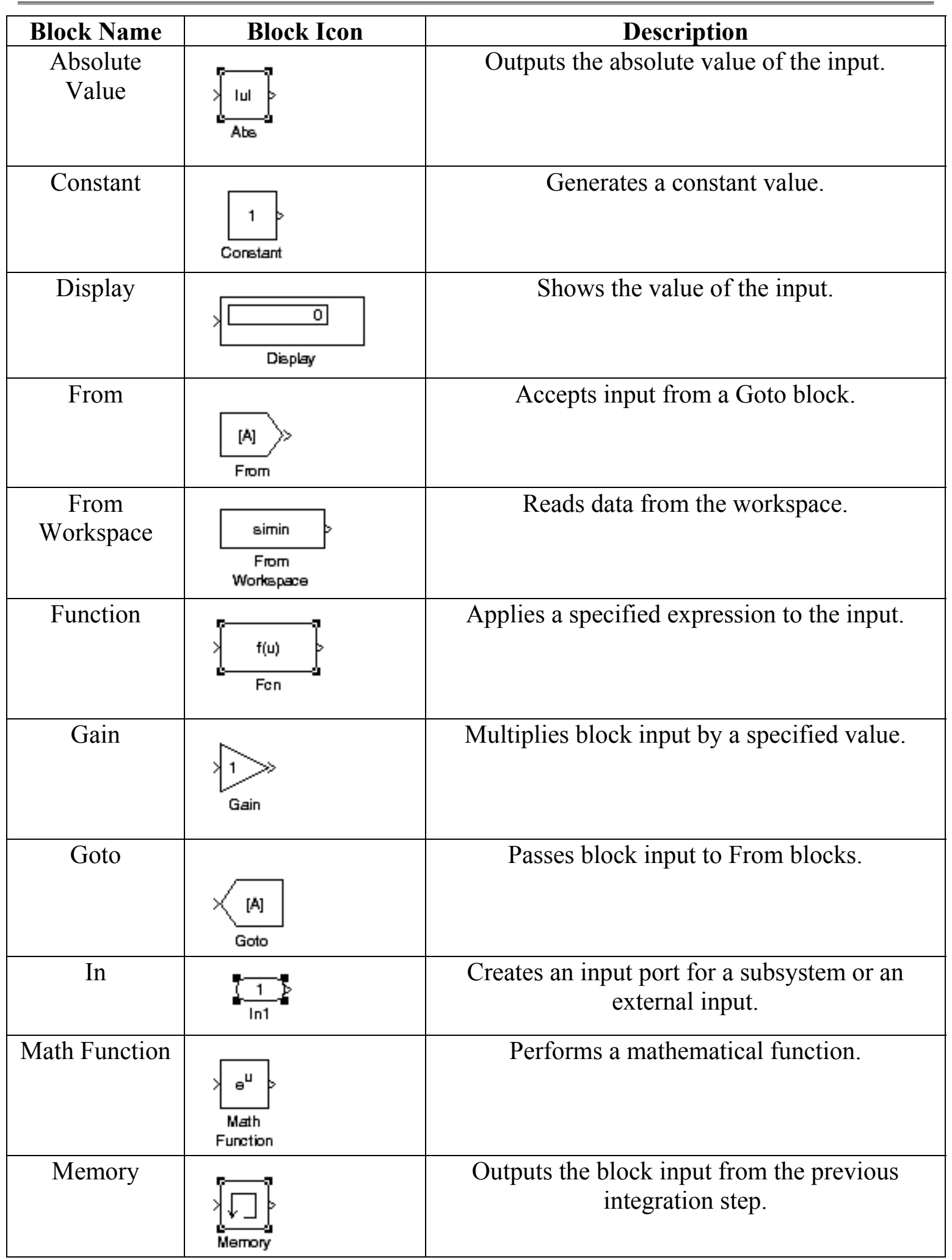




\begin{tabular}{|c|c|c|}
\hline Out & $\begin{array}{c}\text { Creates an output port for a subsystem or an } \\
\text { external output. }\end{array}$ \\
\hline Product & $\begin{array}{c}\text { Generates the element-wise product, quotient, } \\
\text { matrix product, or inverse of block inputs. }\end{array}$ & Performs the specified relational operation on \\
the input.
\end{tabular}




\section{Appendix B - Simulation Models}

\section{B.1 CVPST Global Model}

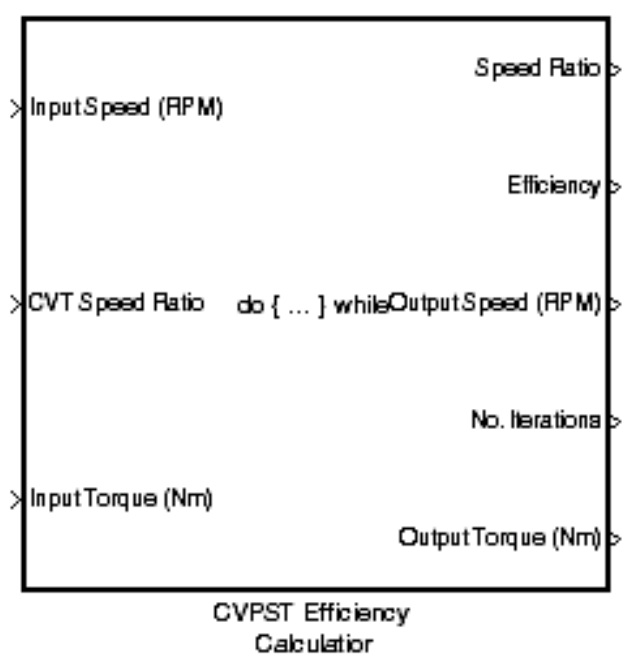

\section{B.1.1 CVSPT Efficiency Calculator}

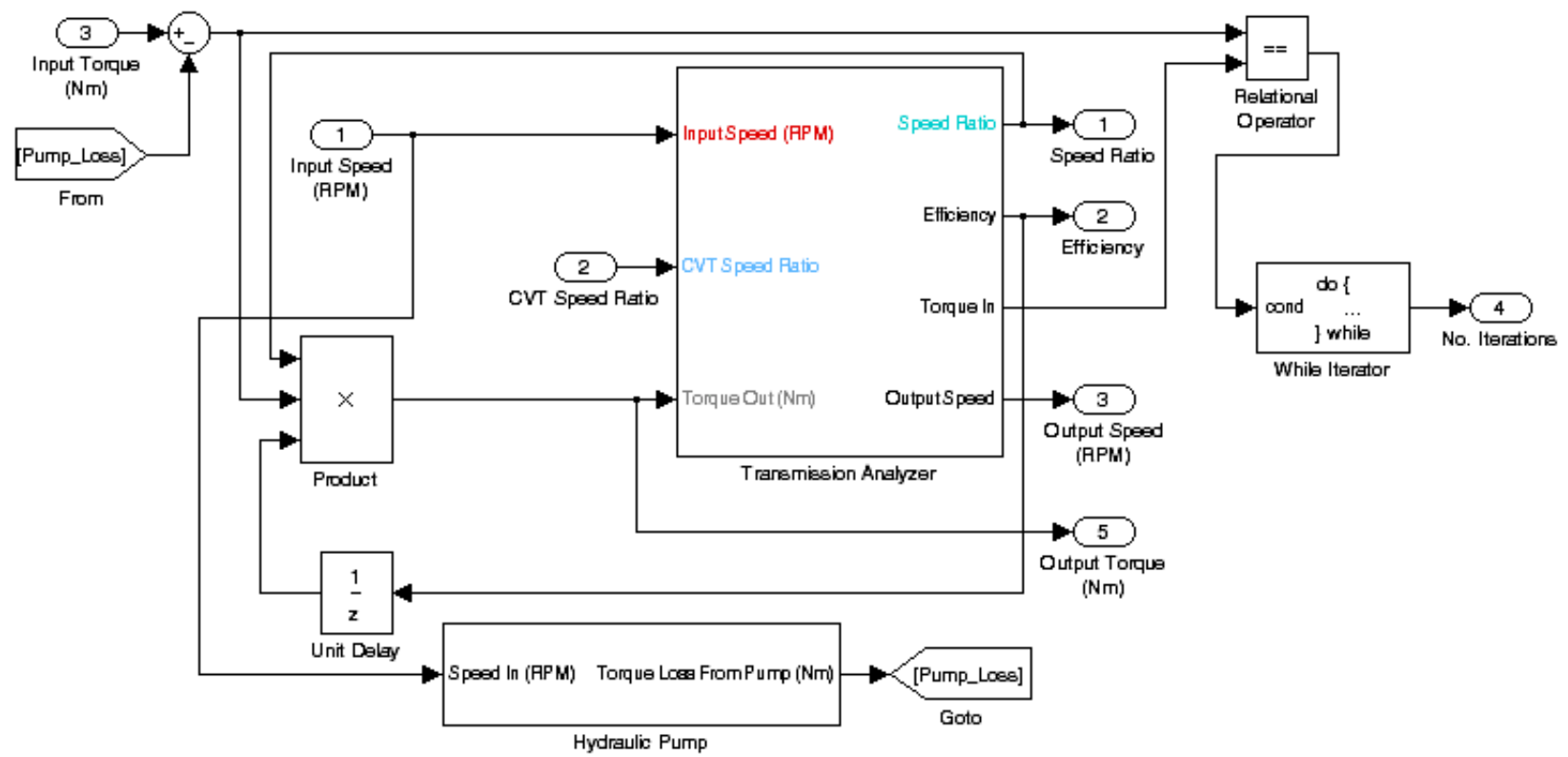




\section{B.1.2 Transmission Analyzer}

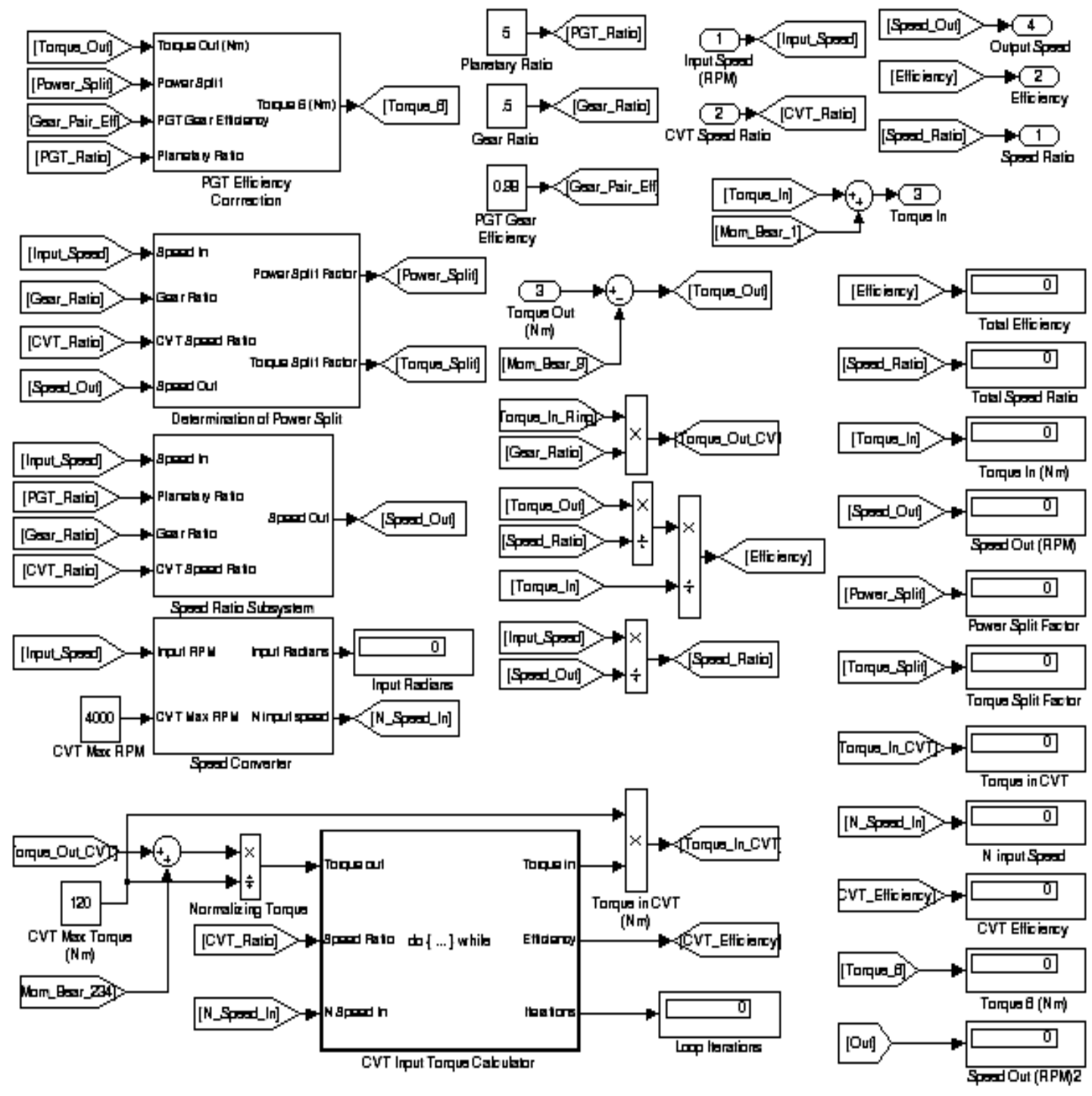




\section{Transmission Analyzer (cont.)}

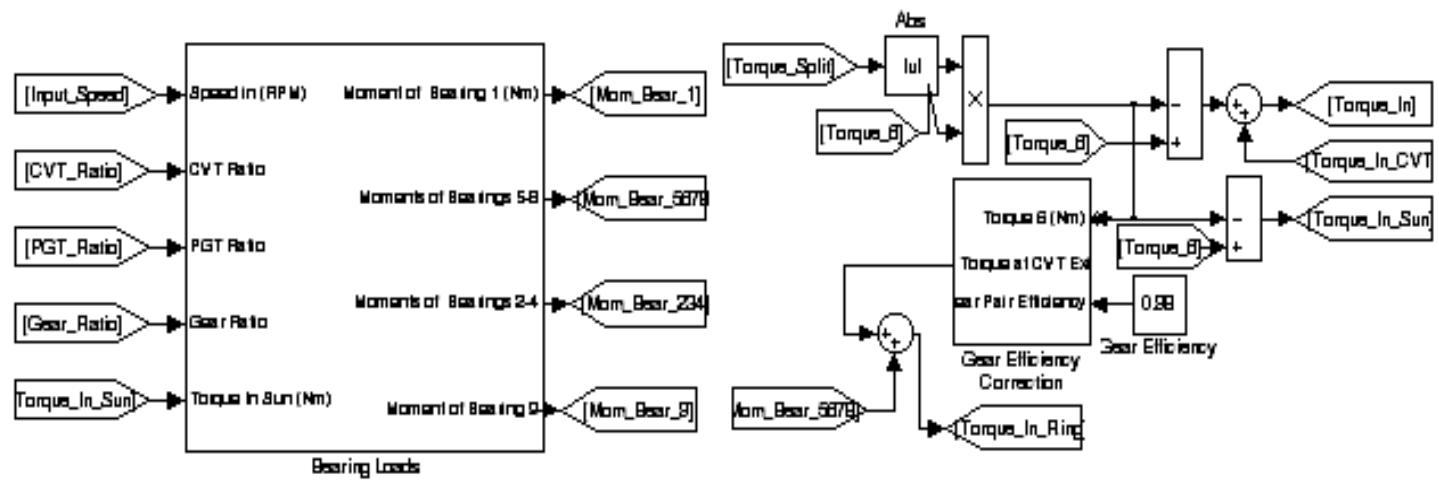

\section{B.1.3 Hydraulic Pump}

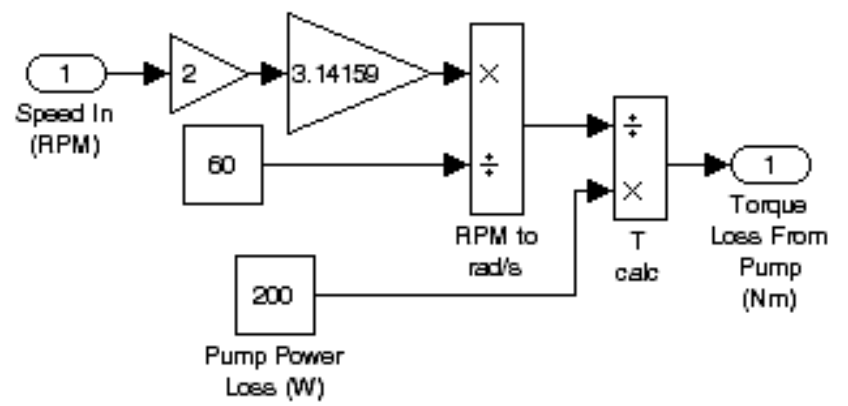

\section{B.1.2.1 Bearing Loads}
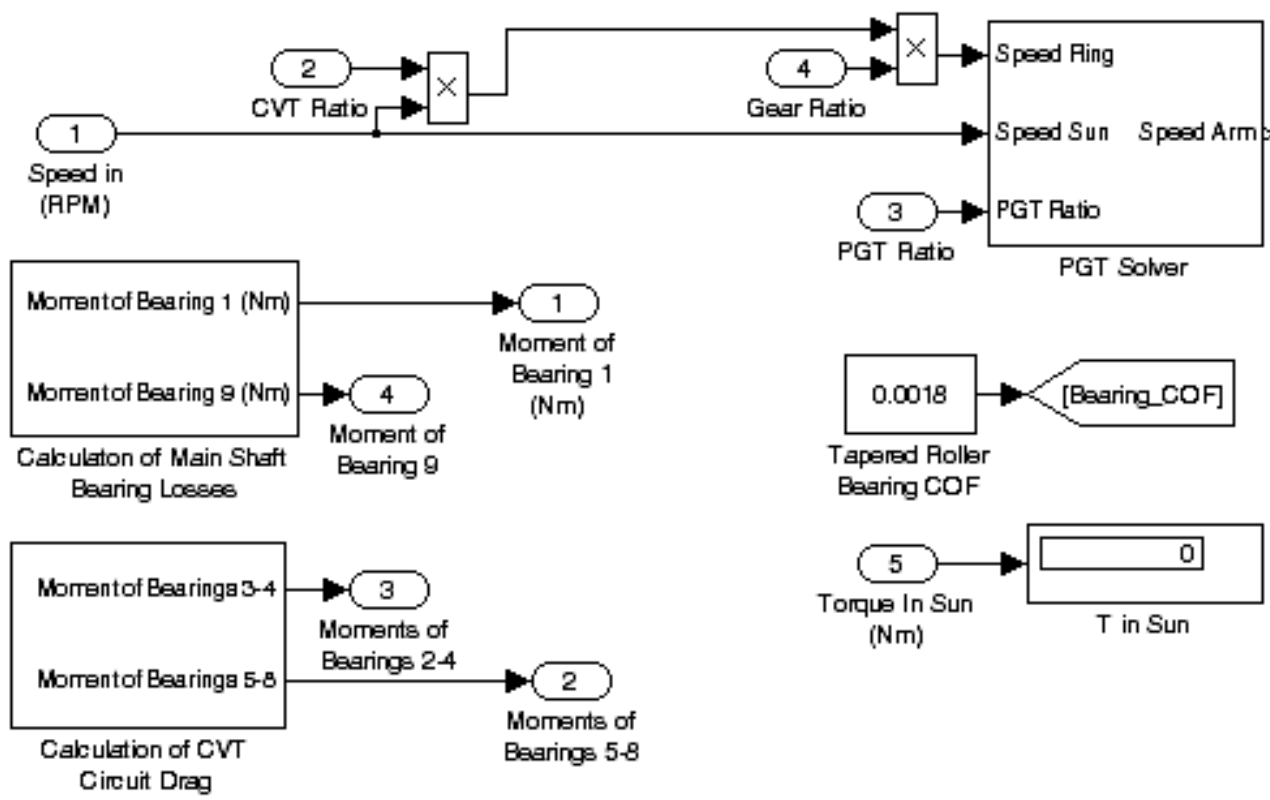


\section{B.1.2.1.1 Calculation of CVT Circuit Drag}

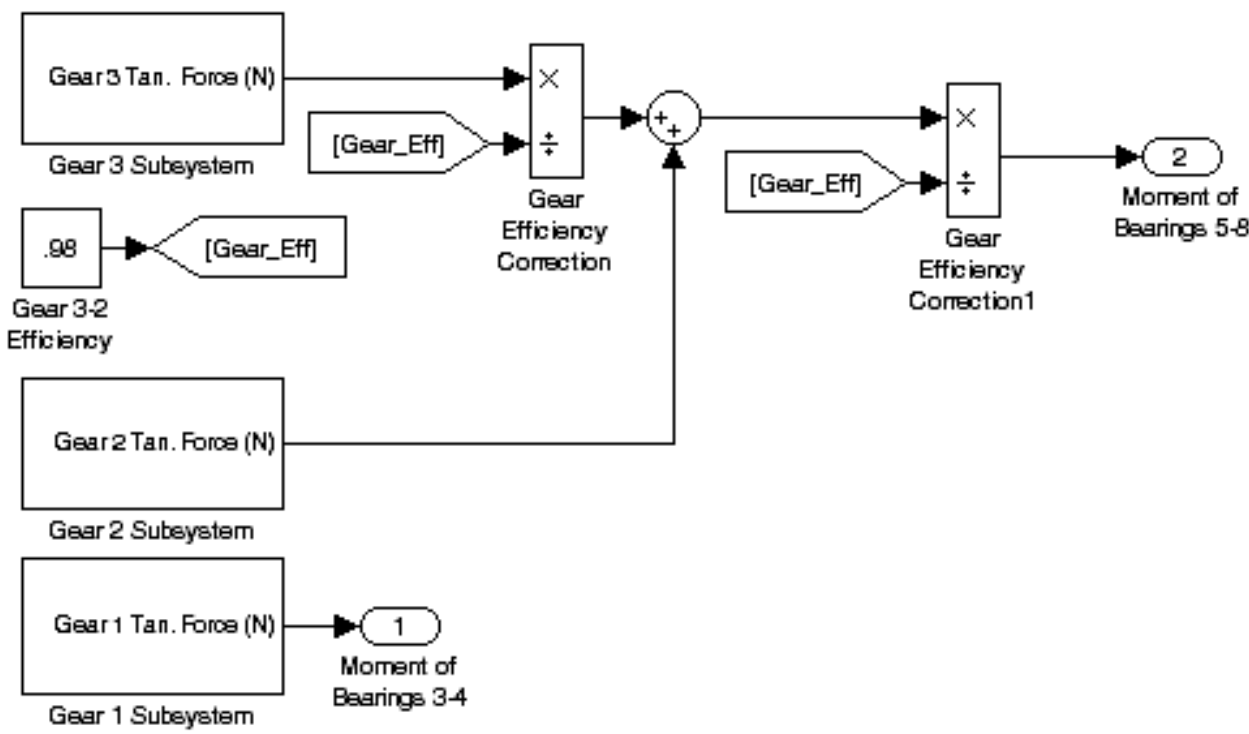

\section{B.1.2.1.2 Calculation of Main Shaft Bearing Losses}

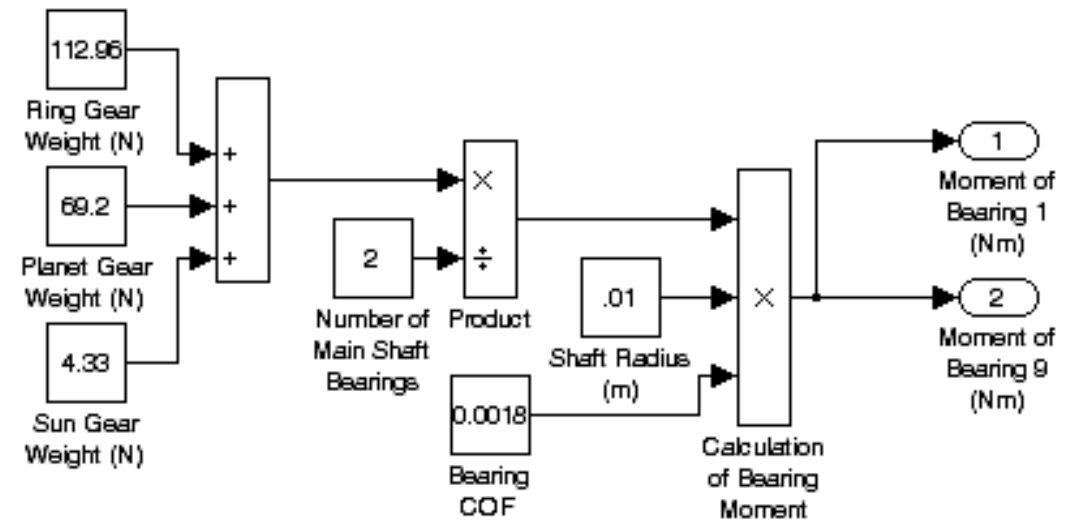

\section{B.1.2.1.3 PGT Solver}

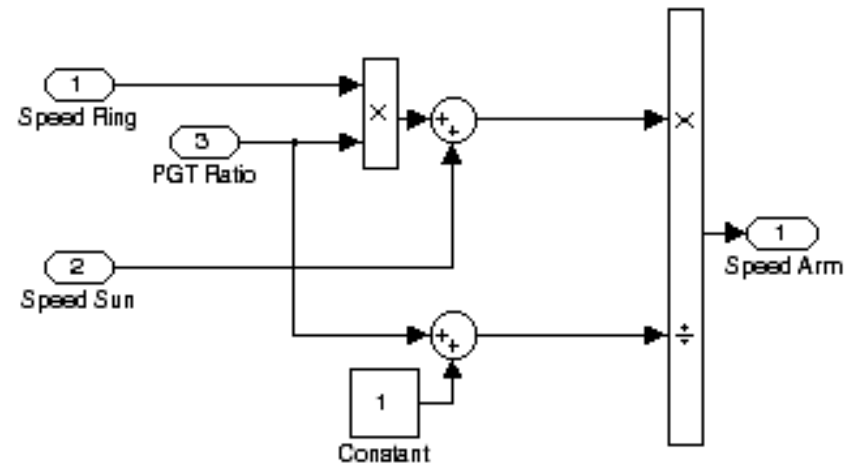




\section{B.1.2.2 CVT Input Torque Calculator}

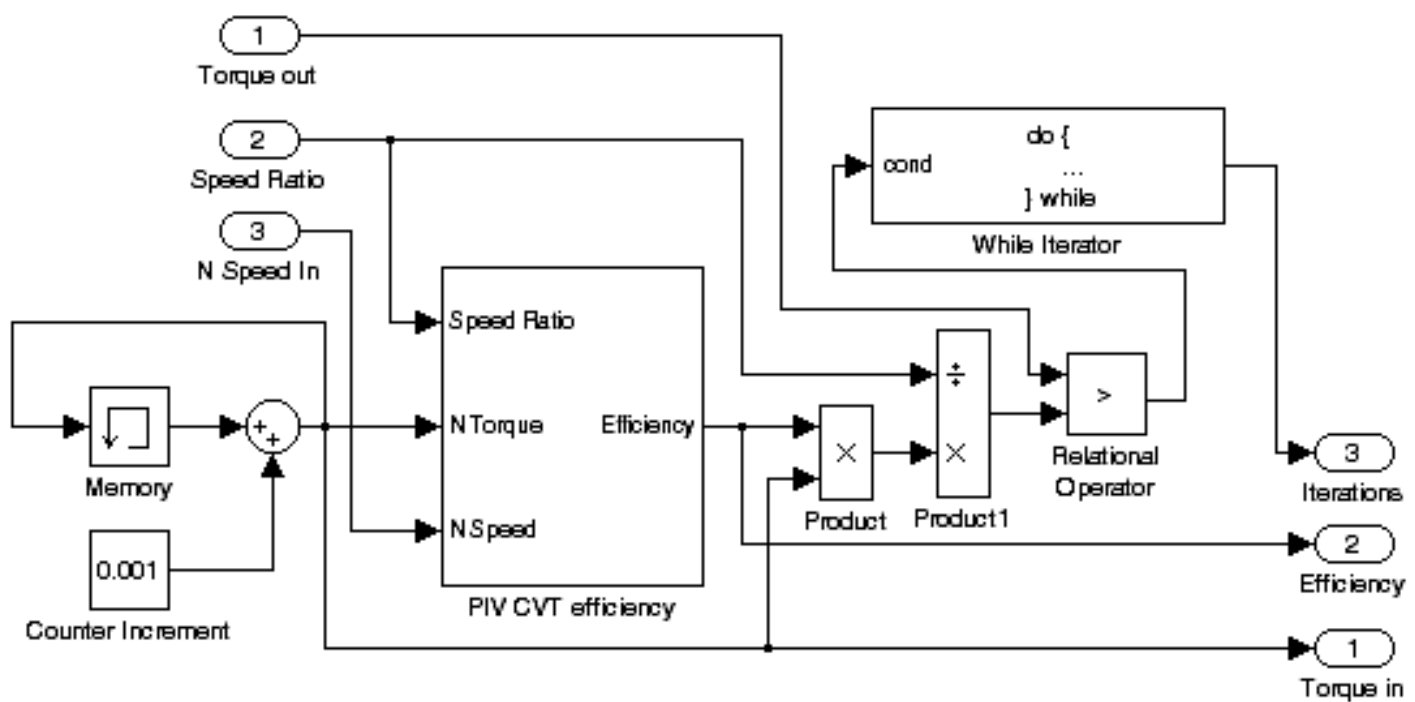

\section{B.1.2.2.1 PIV CVT Efficiency}

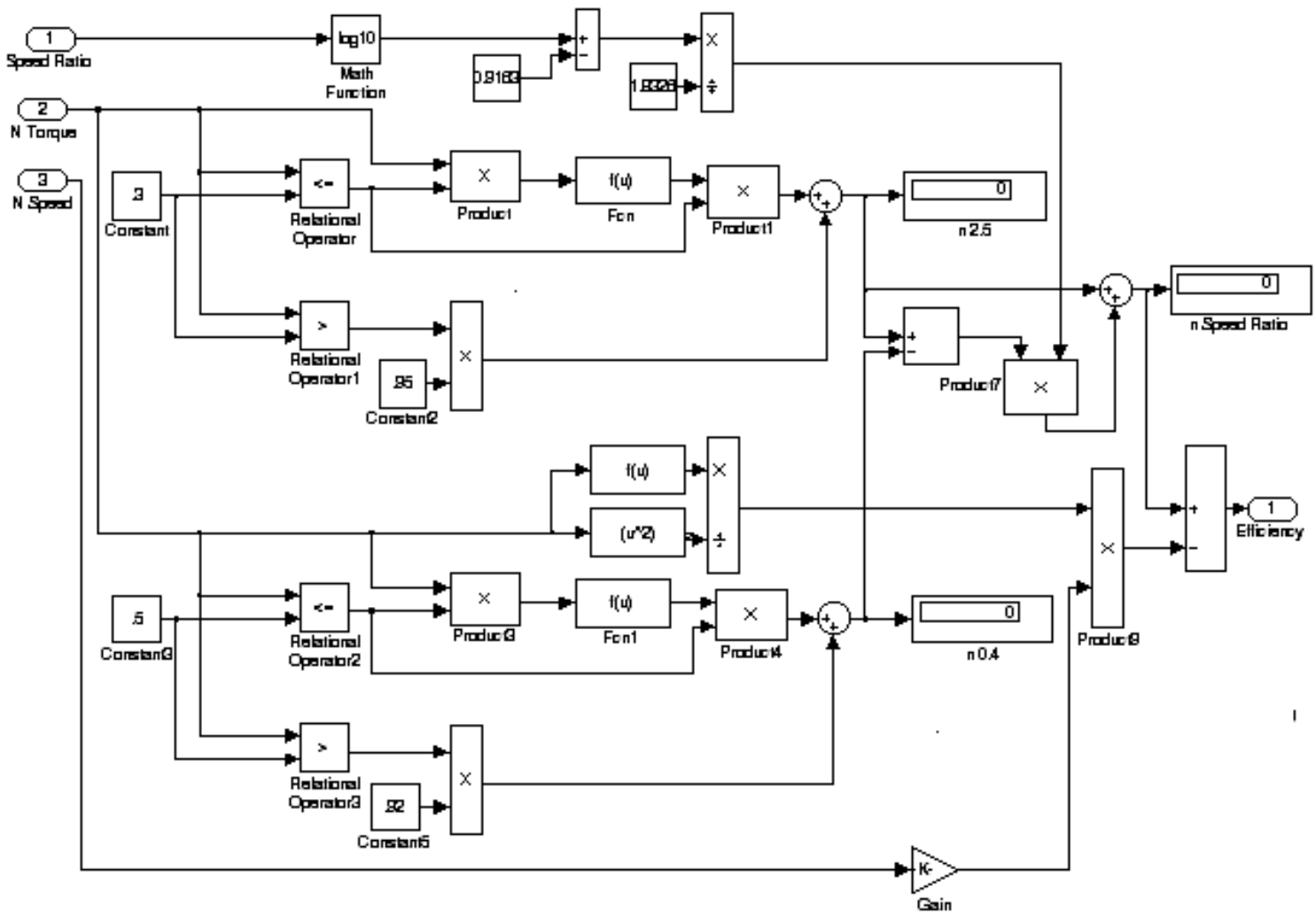




\section{B.1.2.3 Determination of Power Split}

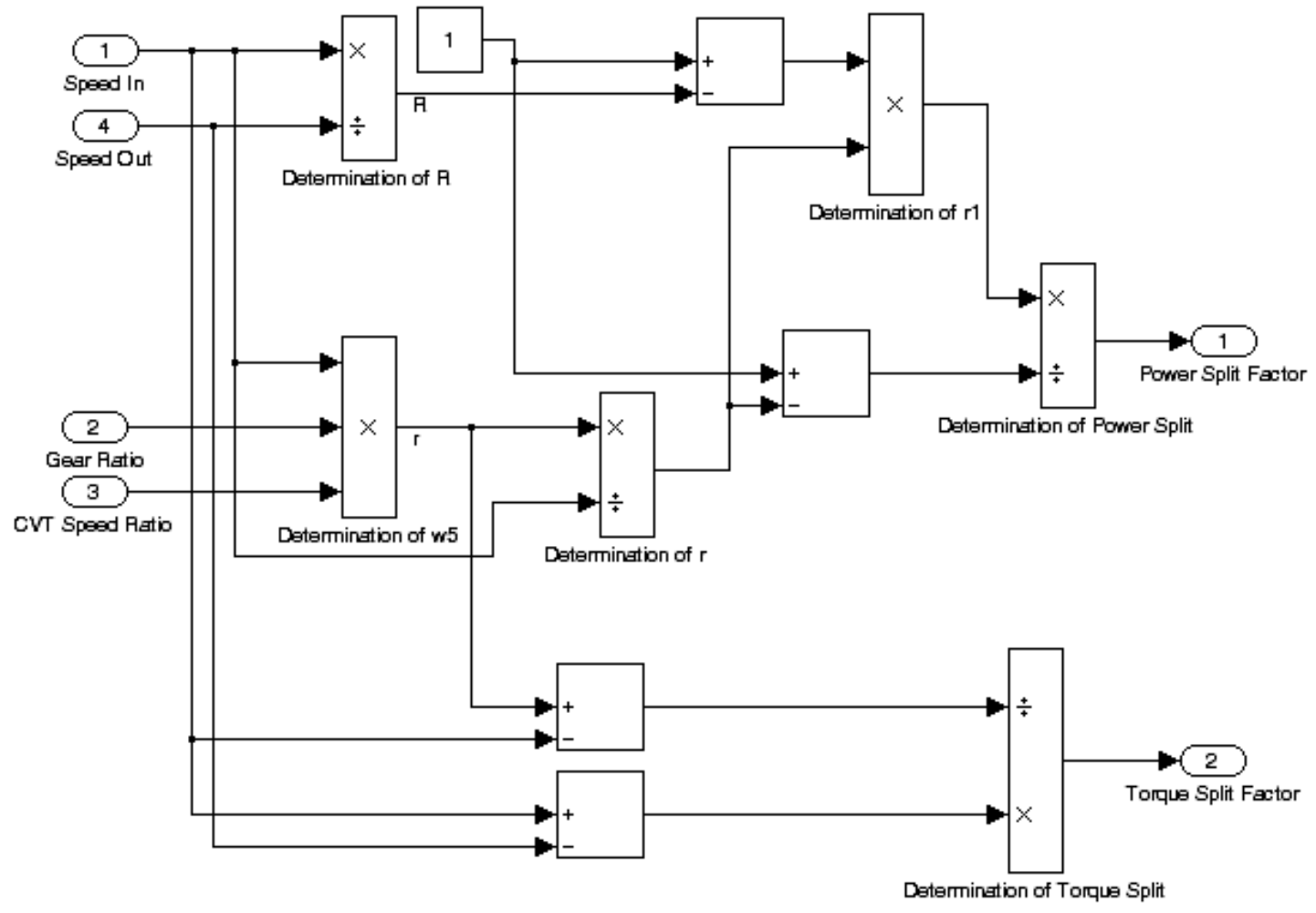

\section{B.1.2.4 Gear Efficiency Correction}

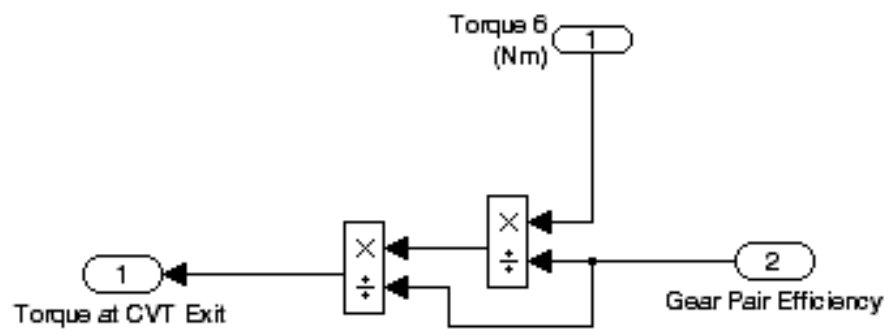




\section{B.1.2.5 PGT Efficiency Correction}

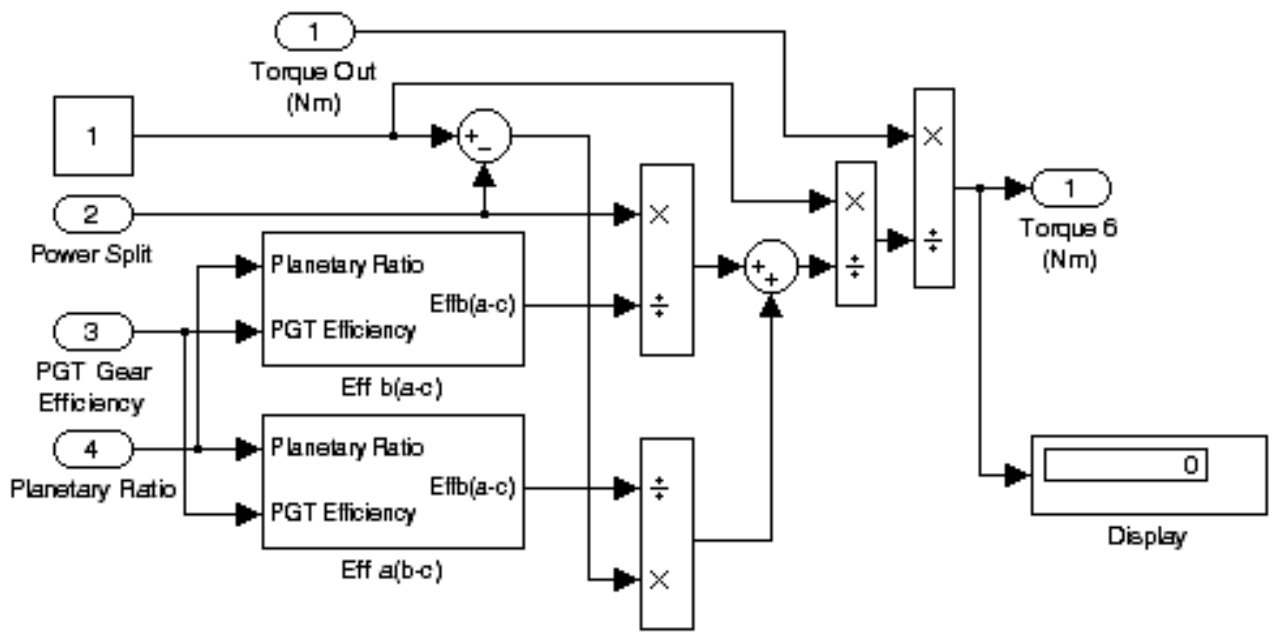

\section{B.1.2.5.1 Eff a(b-c)}

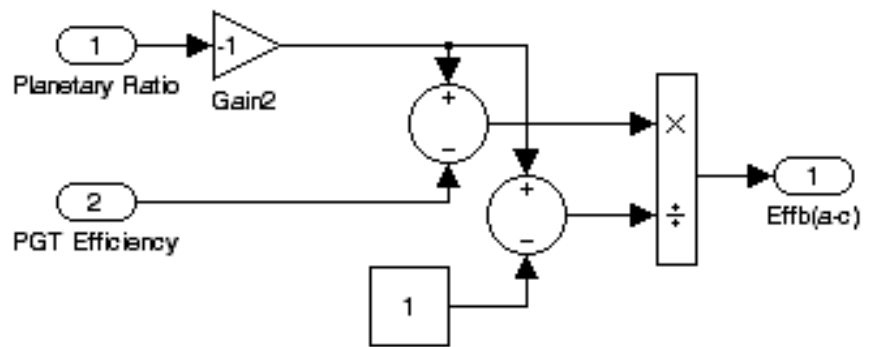

\section{B.1.2.5.2 Eff $b(a-c)$}

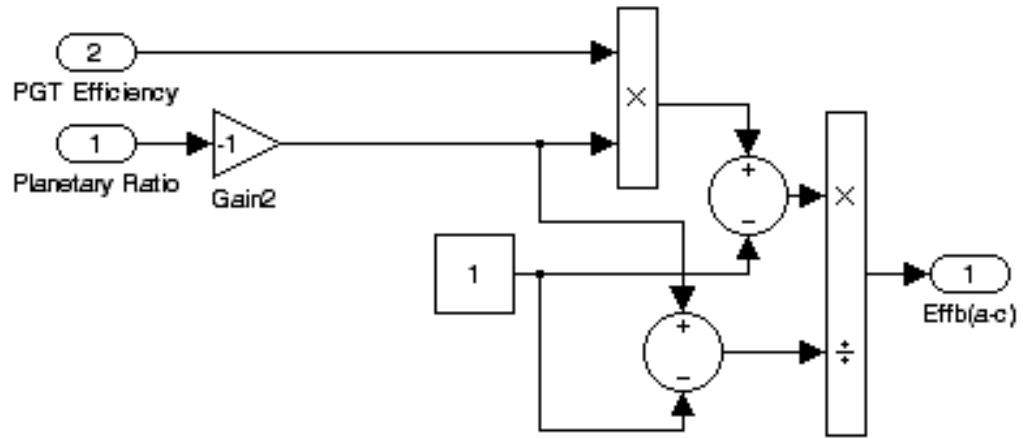




\section{B.1.2.6 Speed Converter}

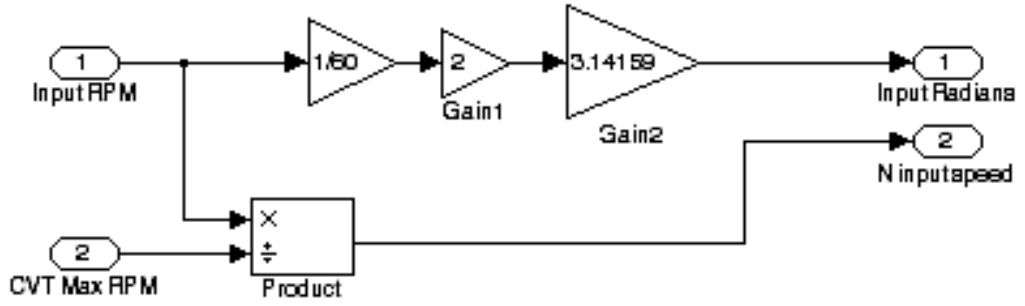

\section{B.1.2.7 Speed Ratio Subsystem}

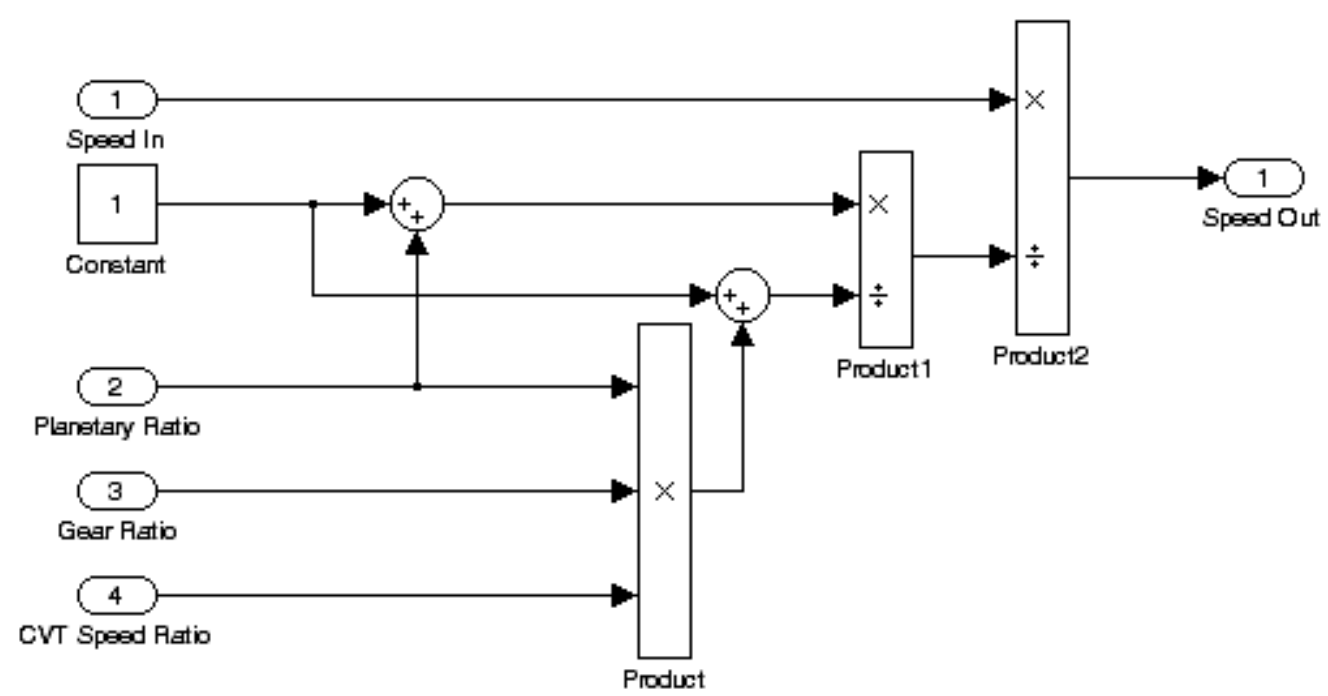

\section{B.2 Modified CVPST Global Model}

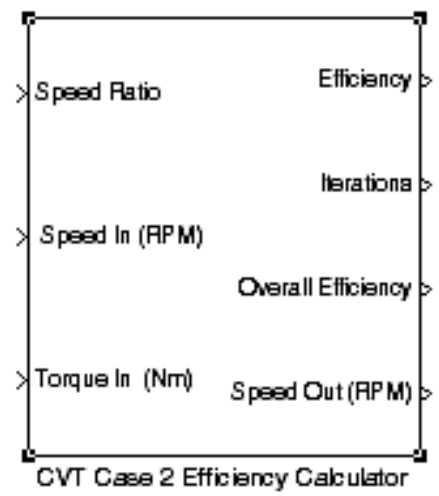




\section{B.2.1 Modified CVPST Efficiency Calculator}

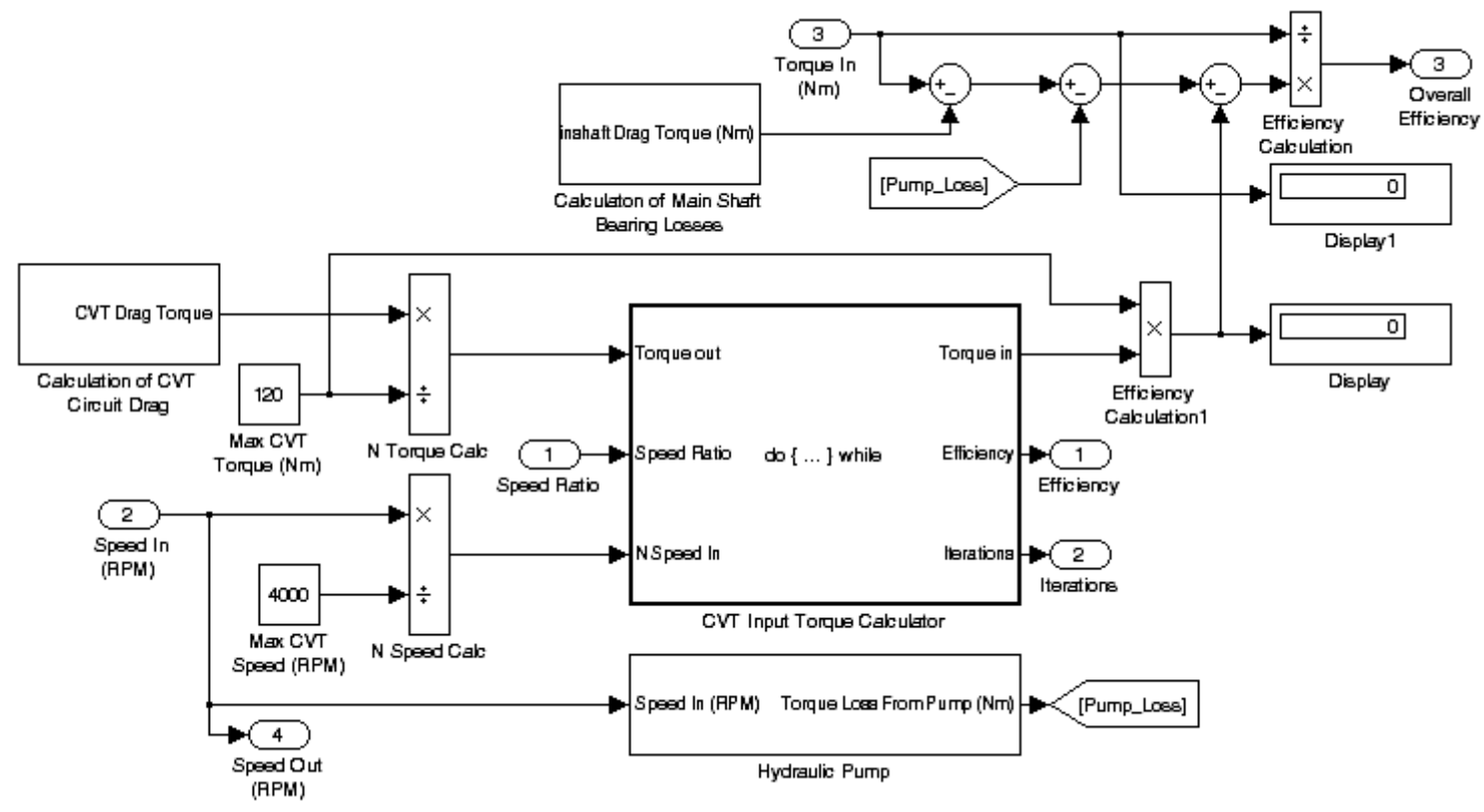

\section{B.3 Direct-Drive CVPST Global Model}

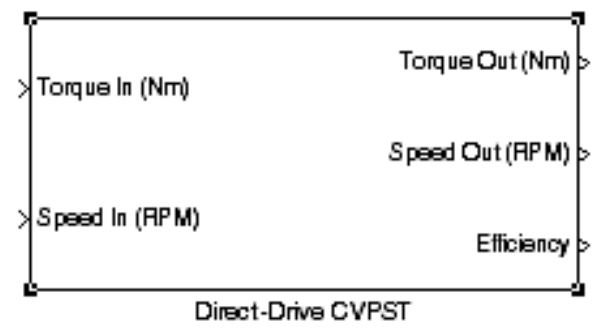

\section{B.3.1 Direct-Drive CVPST Global Model Efficiency Calculator}

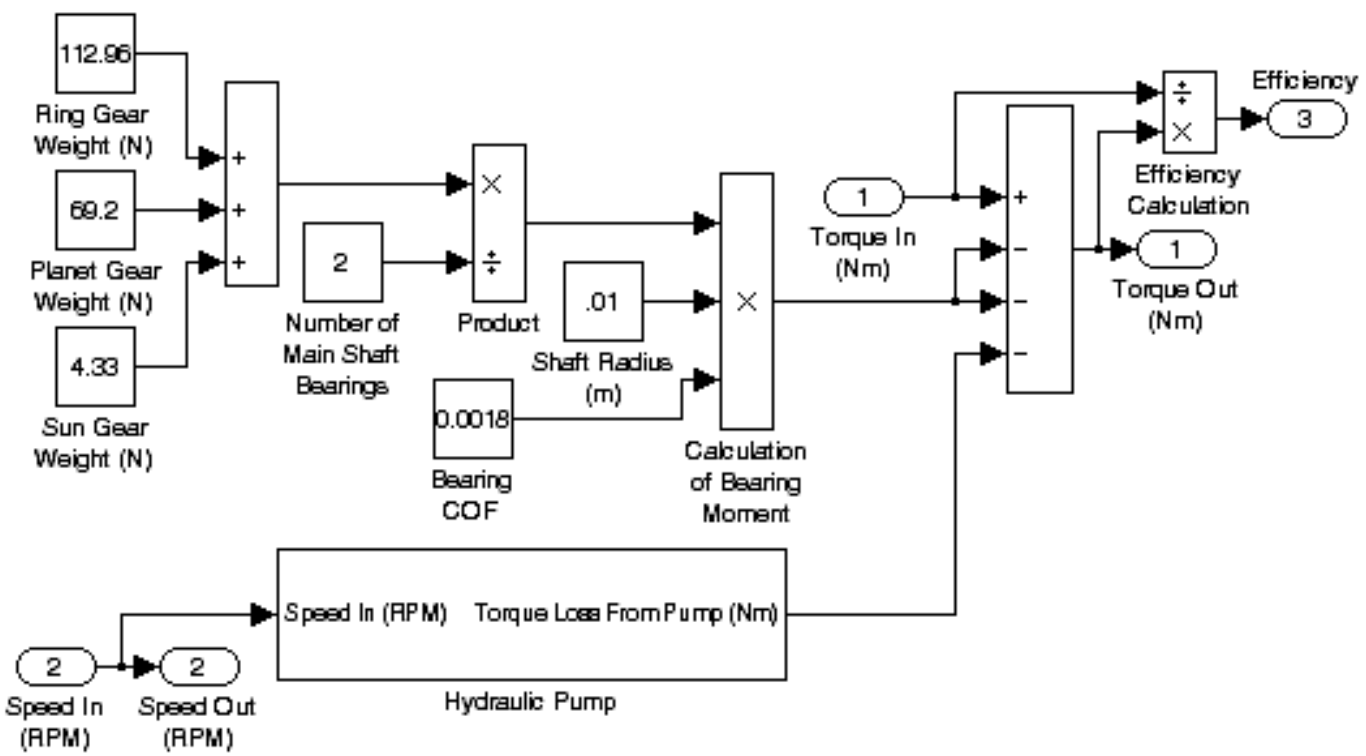




\section{Appendix C - Gear Design Model}

\section{C.1 Transmission Load Model}
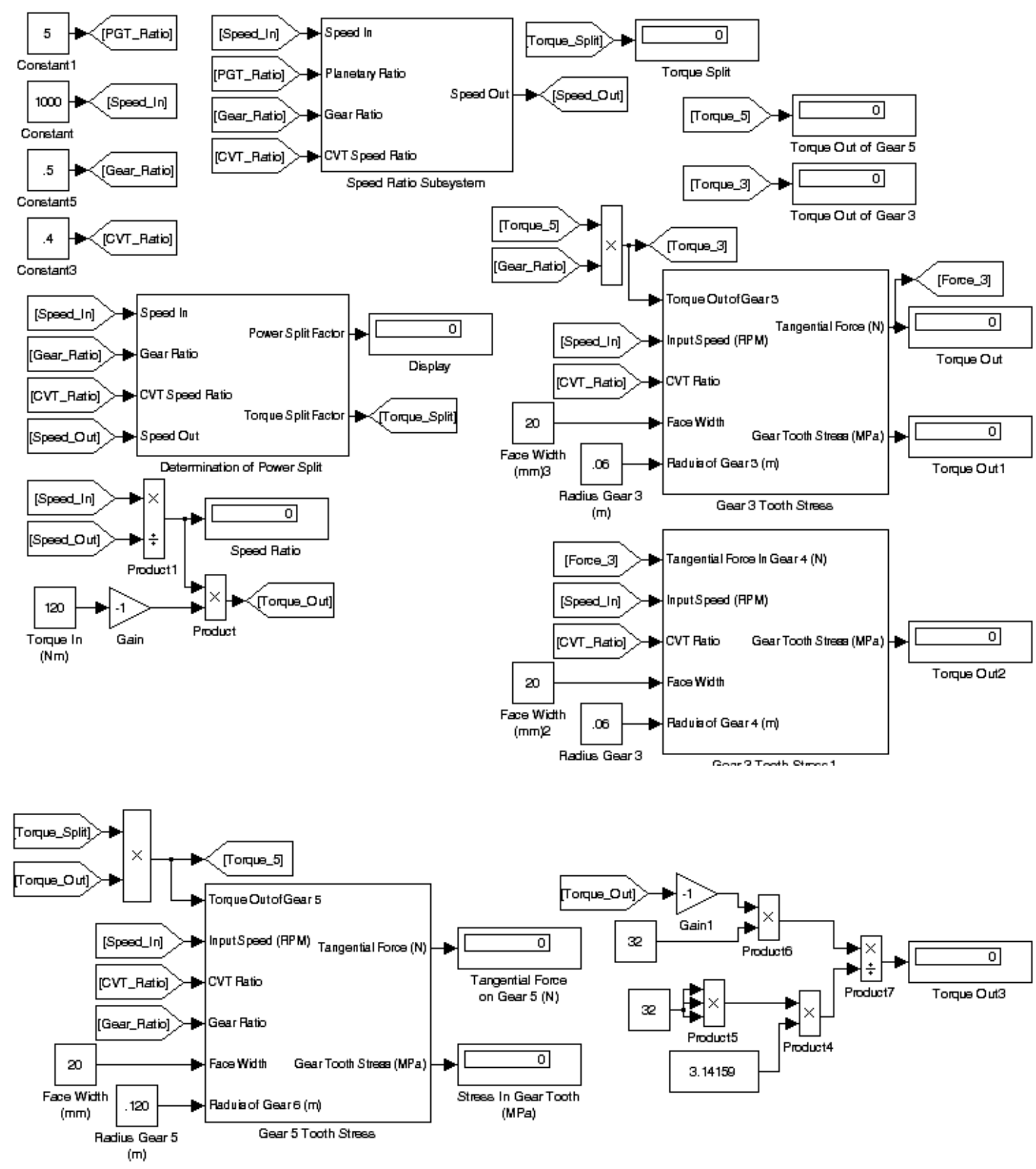


\section{C.1.1 Gear Tooth Stress Calculator}

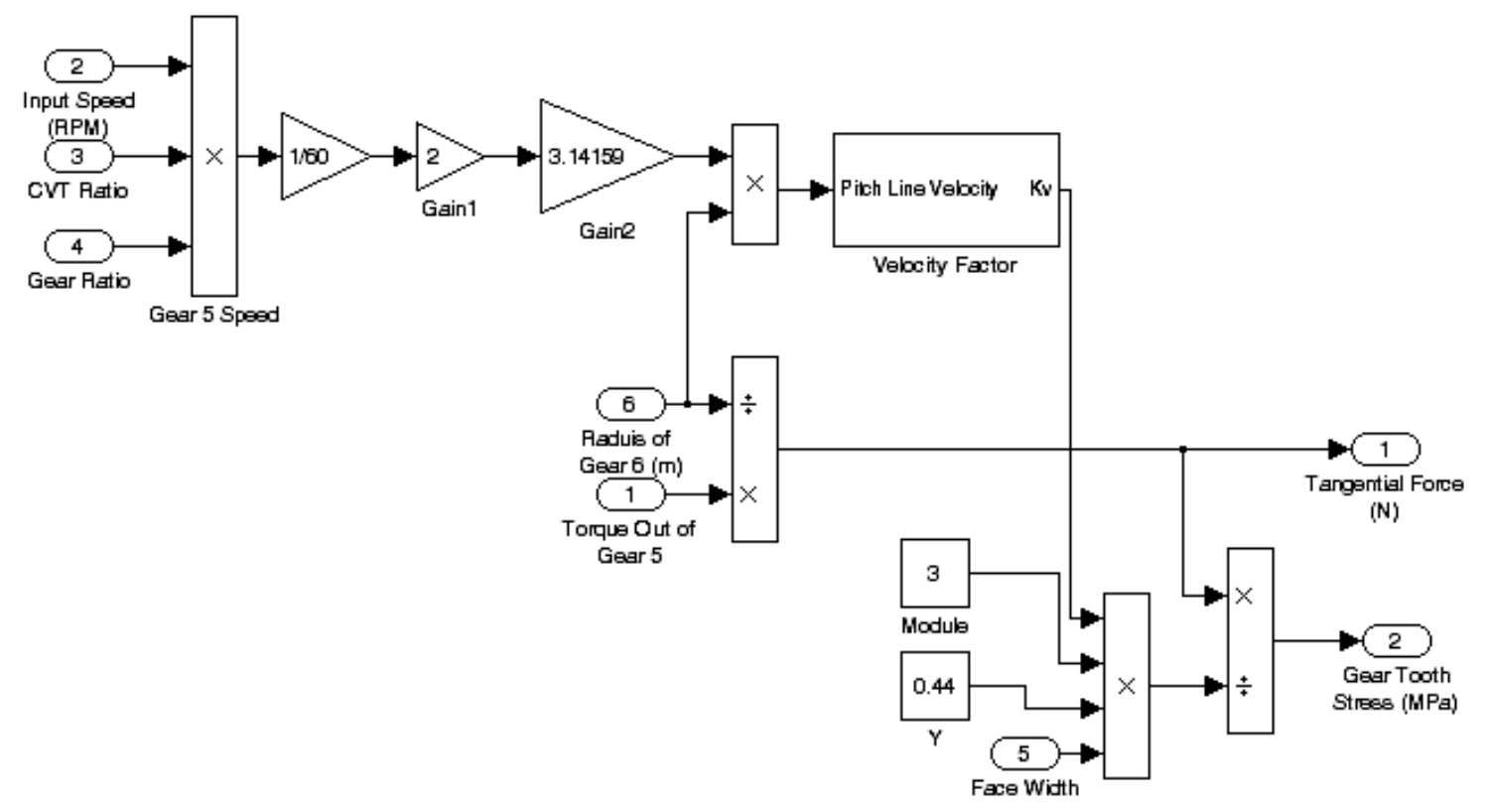




\section{Appendix D - Simulation Data}

Simulation Data-Efficiency with Respect to Constant Input Speed

\begin{tabular}{|c|c|c|c|}
\hline & & $\mathrm{N}=1000$ & \\
\hline Torque & CVPST & M CVPST & DD CVPST \\
\hline 1 & 0.000 & -5.594 & -0.913 \\
\hline 10 & 0.641 & 0.341 & 0.809 \\
\hline 20 & 0.721 & 0.670 & 0.904 \\
\hline 30 & 0.820 & 0.780 & 0.936 \\
\hline 40 & 0.864 & 0.835 & 0.952 \\
\hline 50 & 0.892 & 0.868 & 0.962 \\
\hline 60 & 0.901 & 0.890 & 0.968 \\
\hline 70 & 0.906 & 0.906 & 0.973 \\
\hline 80 & 0.912 & 0.918 & 0.976 \\
\hline 90 & 0.912 & 0.927 & 0.979 \\
\hline 100 & 0.913 & 0.934 & 0.981 \\
\hline 110 & 0.914 & 0.940 & 0.983 \\
\hline 120 & 0.914 & 0.945 & 0.984 \\
\hline
\end{tabular}

\begin{tabular}{|c|c|c|}
\cline { 2 - 3 } \multicolumn{1}{c|}{} & $\mathrm{N}=2000$ & \\
\hline CVPST & M CVPST & DD CVPST \\
\hline 0.000 & -6.486 & 0.042 \\
0.610 & 0.252 & 0.904 \\
0.673 & 0.626 & 0.952 \\
0.779 & 0.751 & 0.968 \\
0.837 & 0.813 & 0.976 \\
0.871 & 0.850 & 0.981 \\
0.884 & 0.875 & 0.984 \\
0.891 & 0.893 & 0.986 \\
0.899 & 0.907 & 0.988 \\
0.901 & 0.917 & 0.989 \\
0.903 & 0.925 & 0.990 \\
0.904 & 0.932 & 0.991 \\
0.906 & 0.938 & 0.992 \\
\hline
\end{tabular}

\begin{tabular}{|c|c|c|c|}
\hline & & $\mathrm{N}=3000$ & \\
\hline Torque & CVPST & M CVPST & DD CVPST \\
\hline 1 & 0.000 & -7.616 & 0.360 \\
\hline 10 & 0.574 & 0.139 & 0.936 \\
\hline 20 & 0.620 & 0.569 & 0.968 \\
\hline 30 & 0.736 & 0.713 & 0.979 \\
\hline 40 & 0.808 & 0.785 & 0.984 \\
\hline 50 & 0.850 & 0.828 & 0.987 \\
\hline 60 & 0.868 & 0.856 & 0.989 \\
\hline 70 & 0.877 & 0.877 & 0.991 \\
\hline 80 & 0.886 & 0.892 & 0.992 \\
\hline 90 & 0.890 & 0.904 & 0.993 \\
\hline 100 & 0.892 & 0.914 & 0.994 \\
\hline 110 & 0.894 & 0.922 & 0.994 \\
\hline 120 & 0.897 & 0.928 & 0.995 \\
\hline
\end{tabular}

\begin{tabular}{|c|c|c|}
\cline { 2 - 3 } \multicolumn{1}{c|}{} & \multicolumn{2}{c|}{ N=4000 } \\
\hline CVPST & M CVPST & DD CVPST \\
\hline 0.000 & -8.714 & 0.519 \\
0.543 & 0.029 & 0.952 \\
0.571 & 0.515 & 0.976 \\
0.688 & 0.676 & 0.984 \\
0.778 & 0.757 & 0.988 \\
0.829 & 0.806 & 0.990 \\
0.851 & 0.838 & 0.992 \\
0.863 & 0.861 & 0.993 \\
0.874 & 0.879 & 0.994 \\
0.879 & 0.892 & 0.995 \\
0.882 & 0.903 & 0.995 \\
0.884 & 0.912 & 0.996 \\
0.887 & 0.919 & 0.996 \\
\hline
\end{tabular}


Simulation Data-Efficiency with Respect to Constant Input Speed

\begin{tabular}{|c|c|c|c|}
\hline & & $\mathrm{T}=10$ & \\
\hline$\overline{\mathrm{RPM}}$ & CVPST & M CVPST & DD CVPST \\
\hline 1 & 6.049 & -190.000 & -190.000 \\
\hline 250 & 0.803 & -0.009 & 0.236 \\
\hline 500 & 0.575 & 0.280 & 0.618 \\
\hline 750 & 0.511 & 0.336 & 0.745 \\
\hline 1000 & 0.474 & 0.341 & 0.809 \\
\hline 1250 & 0.449 & 0.326 & 0.847 \\
\hline 1500 & 0.421 & 0.304 & 0.872 \\
\hline 1750 & 0.395 & 0.279 & 0.891 \\
\hline 2000 & 0.368 & 0.251 & 0.904 \\
\hline 2250 & 0.339 & 0.223 & 0.915 \\
\hline 2500 & 0.313 & 0.195 & 0.923 \\
\hline 2750 & 0.285 & 0.167 & 0.930 \\
\hline 3000 & 0.260 & 0.138 & 0.936 \\
\hline 3250 & 0.236 & 0.110 & 0.941 \\
\hline 3500 & 0.211 & 0.083 & 0.945 \\
\hline 3750 & 0.188 & 0.056 & 0.949 \\
\hline 4000 & 0.166 & 0.029 & 0.952 \\
\hline
\end{tabular}

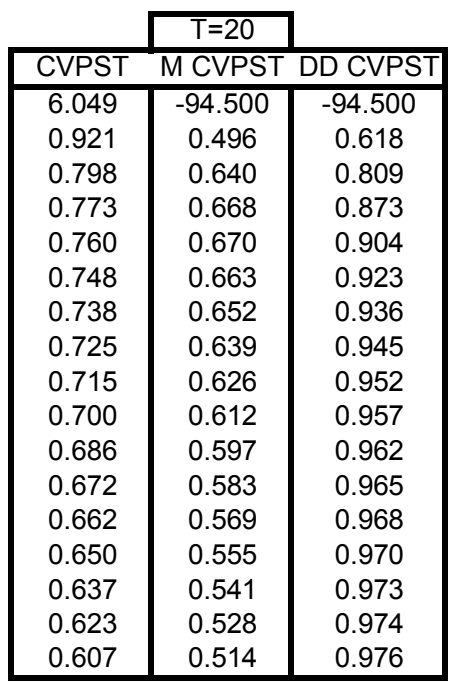

\begin{tabular}{|c|c|c|}
\hline & $\mathrm{T}=40$ & \\
\hline CVPST & M CVPST & DD CVPST \\
\hline 6.049 & -46.750 & -46.750 \\
\hline 0.923 & 0.748 & 0.809 \\
\hline 0.881 & 0.820 & 0.904 \\
\hline 0.874 & 0.834 & 0.936 \\
\hline 0.870 & 0.835 & 0.952 \\
\hline 0.866 & 0.832 & 0.962 \\
\hline 0.859 & 0.826 & 0.968 \\
\hline 0.854 & 0.820 & 0.973 \\
\hline 0.848 & 0.813 & 0.976 \\
\hline 0.841 & 0.806 & 0.979 \\
\hline 0.837 & 0.799 & 0.981 \\
\hline 0.830 & 0.792 & 0.983 \\
\hline 0.825 & 0.785 & 0.984 \\
\hline 0.819 & 0.778 & 0.985 \\
\hline 0.812 & 0.771 & 0.986 \\
\hline 0.807 & 0.764 & 0.987 \\
\hline 0.801 & 0.757 & 0.988 \\
\hline
\end{tabular}

\begin{tabular}{|c|c|c|c|}
\hline & & $T=60$ & \\
\hline$\overline{R P M}$ & CVPST & M CVPST & DD CVPST \\
\hline 1 & 6.049 & -30.830 & -30.830 \\
\hline 250 & 0.923 & 0.832 & 0.873 \\
\hline 500 & 0.909 & 0.880 & 0.936 \\
\hline 750 & 0.905 & 0.889 & 0.958 \\
\hline 1000 & 0.901 & 0.890 & 0.968 \\
\hline 1250 & 0.896 & 0.888 & 0.975 \\
\hline 1500 & 0.892 & 0.884 & 0.979 \\
\hline 1750 & 0.890 & 0.880 & 0.982 \\
\hline 2000 & 0.885 & 0.875 & 0.984 \\
\hline 2250 & 0.881 & 0.871 & 0.986 \\
\hline 2500 & 0.877 & 0.866 & 0.987 \\
\hline 2750 & 0.873 & 0.861 & 0.988 \\
\hline 3000 & 0.868 & 0.856 & 0.989 \\
\hline 3250 & 0.865 & 0.852 & 0.990 \\
\hline 3500 & 0.861 & 0.847 & 0.991 \\
\hline 3750 & 0.857 & 0.843 & 0.992 \\
\hline 4000 & 0.854 & 0.838 & 0.992 \\
\hline
\end{tabular}

\begin{tabular}{|c|c|c|}
\hline CVPST & M CVPST & DD CVPST \\
\hline 6.049 & -22.880 & -22.880 \\
\hline 0.909 & 0.874 & 0.905 \\
\hline 0.918 & 0.910 & 0.952 \\
\hline 0.914 & 0.917 & 0.968 \\
\hline 0.911 & 0.918 & 0.976 \\
\hline 0.909 & 0.916 & 0.981 \\
\hline 0.905 & 0.913 & 0.984 \\
\hline 0.901 & 0.910 & 0.986 \\
\hline 0.899 & 0.906 & 0.988 \\
\hline 0.896 & 0.903 & 0.989 \\
\hline 0.892 & 0.899 & 0.990 \\
\hline 0.889 & 0.896 & 0.991 \\
\hline 0.886 & 0.892 & 0.992 \\
\hline 0.883 & 0.889 & 0.993 \\
\hline 0.880 & 0.885 & 0.993 \\
\hline 0.877 & 0.882 & 0.994 \\
\hline 0.874 & 0.879 & 0.994 \\
\hline
\end{tabular}

\begin{tabular}{|c|c|c|}
\cline { 2 - 3 } \multicolumn{1}{c|}{} & \multicolumn{1}{c|}{$T=100$} & \multicolumn{1}{c|}{} \\
\hline CVPST & M CVPST & DD CVPST \\
\hline 6.049 & -18.100 & -18.100 \\
0.921 & 0.899 & 0.924 \\
0.919 & 0.928 & 0.962 \\
0.917 & 0.934 & 0.975 \\
0.914 & 0.934 & 0.981 \\
0.911 & 0.933 & 0.985 \\
0.909 & 0.930 & 0.987 \\
0.906 & 0.928 & 0.989 \\
0.903 & 0.925 & 0.990 \\
0.900 & 0.922 & 0.992 \\
0.898 & 0.920 & 0.992 \\
0.895 & 0.917 & 0.993 \\
0.892 & 0.914 & 0.994 \\
0.889 & 0.911 & 0.994 \\
0.887 & 0.908 & 0.995 \\
0.885 & 0.906 & 0.995 \\
0.882 & 0.903 & 0.995 \\
\hline
\end{tabular}

\begin{tabular}{|c|c|c|c|}
\cline { 3 - 4 } \multicolumn{1}{c}{} & \multicolumn{3}{c|}{ T=120 } \\
\hline RPM & CVPST & \multicolumn{1}{c|}{ M CVPST } & DD CVPST \\
\hline 1 & 6.049 & -14.920 & -14.920 \\
250 & 0.922 & 0.916 & 0.936 \\
500 & 0.919 & 0.940 & 0.968 \\
750 & 0.918 & 0.945 & 0.979 \\
1000 & 0.915 & 0.945 & 0.984 \\
1250 & 0.913 & 0.944 & 0.987 \\
1500 & 0.910 & 0.942 & 0.989 \\
1750 & 0.908 & 0.940 & 0.991 \\
2000 & 0.905 & 0.938 & 0.992 \\
2250 & 0.904 & 0.935 & 0.993 \\
2500 & 0.901 & 0.933 & 0.994 \\
2750 & 0.899 & 0.931 & 0.994 \\
3000 & 0.897 & 0.928 & 0.995 \\
3250 & 0.895 & 0.926 & 0.995 \\
3500 & 0.892 & 0.924 & 0.995 \\
3750 & 0.889 & 0.921 & 0.996 \\
4000 & 0.887 & 0.919 & 0.996 \\
\hline
\end{tabular}




\section{Vita}

Andrew Fox was born on March 26, 1979 in Fairmont, West Virginia. He attended Grafton High School in Grafton, West Virginia where he graduated as class

Salutatorian. Afterward, he was admitted to West Virginia University where he graduated with a Bachelor of Science Degree in Mechanical Engineering in 2001. He was then admitted to Master of Science program in Mechanical Engineering immediately upon graduation where he is currently employed as a Graduate Research Assistant. 